\title{
Marshalling Resources: Crisis Citizen Engagement and the Marshall Decisions
}

by

\author{
Frank Gale
}

A thesis submitted to the Faculty of Graduate and Postdoctoral Affairs in partial fulfillment of the requirements for the degree of

Master of Arts

in

Political Economy

Carleton University

Ottawa, Ontario

(C) 2012, Frank Gale 
Library and Archives

Canada

Published Heritage

Branch

395 Wellington Street

Ottawa ON K1A ON4

Canada
Bibliothèque et

Archives Canada

Direction du

Patrimoine de l'édition

395 , rue Wellington

Ottawa ON K1A ON4

Canada
Your file Votre référence

ISBN: 978-0-494-91599-8

Our file Notre référence

ISBN: 978-0-494-91599-8
NOTICE:

The author has granted a nonexclusive license allowing Library and Archives Canada to reproduce, publish, archive, preserve, conserve, communicate to the public by telecommunication or on the Internet, loan, distrbute and sell theses worldwide, for commercial or noncommercial purposes, in microform, paper, electronic and/or any other formats.

The author retains copyright ownership and moral rights in this thesis. Neither the thesis nor substantial extracts from it may be printed or otherwise reproduced without the author's permission.
AVIS:

L'auteur a accordé une licence non exclusive permettant à la Bibliothèque et Archives Canada de reproduire, publier, archiver, sauvegarder, conserver, transmettre au public par télécommunication ou par l'Internet, prêter, distribuer et vendre des thèses partout dans le monde, à des fins commerciales ou autres, sur support microforme, papier, électronique et/ou autres formats.

L'auteur conserve la propriété du droit d'auteur et des droits moraux qui protege cette thèse. $\mathrm{Ni}$ la thèse ni des extraits substantiels de celle-ci ne doivent être imprimés ou autrement reproduits sans son autorisation.
In compliance with the Canadian Privacy Act some supporting forms may have been removed from this thesis.

While these forms may be included in the document page count, their removal does not represent any loss of content from the thesis.
Conformément à la loi canadienne sur la protection de la vie privée, quelques formulaires secondaires ont été enlevés de cette thèse.

Bien que ces formulaires aient inclus dans la pagination, il n'y aura aucun contenu manquant. 


\begin{abstract}
This thesis addresses the implementation of public participation in government approaches to crisis management. It focuses on feasibility of public participation to meet short-and long-term objectives. The case study selected is the 1999 Marshall decisions and ensuing crisis in the Maritime commercial lobster fishery. The thesis constructs a narrative of events and public participation prior to and during the crisis, using primary interviews with involved individuals and secondary literature to explore how public participation impacted crisis management. A modified public participation spectrum will then analyze crisis management, based on the use of two academic orienting concepts, traditional public participation and citizen engagement. The spectrum is refined by aligning this dichotomy with concepts of representative and deliberative democracy, practical methods and external factors. The main argument of this thesis is that greater incorporation of citizen engagement in crisis management is possible, and could lead to improved short- and long-term outcomes.
\end{abstract}




\section{Acknowledgements}

First and foremost, I would like to thank Professor Frances Abele for her direction and encouragement throughout the process of writing and defending this thesis. I would also like to thank Professors Janet Siltanen and Wally Clement for their valuable insights and for agreeing to be my respective second and external readers. In addition, I would like to acknowledge the administrative and moral support provided by Donna Coghill of the Institute of Political Economy throughout this process. I owe a significant debt of gratitude to the five individuals who agreed to be interviewed for this thesis. Without their unique perspectives on the Marshall crisis, this thesis simply would not have been possible. I also owe many thanks to my supportive family, friends and colleagues, who all provided encouragement and support. Finally, I dedicate this thesis to my wife, Amber, to who I owe a significant debt of gratitude for her patience and support throughout the writing process. 


\section{Table of Contents}

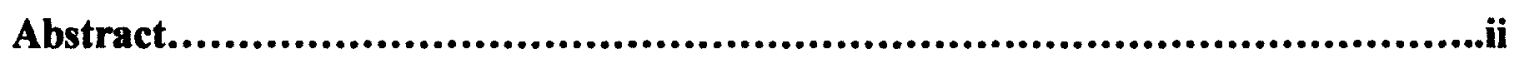

Acknowledgements......................................................................iii

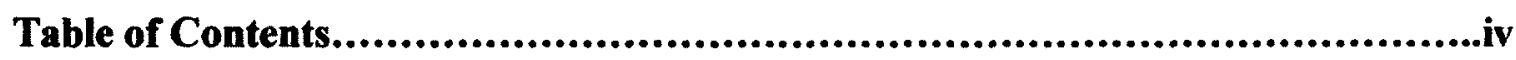

List of Tables.................................................................................iii

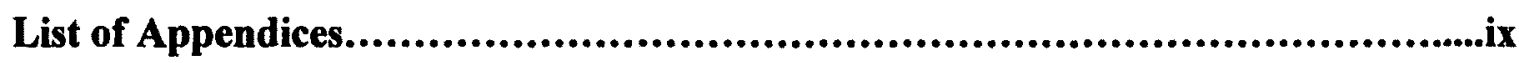

1 Chapter - Introduction: The Marshall Decisions, Crisis and Public

Participation...............................................................................1

1.1 Introduction: Crisis Management and Citizen Engagement................1

1.2 Case Study: The Marshall Decisions and the Ensuing Crisis...............3

$1.3 \quad$ Research Plan and Resources.............................................

$1.4 \quad$ Chapter Outlines..................................................... 14

1.4.1 Chapter 2 - A Brief History of the Marshall Crisis........................14

1.4.2 Chapter 3 - Public Participation and Policy Making in Canada.............14

1.4.3 Chapter 4 - Public Participation Prior to and During the Marshall

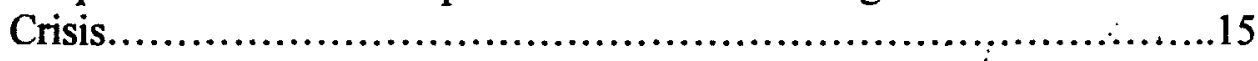

1.4.4 Chapter 5 - New Possibilities for Crisis Management Through Public Participation.........................................................16

1.4.5 Chapter 6 - Conclusion: New Possibilities?..............................17

2 Chapter - A Brief History of the Marshall Crisis....................................18

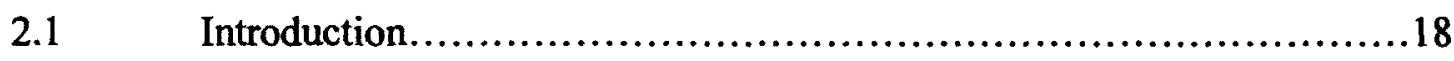

2.2 Prologue to the Marshall Crisis........................................19

2.3 Events During and After Marshall I (September 17, 1999)...............24

2.4 Events During and After Marshall 2 (November 17, 1999)..............45

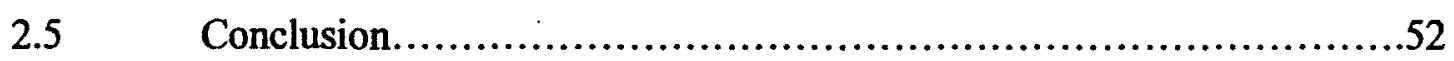


3 Chapter - Public Participation and Policy Making in Canada.....................54

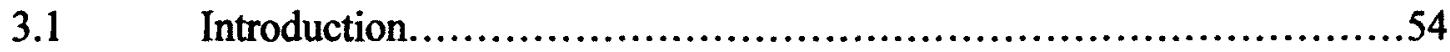

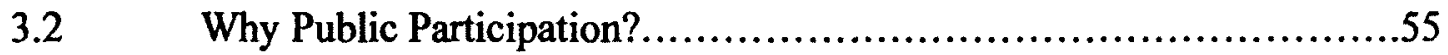

3.3 Toward a Public Participation Analytical Framework.....................59

3.4 Public Participation Methods.........................................74

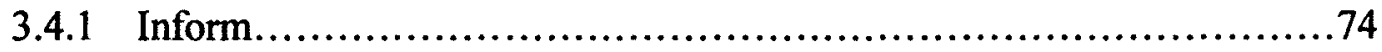

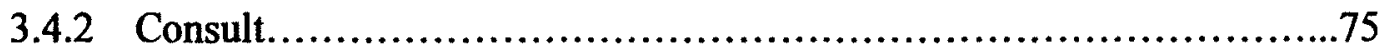

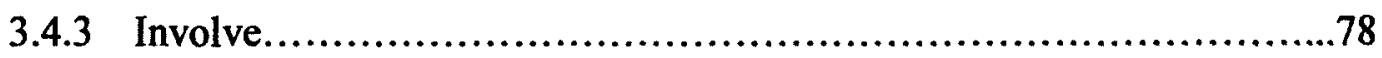

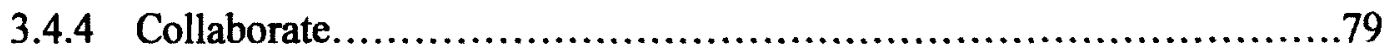

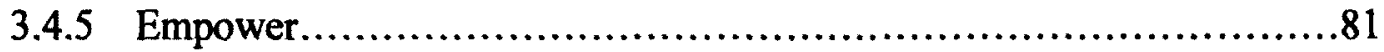

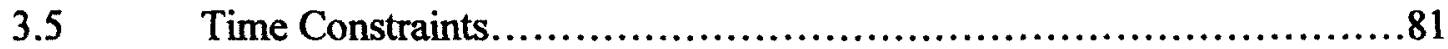

3.6 Financial and Human Resource Availability...........................82

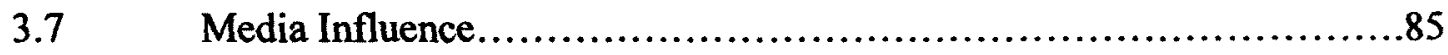

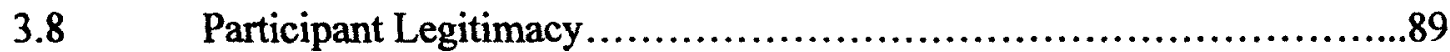

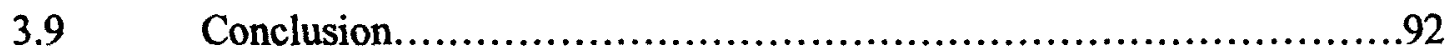

4 Chapter - Public Participation Prior to and During the Marshall Crisis.........96

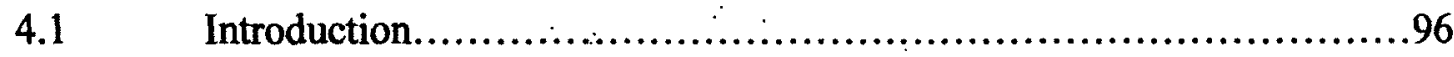

4.2 Public Participation Prior to the Marshall Crisis........................98

4.3 Public Participation During the Marshall Crisis..........................105

4.3.1 Community and Group Engagements................................107

4.3.2 Federal Negotiations..............................................111

4.3.3 Legislative and Parliamentary Hearings.................................119

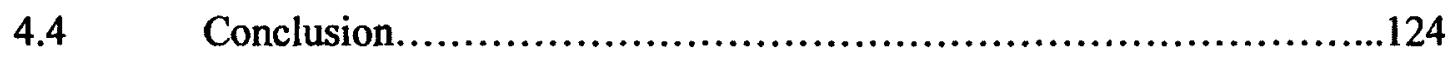

5 Chapter - New Possibilities for Crisis Management Through Public Participation...........................................................................128

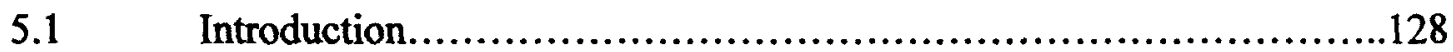


5.2 New Possibilities: Primary Source Interviews........................131

5.2.1 Broader Engagement from the Beginning............................131

5.2.2 Community Meetings................................................. 133

5.2.3 Systemic Public Participation...........................................134

5.3 Involve, Citizen Engagement and Deliberative Democracy Techniques............................................................. 137

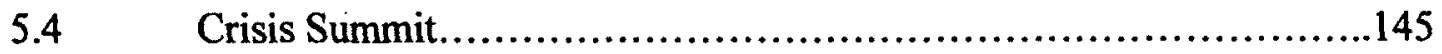

5.4.1 Spanning and Bridging...........................................146

5.4.2 Pre-Workshop Sessions................................................. 147

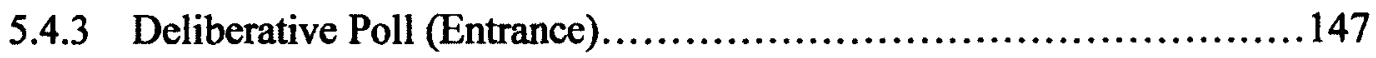

5.4.4 Workshop (Policy Conference) ......................................148

5.4.5 Workshop (Policy Roundtable) .................................... 150

5.4.6 Deliberative Polling (Exit)...........................................151

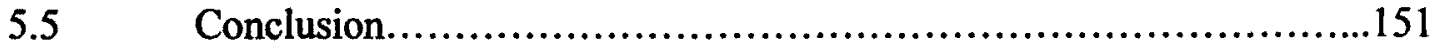

6 Chapter - Conclusion: New Possibilities?...........................................153

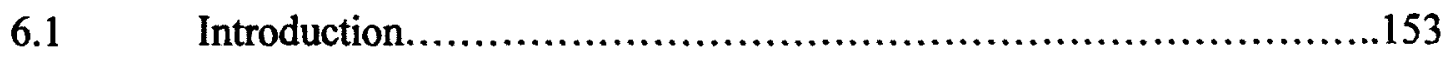

$6.2 \quad$ Summary of Research Plan and Its Three Contributions.................153

6.2.1 Analysis of Public Participation Prior to the Marshall Crisis.............157

6.2.2 Analysis of Outcomes During the Marshall Crisis.......................158

6.2.2.1 Community and Group Engagements..........................159

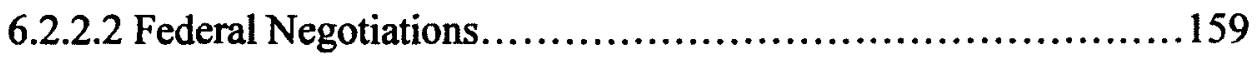

6.2.2.3 Legislative and Parliamentary Hearings..........................161

6.2.3 Involve as a Possible Public Participation Method.......................162

6.3 2007 Atlantic Lobster Summit and the Lobster Council of Canada......164

6.4 Recommendations for Further Research............................170

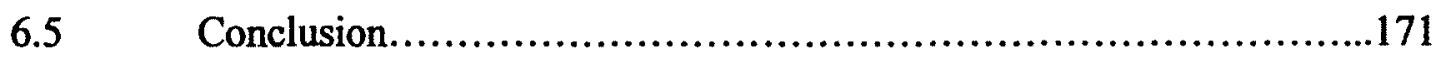




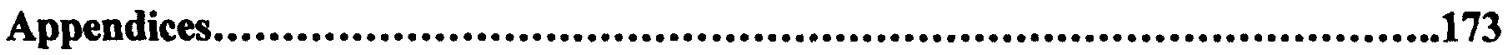

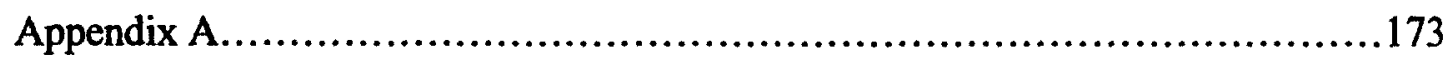

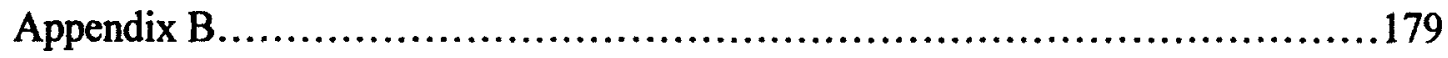

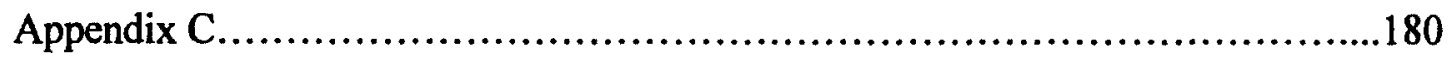

Works Cited..............................................................................189

Aboriginal Treaty Rights and the Legal Duty to Consult and Accommodate........189

Citizen Engagement and Public Participation......................................189

Critical and Mass Communication Theory .........................................190

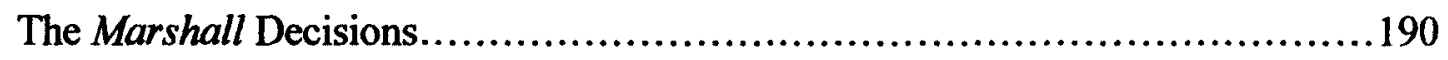

Organized Labour and the Atlantic Commercial Fishery.........................190

Primary Source Interviews.....................................................191

Supreme Court of Canada Decisions.................................................191 


\section{List of Tables}

Table 1 International Association for Public Participation (IAP2)

Public Participation Spectrum..........................................71

Table 2 Actual and Estimated Funding for C\&PD 1998/1999-

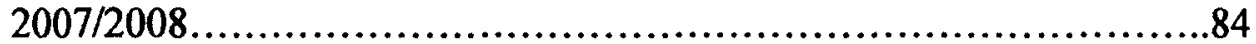

Table 3 Modified Public Participation Spectrum.............................93 


\section{List of Appendices}

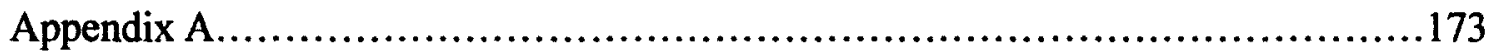

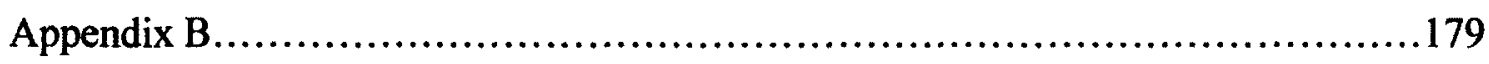

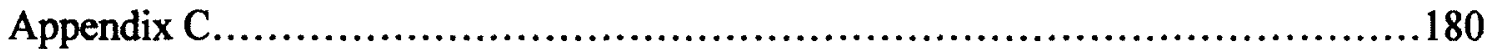


This appeal should be allowed because nothing less would uphold the honour and integrity of the Crown in its dealings with the Mi'kmaq people to secure their peace and friendship, as best the content of those treaty promises can now be ascertained.

Supreme Court of Canada,

17 September 1999

The events of the fall of 1999 caught Canadians unaware. No one - Mi'kmaq, Department of Fisheries and Oceans personnel, officials from the Department of Indian Affairs, academic experts, or the public at large - anticipated either the specifics of the Supreme Court decision on the case of Donald Marshall Jr. or the controversy that followed. It is easy with hindsight to criticize people in the positions of authority for failing to plan for the fallout from the Supreme Court ruling. Even though the decision was unexpected, it was not outside the pattern of recent judgments on Aboriginal matters (Coates, ix).

\section{Chapter - Introduction: The Marshall Decisions, Crisis and Public Participation}

\subsection{Introduction: Crisis Management and Citizen Engagement}

This section will begin by explaining the topic of research in general terms, based on what interests led to the research question and it will then state the question. The second section will explain the relevance of using the Marshall crisis as a case study on which to base the research question. The third section will present the research plan in terms of original contributions that the research will make to the body of knowledge on the topics involved, and it will provide a description of the primary and secondary sources that will be drawn for review. The final section of this chapter will provide brief summaries of what to expect in the remaining five chapters.

The general interest that led to researching for this thesis stems from two areas of policy development, which for at least some Aboriginal peoples are all too familiar: 
public participation and crisis management ${ }^{1}$. Under normal circumstances, governments have used public participation (or engagement ${ }^{2}$ ) sessions to accomplish a variety of policy objectives, from informing the public about a new approach to delivering services, to seeking the public's input on a draft policy that is nearing readiness for implementation, to working collaboratively with citizens to seek their input from the beginning of a process to address a particular policy objective.

The use of public participation to seek input from Aboriginal peoples on socioeconomic issues is rather commonplace, which for example can range from targeted health programming to how First Nations on reserves can build sustainable small and medium-sized enterprises. In addition, much has been written concerning public participation among several levels of government and societal groups under normal circumstances, whereby governments seek input to varying degrees on a particular policy-making process to solve various issues.

Very little, if anything has been written concerning whether governments in Canada have used public participation approaches to engage with the public, including different citizen groups, during the onset of a crisis. Nor has there been much written

\footnotetext{
'The term "crisis management" will refer to the government responses to crisis situations, including the federal response to the Marshall crisis. In the case of the Marshall crisis for the purposes of this thesis, crisis management will also encapsulate a short-term objective of reducing tensions to ease occurrences of violent conflict, while setting in place the possibility of future management of natural resources among First Nations and non-Aboriginal groups through partnerships, while respecting treaty rights.

2 "Engagement" and "public participation" will be used interchangeably throughout this thesis as umbrella terms for the spectrum of techniques and methods that an entity can use to engage with individuals and groups. However, the term "citizen engagement" will be used to refer to a specific grouping of techniques under the Involve method. All of these terms will be elaborated and explained in Chapter 3, as part of the modified public participation spectrum that will form the analytical framework for this thesis.
} 
concerning how the degree of public involvement in a policy-making process could help potentially reduce tensions over the short term, and lead to positive outcomes over the longer term, such as the establishment of partnerships to co-manage a resource, while respecting treaty rights to that resource. All of this, coupled with the case study narrative of the Marshall crisis, which will be described in the following section, has led to the following research question: What public participation methods did the federal government implement prior to and during the Marshall crisis, and are there possibilities for strengthening public participation in crisis management over the short and long term?

The research question above will guide the progression of the remainder of this chapter and thesis. The following section will explain why the Marshall decisions and the ensuing crisis will be presented as a strong case study to research the intersection of public participation and crisis management.

\subsection{Case Study: The Marshall Decisions and the Ensuing Crisis}

The Marshall crisis case study represents a formidable opportunity to conduct research on the importance of public participation as a means to address crisis management. The question of addressing crises arising from treaty rights issues is especially pertinent now, approximately 12 years after the Marshall decisions, as several Supreme Court of Canada decisions concerning Aboriginal treaty rights have also been concluded, many of which have sided with First Nations, Métis and other section 35 treaty rights holders. In addition, Marshall was a landmark case with regard to the acknowledgement of First Nations' treaty rights on the basis of historic treaties, which led to significant disagreements among those with a stake in the Maritime commercial 
lobster fishery and led to the ensuing crisis ${ }^{3}$.

The complexities surrounding the Marshall decisions, including First Nations and non-Aboriginal groups that wanted to work together; some groups that did not want to work together; public participation approaches that were implemented before and during the Marshall crisis; the length of time that lapsed during the crisis; and the eventual resolution of the crisis all contribute to its being a well-rounded case study to analyze and propose methods of public participation that present new possibilities for citizen involvement in crisis management. In addition, external factors that were present during the Marshall crisis, including time constraints, financial/human resource constraints, media influence and participant legitimacy can create barriers to achieving positive outcomes in a public participation process. These factors will all be taken into consideration in the chapters that follow.

Since treaty rights were enshrined under section 35 of Canada's Constitution Act 1982, the number of Aboriginal road and site blockades, protests and litigation cases has increased (Isaac, 70). There have been many crisis situations since 1982 involving Aboriginal peoples across Canada, such as the Oka Crisis in 1990, Gustafson Lake in British Columbia in 1995, and the Six Nations protest of the Douglas Creek Estates land in Caledonia, Ontario more recently. In all of these cases, First Nations, non-Aboriginal citizens and different levels of government have engaged in discussions to determine how to resolve disputes over treaty and natural resource rights, while considering the overall

\footnotetext{
${ }^{3}$ The full narrative of the Marshall decisions and crisis is elaborated in Chapter 2.
} 
needs of society. Such disputes can be difficult to resolve because they often involve vaguely worded legal interpretations of centuries' old treaties, which lay out rights to lands and natural resources that are often already owned by non-Aboriginal and/or government entities. In many cases, lands and natural resources represent the economic lifeblood of a region, especially in rural areas. Recognizing a First Nations right that supersedes other groups that are currently in possession of, and benefitting economically from, the management of lands and resources in question can very quickly lead to confrontations in some cases. Such situations may become especially tense if those whose economic livelihoods are at stake are not considered in discussions to resolve the issues at hand.

With each new Supreme Court decision on section 35 rights, there is a greater need to clarify and re-balance how governments can honour those rights while respecting the needs of the rest of the citizenry. In recent years, the Supreme Court of Canada has also affirmed that the Crown has a legal duty to consult and accommodate First Nations in those cases where a potential or existing treaty right exists ${ }^{4}$. This includes the first and second Marshall decisions, also known as Marshall 1 and 2, which the Supreme Court of Canada rendered on September $17,1999^{5}$, and November $17,1999^{6}$, respectively.

This case study will provide a solid foundation to analyze the public participation

\footnotetext{
${ }^{4}$ Please note that the legal duty to consult and accommodate Aboriginal peoples is not considered in this thesis. The term "traditional public consultation" is considered to be an analytical concept for use in policy-making processes in this case.

${ }^{5}$ R. v. Marshall (No. 1) [1999] 3 S.C.R. 456.

${ }^{6}$ R. v. Marshall (No. 2) [1999] 3 S.C.R. 533.
} 
methods that were implemented before and during the Marshall crisis because the Maritimes are known to have First Nations communities that are generally amenable to working with non-Aboriginal peoples and the different levels of government (Coates 164). Including a case study that has a number of co-operative First Nations will help to establish what, if any approach to public participation might have posed additional possibilities to reduce tensions and establish partnerships to manage the Maritime commercial lobster fishery over the long term. This will set the stage to consider additional public participation methods that might present new possibilities to meet the short- and long-term outcomes identified.

The 1999 Marshall decisions and the crisis that ensued will be used as a case study to analyze firstly, what public participation methods were implemented by the federal government prior to and during the crisis. In addition, the case study will be used to determine how those approaches differed overall prior to and during the crisis. Analysis will then be presented to determine if different public participation techniques and methods that were not implemented, could have been during the crisis. Finally, these alternative methods will be analyzed for their potential to contribute to crisis management by reducing tensions and helping to establish long-term partnerships in the management of the Maritime commercial lobster fishery.

The Marshall crisis, for the purposes of this paper, will be defined as the period when violent confrontations began to occur among the Department of Fisheries and Oceans, First Nations (primarily Mi'kmaq) and non-Aboriginal fishers, starting on September 17, 1999, when the Supreme Court of Canada rendered the first Marshall 
decision (Marshall 1) ${ }^{7}$, through to November 17, 1999, when the Supreme Court issued a clarification of the first decision (Marshall 2$)^{8}$, and for approximately one year following. A full narrative of the Marshall crisis, based on primary interviews and secondary literature, will be presented in Chapter 2.

\subsection{Research Plan and Resources}

This section will elaborate on the research plan, or methodology, for researching the thesis. The research plan will include a description of three contributions that $I$ intend to achieve while conducting analysis of the research. The second part of this section will explain the sources to be used and why.

The research plan for this thesis will require a variety of sources from different disciplines, including work on public participation/engagement and the case study of the Marshall crisis. While specific primary and secondary sources will be discussed later in this section, the initial part of this section will outline how the research plan will be developed.

As part of the research plan, the first contribution will be a presentation of a narrative concerning events that occurred prior to and during the Marshall crisis ${ }^{9}$. This narrative of events will include primary source interviews that sought the perspectives of key individuals involved on all sides of the dispute over access to the Maritime commercial lobster fishery. Their perspectives will be compared and contrasted, and then

\footnotetext{
${ }^{7}$ R. v. Marshall (No. I) [1999] 3 S.C.R. 456.

${ }^{8}$ R. v. Marshall (No. 2) [1999] 3 S.C.R. 533.

${ }^{9}$ A full narrative of the Marshall crisis is presented in Chapter 2 and a crisis timeline is located in Appendix 1 for reference.
} 
I will present secondary literature on the Marshall decisions and the resulting crisis to support the perspectives presented in the primary source interviews.

Public participation approaches implemented by the Department of Fisheries and Oceans, and communicated by primary and secondary sources will form important analyses of the crisis period. There are many questions to consider when comparing and contrasting the public participation methods that were implemented during the crisis, such as how did the implementation increase the variety and intensity of techniques and methods once the crisis was underway? Such questions lead to a second contribution of this thesis, which is elaborated below.

There are two orienting concepts that I will use as the means of analysis in this thesis: traditional public consultation and citizen engagement. While there are many ways that these two concepts can be compared and contrasted, the most important for my purposes is the differentiation in the degree of impact that the public can have on the policy-making process through one of these two processes. Generally speaking, citizen engagement is a newer means for governments to engage with the public. This approach presents a greater opportunity for citizen involvement in the policy-making process ${ }^{10}$. An additional consideration verified through the research was whether any citizen engagement processes occurred during the Marshall crisis and if so, what possibilities might have contributed to meeting the short- and long-term objectives?

In addition to the orienting dichotomy of traditional public consultation and

\footnotetext{
${ }^{10}$ Further information on the conceptual and analytical elements, including the scholars and writers of each concept, is presented in Chapter 3.
} 
citizen engagement, this thesis will also align these two analytical concepts with the analytical concepts of representative democracy and deliberative democracy. These four concepts represent two poles along a continuum of public impact on the policy-making process, with traditional public consultation/representative democracy being at the lower end of public impact and citizen engagement/deliberative democracy being at the higher end. The alignment of these similar concepts will help to further define the varying degrees of citizen involvement in public participation processes, especially as it pertains to the federal government response to crisis management. Additionally, these concepts will be further aligned with practical administrative public participation approaches identified by the International Association for Public Participation (IAP2) practitioners' network, which has assembled five methods in ascending order of public impact along a public participation spectrum, with practical techniques falling under each that are to be implemented at the ground level. Thus, the second contribution of this thesis will be to align the orienting dichotomy of concepts that are academic in nature (traditional public participation and citizen engagement) with similar concepts (representative and deliberative democracy). I will then align the set of analytical concepts with practical administrative techniques and methods of public participation identified in the public participation spectrum. I was unable to find an alignment of academic and practical concepts through my research.

Each of the five methods identified in the public participation spectrum, including Inform, Consult, Involve, Collaborate and Empower, encompass their own practical administrative techniques, which are implemented at the ground level during a public 
participation process. By citing these five methods and further breaking down the orienting dichotomy into practical elements, greater precision will be afforded to my analysis, including the possibilities presented by public participation methods that could assist in crisis management over the short term by reducing tensions, and the longer term through the establishment of partnerships to manage natural resources, while respecting First Nations treaty rights. Additionally, external factors that can have an influence on public participation will all be considered as part of the broader analytical framing for this thesis. Four external factors, including time and financial/human resource constraints, media influence and participant legitimacy all have the potential to influence the engagement method selected, as well as the outcomes of public participation processes.

All of the elements cited above, including the initial orienting dichotomy of traditional public consultation and citizen engagement, representative and deliberative democracy, further sub-division of analytical concepts through the five practical administrative methods cited in the public participation spectrum, and external factors that can influence public participation processes, provide a broader analytical and conceptual framework through which to consider increased possibilities of public participation that could involve citizens in the policy-making process in the context of crisis management. This new analytical framework, which will be referred to as the modified public participation spectrum for the remainder of the thesis, provides a full array of public participation possibilities to review the narrative and perspectives provided on the events of the Marshall crisis. This will be my third contribution of the 
thesis, which is that the modified public participation spectrum presents additional insights into the narrative of the Marshall crisis when considering a) what happened in terms of public participation prior to and during the crisis; $b$ ) what were the shorter-term and longer-term consequences of what happened; and c) what are the possibilities presented for new techniques and methods of public participation in a similar crisis management context?

The research plan for this thesis requires significant resources in terms of three primary areas: academic writing, such as documentation written concerning traditional public consultation and citizen engagement; writing concerning the practical administrative approaches to public participation; and a variety of sources to provide the narrative concerning the Marshall decisions and their outcomes.

Five primary source interviews were conducted with individuals who worked for federal departments, a First Nations organization, and a commercial fishermen's union during the Marshall crisis. The individuals interviewed include: James Jones, former Director General (Gulf Region), Department of Fisheries and Oceans; Joëlle Montminy, former Associate Chief Federal Negotiator (Atlantic) with Indian and Northern Affairs Canada (now Aboriginal Affairs and Northern Development Canada); James (Jim) MacKenzie, former Chief Federal Negotiator with the Department of Fisheries and Oceans; John Paul, Executive Director of the Aboriginal Policy Congress of First Nations Chiefs; and Réginald Comeau, a full-time employee of the Maritime Fisherman's Union. I interviewed these five individuals to gather their perspectives on how the crisis was managed from within their respective organizations, and to seek new perspectives on 
the Marshall crisis narrative after the fact. Questions asked tended to focus on what techniques and/or methods of public participation were implemented prior to and during the crisis by the Department of Fisheries and Oceans; did they think the approach taken by the Department of Fisheries and Oceans was successful; what were external factors that influenced engagements with First Nations and non-Aboriginal fishers; and what would each individual have changed in terms of approaches to public participation?

The individual perspectives collected were then cross-referenced to determine where they compared or contrasted on an issue or set of issues, such as media bias having an effect on the negotiation of a commercial fishing buyback program by Department of Fisheries and Oceans officials. Secondary sources, including a variety of legal and academic books relating to the ultimate outcomes of the case, academic journal articles that were specific to the Marshall decisions, news stories primarily compiled in Ken Coates' book entitled The Marshall Decisions and Native Rights, and government publications such as standing committee reports and summative evaluations of programming relating to the aftermath of Marshall were then used to support statements - from the primary source interviews.

While the cross-section of interviews for this thesis is well rounded, I attempted to interview approximately 10 additional individuals from the Department of Fisheries and Oceans, Indian and Northern Affairs Canada, non-Aboriginal commercial fishing organizations and unions, First Nations reserves such as Burnt Church, and additional federal negotiators. Those individuals who were not interviewed did not respond to the request for interview, recommended another individual to be interviewed, or declined the 
interview on the basis of not wanting to be quoted publicly about the Marshall case.

Historical records and secondary sources will provide an accurate record through which to analyze the outcomes during the crisis. These records and sources will be analyzed against the concept of public participation, which mostly involves description of the most critical elements required to seek a variety of input, especially with the roles of experts and citizens, who have their own unique contributions to make (Abele, Graham, et al., Talking with Canadians 11). This is important, as citizens are increasingly expected to interface with governments in a dialogue to support public policy making from the ground up, as governments become smaller and have greater turnover, which leads to an increased reliance on the public to support in-house capacity (Phillips and Orsini, Mapping the Links 5).

To address external factors, references to primary literature, and an analysis of the media, using agenda-setting and political economy angles, including the pivotal book by Edward S. Herman and Noam Chomsky entitled, Manufacturing Consent, will provide insights into why and how media bias may have played a role in the crisis, and to what degree it had an effect on relations among those who were engaged in public participation efforts and in the confrontational atmosphere throughout the Marshall crisis. Media analysis will be conducted to discern whether there was any media bias present throughout the Marshall crisis, but also to illustrate how it may have contributed to increased tensions and a lack of concern for social justice issues (i.e. treaty rights). Another external factor that I examined was participant legitimacy. I drew from articles of the International Association for Public Participation's online journal that 
described potential issues with participants. Concepts, such as fake public participation, will be analyzed to consider how they work and what potential pitfalls they will present when considering a public participation process.

\subsection{Chapter Outlines}

\subsubsection{Chapter 2 - A Brief History of the Marshall crisis}

This chapter will provide a refreshed narrative of critical events that occurred prior to and during the Marshall crisis for use as a case study. Dates and events identified in this chapter will provide the necessary historical context to aid the reader in understanding the Marshall crisis to conduct an analysis of public participation techniques and methods that were employed by the Department of Fisheries and Oceans. The narrative will then establish a historical basis from which to analyze potential methods of public participation that were not used, such as Involve and which may have proven feasible for implementation.

\subsubsection{Chapter 3 - Public Participation and Policy Making in Canada}

This chapter will present public participation concepts on the basis of the orienting dichotomy, align them representative and deliberative involvement (democracy), then further align those concepts with practical administrative public participation methods and external factors selected to construct an analytical framework that will be used to: a) determine techniques and methods of public participation that were implemented prior to and during the Marshall crisis; b) what were the shorter-term and longer-term consequences of what happened; and c) what are the possibilities presented for new techniques and methods of public participation in a similar crisis 
management context.

The second part of this chapter will provide general definitions and an overview of public participation concepts; briefly describe the authors from each body of analysis that will be used, including brief descriptions of their conceptual and analytical work, its original intent and how it will be applied to analysis in this thesis; and describe external factors, such as time constraints and media influence, which should be considered when deciding which public participation techniques and methods should be used in crisis management.

The final part of this chapter will start with the public participation spectrum, which includes public participation techniques and methods, and will provide a description of each technique, method and how those relate to the other concepts that have been written about, such as traditional public consultation, citizen engagement, and representative and deliberative citizen involvement. Finally, external factors will be added. The chapter will end with a modified public participation spectrum, encompassing all analytical concepts and elements to be considered in the chapters that follow.

\subsubsection{Chapter 4-Public Participation Prior to and During the Marshall Crisis}

This chapter will focus on the few instances prior to and during the Marshall crisis where public participation techniques and methods were implemented by the Department of Fisheries and Oceans, primarily with the leaders of various groups through the use of unofficial meetings, negotiations and ad hoc public consultations. Analysis will demonstrate that while the public participation techniques that were implemented by 
the Department of Fisheries and Oceans prior to and during the Marshall crisis changed and increased in intensity, those very techniques all remained within the same methods. The use of the same methods left little opportunity for increased public impact in policy making to manage the crisis and achieve the stated short- and long-term objectives of this thesis. This analysis will set the stage for Chapter 5 , which will draw from the modified public participation spectrum and propose new possibilities that additional methods pose to be increase public participation and public impact on policy during a crisis and to potentially contribute improved short- and long-term crisis management outcomes.

\subsubsection{Chapter 5 - New Possibilities for Crisis Management Through Public Participation}

This chapter builds on the developments in Chapters 2, 3 and 4, and considers new possibilities of public participation methods that could have been implemented during the Marshall crisis, based on the modified public participation spectrum. This chapter will draw from primary interviews highlighted in Chapter 2 to determine what the individuals who were interviewed for this thesis would have changed in the Marshall crisis response. This chapter will then propose that one method poses new possibilities for techniques that would address the changes recommended by the interviews and enable an increase in public participation and public impact in the policy-making process. The techniques associated with the recommended method will then be elaborated as part of a crisis summit, as if it were held at the beginning of the Marshall crisis, to demonstrate what an alternative approach to public participation might have looked like. 


\subsubsection{Chapter 6 - Conclusion: New Possibilities?}

The concluding chapter will include summaries of what I attempted to achieve in the thesis, namely the three contributions mentioned at the beginning of this chapter; the outcomes that I achieved through my analysis, including analyses using the modified public participation spectrum with the Marshall crisis case study to pose the question of what additional methods of public participation would pose new possibilities for crisis management; analyze an Atlantic Lobster Summit and Canadian Lobster Council that was established out of the Summit in 2007; and recommended areas for further research, such as additional case studies that could provide an evidentiary basis to evaluate my conclusions. 


\section{Chapter: A Brief History of the Marshall Crisis}

\subsection{Introduction}

This chapter will provide a summary of critical events that occurred prior to and during the Marshall crisis, including a Marshall Crisis Timeline for use as a point of reference. The Marshall crisis is defined as the time period when violent confrontations occurred among the Department of Fisheries and Oceans, First Nations and nonAboriginal fishers, starting on September 17, 1999, when the Supreme Court of Canada rendered the first Marshall decision (Marshall I) ${ }^{I I}$, through to November 17, 1999, when the Supreme Court issued a clarification of the first decision (Marshall 2$)^{12}$, and for approximately one year following, when additional violent confrontations occurred, primarily around Burnt Church, New Brunswick. Dates and events identified in this chapter will provide the necessary historical context to aid the reader in understanding the Marshall crisis as a case study through which to conduct comparative analysis of public participation techniques and methods that were employed by the Department of Fisheries and Oceans to achieve the short- and long-term objectives highlighted earlier in this thesis. Comparative analysis will then establish a basis to analyze potential techniques and methods of public participation that were not used, such as citizen engagement, but that may have contributed toward reducing tensions during the Marshall crisis. Such techniques may have also represented an opportunity for establishing partnerships among the groups involved to manage the Maritime commercial lobster fishery over the long

\footnotetext{
" R. v. Marshall (No. 1) [1999] 3 S.C.R. 456.

${ }^{12}$ R. v. Marshall (No. 2) [1999] 3 S.C.R. 533.
} 
term, while respecting First Nations' treaty rights.

This chapter is divided into the following sections: Prologue to the Marshall Crisis; Events During and After Marshall 1 (September 17, 1999); and Events During and After Marshall 2 (November 17 1999). The Marshall Crisis Timeline, located in Appendix A, will serve as a reference point for key events throughout the crisis. Each of these key events is further elaborated in the sections that follow.

\subsection{Prologue to the Marshall Crisis}

It has been approximately twelve years since the Supreme Court of Canada rendered the Marshall decision (Marshall 1), on September 17, 1999, and its subsequent clarification (Marshall 2) on November 17, 1999. The event that triggered these legal decisions was the 1993 arrest of Donald Marshall Jr., a Mi'kmaq fisher. The Department of Fisheries and Oceans fined Marshall Jr. for illegally fishing eels out of season (Coates 3). Ken Coates describes Marshall Jr.'s reaction to the arrest: "Convinced that he had a right to fish, he contacted the chief of his reserve, who told him to keep fishing" (3). Marshall Jr. went back on the water and had his catch seized twice more by Department of Fisheries and Oceans officers, who charged him with several offences, including "fishing without a licence, selling eels without a licence, and fishing during a closed season" (Coates 3-4). Marshall Jr. was convicted of these charges in Nova Scotia provincial court in June 1996 (Coates 5). Morellato comments:

The accused, a Mi'kmaq Indian, was charged with Federal Fisheries Regulation offences. He admitted that he had caught and sold 463 pounds of eel without a licence (worth less than $\$ 800$ ). The only issue at trial was 
whether he possessed a treaty right to catch and sell fish under the treaties of 1760-61 so as to exempt him from compliance with the Regulations (10).

Marshall Jr. was found to not possess an exemption by the provincial court that tried him. Once convicted, Marshall Jr. appealed the charges, but they were struck down on appeal to the Supreme Court of Nova Scotia, which, in a unanimous decision, upheld the lower court's decision on March 26, 1997 (Isaac 106).

Finally, Marshall Jr. appealed his case to the Supreme Court of Canada (Coates 57). Marshall Jr. received a favourable response to his assertion of a Mi'kmaq treaty right to fish on September 17, 1999, when the Supreme Court of Canada rendered its first decision, Marshall 1, in which it sided with the Mi'kmaq on their right to fish for a moderate livelihood. The outcomes of the Supreme Court of Canada appeal case would eventually lead to the tumultuous period in the Maritimes known as the Marshall crisis, which would cause First Nations and non-Aboriginal fishers to engage in violent confrontations on land and water over the right to fish commercially for lobster, one of the primary economic drivers in coastal Maritime areas at the time.

Prior to the Marshall decisions, there were few instances where the federal government engaged with First Nations to formally discuss treaty rights, including the treaty right to fish commercially for lobster and other fish, which became the primary concern of fishers as a result of the Marshall decisions. John Paul, Executive Director of the Atlantic Policy Congress of First Nations Chiefs, states that the "federal government did not want to discuss" treaty rights to fish for lobster prior to Marshall 1 because "they 
thought they would win the case" (Interview). Whether or not this is an accurate understanding of federal motives, the response by the Department of Fisheries and Oceans was considered slow and no formal plans were in place to address the fallout from the vagueness of Marshall I (The Marshall Decision and Beyond).

The Department of Fisheries and Oceans requested a stay of the ruling for several months to prepare for its implementation (Montminy Interview). The Supreme Court responded by stating that the judgement would remain effective immediately (The Marshall Decision and Beyond). Such a request may also lend credence to the view that the Department of Fisheries and Oceans lacked a contingency plan (Coates 131). However, despite a slow start, the Department did become involved at the ground level in an attempt to reduce tensions.

Despite the lack of formal engagement prior to the Marshall decisions, there were informal relations established by the Department of Fisheries and Oceans and First Nations Chiefs and Councils, prior to Marshall 1 , on the basis of the Sparrow decision. James Jones, former Regional Director General (Gulf Region) of the Department of Fisheries and Oceans, states that Sparrow enabled First Nations to fish for "food, social and ceremonial purposes" (Interview). These informal relationships helped in keeping the lines of communication open among the Department of Fisheries and Oceans officials and First Nations throughout the Marshall crisis. Jones contends that prior to Marshall I, the Department had at least developed "a fair relationship with Chiefs and Councils, which helped considerably in managing engagement" throughout the Marshall crisis (Interview). 
The Sparrow decision ${ }^{13}$, which was rendered by the Supreme Court of Canada on May 31,1990 , approximately nine years before Marshall 1 , led to a significant degree of interaction with First Nations on the issues of "salmon rivers and the food fishery for lobster" (Jones Interview). Réginald Comeau, a full-time employee of the Maritime Fisherman's Union, which represents the commercial lobster fishermen in the East Coast of New Brunswick, further agrees that an informal relationship was established among the Department of Fisheries and Oceans and First Nations on the basis of Sparrow (Interview). However, Comeau felt that the lack of engagement with non-Aboriginal fishers was a significant catalyst leading to the violent confrontations of the Marshall crisis, as non-Aboriginal fishers felt they had no say in how the lobster fishery would be managed with First Nations fishers (Interview). While there was some engagement prior to the Marshall decisions among the Department of Fisheries and Oceans and First Nations, and the relationships that were formed helped to keep the lines of communication open during some of the darker points of the Marshall crisis, it is apparent, on the basis of the cited interviews and the Standing Committee on Fisheries and Oceans' report that the Department of Fisheries and Oceans did not wish to formally engage with First Nations and non-Aboriginal fishing communities en masse to seek solutions to manage the fishery to everyone's benefit at the time. The Department of Fisheries and Oceans' approach could be in part due to the vast amount of nonAboriginal commercial fishing organizations that would have to be engaged, and because

\footnotetext{
${ }^{13}$ R. v. Sparrow [1990] 1 S.C.R. 1075.
} 
the treaty right to fish was considered a legal treaty rights issue among the federal government and First Nations only.

James MacKenzie, the Chief Federal Negotiator appointed by the Minister of Fisheries and Oceans to negotiate with First Nations fishers during the crisis, felt that "there was not much engagement prior to Marshall' (Interview). MacKenzie suggests public participation initiatives that did occur prior to Marshall were held on "an issue by issue basis," which had an effect on the " 200 plus existing fisheries organizations, including the Maritime Fishermen's Union, [which] was grassroots, hourly paid, and small operations" (Interview). The sheer number of organizations that would have to be included as part of any broader public participation initiative by the Department of Fisheries and Oceans would have been quite large and potentially unfeasible. The number of non-Aboriginal fishing organizations will again be demonstrated as a challenge that Department of Fisheries and Oceans attempts to manage during the Marshall crisis when Gilles Thériault is appointed as Associate Chief Federal Negotiator to help James MacKenzie receive input from non-Aboriginal fishers while negotiating communal fishing licences with First Nations (Jones Interview).

In sum, in the pre-Marshall crisis period, First Nations Chiefs and Councils were engaged informally by Department of Fisheries and Oceans officials on fishing for food and ceremonial purposes, on the basis of the Sparrow decision. However, there was no formal engagement on treaty rights. In addition, non-Aboriginal fishers received little engagement on their perspectives, except on a case-by-case basis with regard to smaller fishery-related matters. This lack of formal engagement presents potential reasons why 
the Marshall crisis may have developed in the way that it did. The lack of departmental communication with non-Aboriginal fishers led to concerns with the viability of the Maritime commercial lobster fishery as a whole, with the new First Nations entrants as a result of Marshall 1. Additionally, First Nations fishers were not formally engaged prior to Marshall 1 on their treaty rights to natural resources, which is in part what spurs the Marshall crisis after Marshall 1 is rendered by the Supreme Court of Canada.

\subsection{Events During and After Marshall 1 (September 17, 1999)}

The Supreme Court of Canada issued the first Marshall decision (Marshall 1) on September 17, 1999, in which it finds in favour of Donald Marshall Jr.:

The eighteenth-century treaties between the British and First Nations covered the commercial use of resources. The right to use the resources - in this case, eels was not unlimited. First Nations could earn a 'moderate income' (not defined) and were obliged to operate within the framework of federal government rules" (Coates 7).

Many individuals on all sides of the issue were concerned with the lack of clarification on what defined a moderate income in the Marshall 1 ruling, which posed serious questions regarding the extent to which the variety of Maritime commercial fisheries, such as eels and lobster among others, would be made available to First Nations for commercial purposes:

In its original judgment, of September 17, 1999, a majority of the Court [Supreme Court of Canada] concluded that Marshall [Jr.] had established the existence and infringement of a local Mi'kmaq treaty right to carry on 
a small scale commercial eel fishery but the Crown had not attempted to justify the infringement of the treaty right (Morellato 11).

Maritime Mi'kmaq fishers felt vindicated that their treaty rights were acknowledged by the Supreme Court and immediately started fishing for lobster out of season and without a licence or quota. They felt a new sense of economic independence based on their treaty right to fish (Coates 7-10). Alex Cameron provides the following description about the First Nations' reaction in response to Marshall 1: "The Decision was celebrated in jubilant native communities throughout the Maritime provinces. Canada's highest court had confirmed a 'constitutionally-protected native treaty right to 'hunt, fish, and gather' for the purpose of gaining a 'moderate livelihood'" (5).

In stark contrast to First Nations' jubilation with the confirmation of their treaty rights by the Supreme Court, non-Aboriginal fishers became angry, wondered what would happen with the commercial fishery and how the new ruling could re-distribute the wealth of the commercial fishery among their groups and First Nations fishers. They were also concerned that too much lobster could be fished out of season and without a quota, which could have led to the eventual collapse of the industry (Coates 9). In Coates' words, "For the non-Aboriginal fishers, the Marshall decision was frightening. One seemingly stable element in the regional economy - the lobster fishery - was under attack. The prospect of expanding Aboriginal rights seemed very real" (Coates xvii). Not only would Marshall 1 present concern over natural resources and the livelihoods of non-Aboriginal fishers. It would also pose significant strain on the First Nations and non-Aboriginal relationships in the region, which would be key to managing any fishery 
over the long term: "To a degree that most Maritimers do not appreciate, the Marshall decision [Marshall 1 and 2]...promises to change forever the face of natural resource use, economic and political relations, and indigenous-newcomer contact in the region" (Coates $\mathrm{x}$ ). Marshall 1 provided good reason for non-Aboriginal fishers to be concerned about their livelihoods and the potential of having the First Nations in the region gain significant control of the Maritime commercial lobster fishery, mainly as the result of their new, yet vaguely-defined rights.

The Standing Committee on Fisheries and Oceans indicates, in its second report of December 1999 that "DFO's initial response was slow and uncertain. It appeared to have been caught off guard by the Supreme Court's ruling and, for several days after, chaos and confusion ruled" (The Marshall Decision and Beyond). The concerns of nonAboriginal fishers were not alleviated by the Department of Fisheries and Oceans' apparent lack of a plan: "caught unaware by the Supreme Court judgment and its implications...Officials ask for calm and for time to sort out the ruling, as First Nations prepared to exercise their newly defined right and as non-Aboriginal fishers complained bitterly about having to surrender a sizeable portion of their industry" (Coates 9). Further evidence of the lack of a contingency plan on the Department's part is provided through its request to the Supreme Court to stay the Marshall 1 decision until Fisheries and Oceans can devise a plan to manage the commercial lobster fishery in accordance with the decision's outcomes. Unfortunately for the Department, the Supreme Court rejected the Department of Fisheries and Oceans' request (The Marshall Decision and Beyond).

James Jones says many questions remained to be answered after Marshall 1 
because the Supreme Court of Canada initially left out the question of who had the regulatory authority over the First Nations and non-Aboriginal fishery. This was especially concerning with the added confusion of the vagueness surrounding the definition of a moderate livelihood (Jones Interview). As previously indicated, Jones maintains the lines of communication remained open between the Department of Fisheries and Oceans and First Nations and the First Nations leadership during the initial period after the decision. However, informal engagements did not generally include individuals from the community (Interview). The informal engagement with the leadership of an organization can become an issue when those who are most likely to benefit or lose economically (i.e. First Nations and non-Aboriginal fishers) are not included in discussions. The fact that none of the people who stood to lose their livelihoods were included in discussions may have helped contribute to the Marshall crisis because most individuals were left out of the informal meetings held among federal representatives and their community/organizational leaders. Some decided to take matters into their own hands.

Non-Aboriginal fishers may have been concerned for their livelihoods, but concerns do not necessarily lead to violent confrontation. One question that remained to be answered was why non-Aboriginal commercial lobster fishers became so angry and confrontational with their First Nations counterparts? One likely reason is because nonAboriginal fishers stood to lose quite a lot with the Maritime commercial lobster fishery, which is the largest economic driver in the coastal regions of the Gulf of St. Lawrence, as well as Québec and Newfoundland and Labrador: 
Lobster is the most widely distributed of Atlantic fish species and contributes to the livelihood of more harvesters than any other species. According to Fisheries and Oceans Canada (DFO) officials, the lobster industry brings close to $\$ 1$ billion a year to the Canadian economy. The landed value of lobster in 2007 was $\$ 562$ million. The lobster fishery is the single most valuable fishery in Atlantic Canada, representing about a third of the total landed value for all commercial fisheries (excluding aquaculture). As such, it has been and remains one of the economic pillars for many Québec and Atlantic Canada communities. There are over 10,000 lobster fishing licences, and together with processing plant workers and people involved in the export of lobster products, more than 25,000 Canadian workers make a living in the utilization of this marine resource (The Canadian Lobster Fishery).

The statistics presented above, while being reported later than the Marshall crisis, still provide an indication of the immensity of the commercial lobster fishery in Atlantic Canada and Québec, which includes the Gulf Region of the Maritimes. Considering that lobster is the number one provider of employment and yields approximately $\$ 1$ billion a year, it would make sense that non-Aboriginal fishers would be angry about losing that resource to First Nations. This response may have also been exacerbated by the First Nations interpretation that given the vague definition of a moderate livelihood, they would have no restrictions on the fishery (i.e. fishing without a licence, quota and out of season) (Coates 3-4). Non-Aboriginal fishers were not in this position. They were 
required to purchase a commercial lobster licence. These are costly and in limited supply. In addition, the non-Aboriginal fishers with licences would be required to abide by specific regulations governing the time of year (season), geographic "Lobster Fishing Area," a maximum landing poundage and minimum size of lobster landed, among others. They were concerned that Aboriginal fishers would not have these constraints. The Standing Committee on Fisheries and Oceans stated the following concerning costs and regulations:

The lobster fishery is managed by areas, the Lobster Fishing Areas or LFAs. There are 38 inshore and one offshore LFAs. The offshore fishery (LFA 41) is prosecuted 50 miles off the coast of Nova Scotia and involves only eight licences. Both inshore and offshore fisheries are closely regulated. Entry is limited, and licence fees range from $\$ 100$ to $\$ 1,890$ annually. Management of the fishery uses input controls as it is subject to seasonal openings and restrictions on licence and trap numbers. The number of licences, which can be transferred with DFO's approval has been stable for several years. Escapement measures such as legal minimum size and prohibiting the landing of berried females are also used as conservation tools. All these measures vary by area or region. There are however no limits on how much lobster may be caught. In some LFAs, there are limits on the number of hauls allowed per day (The Canadian Lobster Fishery).

Considering the difficulty associated with getting into the commercial lobster fishery as 
an individual through its licensing regime, the amount of money it costs and the significant regulations that must be abided to ensure the future sustainability of the fishery, it would not be too difficult to understand why non-Aboriginal fishers would become angry at First Nations fishing without a licence initially, out of season and with no maximum landing amounts imposed. Conversely, First Nations felt their rights, based on the historic treaties, had been ignored since the 1700 s. In sum, there was likely a lot of animosity growing on both sides toward each other, and the Department of Fisheries and Oceans appeared unready to enforce regulations because officials did not know what the definition of a moderate livelihood entailed. The concerns over losing the fishery to First Nations, who at least initially refused to obey the regulations set forth for everyone else, was likely the primary catalyst for non-Aboriginal anger toward First Nations after Marshall 1.

Before entering into a detailed description of each confrontation and event that occurred, the following summary, provided by Alex Cameron, serves as a useful reference point to enable the reader to view the extent and scope of the Marshall crisis from start to finish:

In early October [1999] in Miramichi Bay, non-natives in perhaps 100 or more boats destroyed several thousand native traps, a scene that was repeated near Yarmouth. A school in Burnt Church and fish processing plants on the north shore of New Brunswick were vandalized. Buildings were burned on the Burnt Church Reserve. Non-native vehicles were torched. Native "warriors" occupied the wharf at Burnt Church, and the 
RCMP reinforced the local detachment. Later that month, charges were laid against non-natives for their part in these events. The violence continued into the summer of 2000 when native fishermen undertook a commercial lobster fishery in St. Mary's Bay, Nova Scotia, and federal fisheries officials boarded their boats and impounded equipment (82). These violent confrontations happened while First Nations and non-Aboriginal fishers complained that federal representatives were nowhere to be found (Coates 152). These types of complaints were commonplace in the media, reports and books written on the Marshall decisions after the fact. However, in Chapter 4, I will demonstrate that the Department of Fisheries and Oceans implemented techniques and methods of public participation prior to and during the Marshall crisis. There are two important distinctions to be conveyed concerning the Department of Fisheries and Oceans' approaches to public participation prior to and during the Marshall decisions. The distinction between engaging with the First Nations' and commercial fishermens' leadership, rather than with all groups, is important because it was the First Nations and non-Aboriginal fishers who could very well lose their livelihoods through the outcomes of the Marshall decisions. As will be elaborated later in this thesis, engaging with the leadership only led to some tensions and dissention among the fishers on both sides, while ignoring potential opportunities to improve relations and establish partnerships. In addition, the distinction between formal and informal public participation is important to capture because a significant amount of engagement that occurred prior to and during the Marshall crisis occurred with the leadership behind closed doors. This frustrated First Nations and non- 
Aboriginal fishers during the proceedings, as they could have contributed something significant in a more formalized public participation process. This will be further discussed in Chapter 5.

As if debate arising from the multiple interpretations of Marshall 1 was not enough, tensions were exacerbated by media stories that favoured non-Aboriginal perspectives and focused primarily on the plight of non-Aboriginal commercial fishing interests. For example, while news stories estimated that a significant portion of the Maritime commercial lobster fishery would go to First Nations interests based on their new found rights, the actual percentage of the overall commercial lobster fishery occupied by First Nations turned out to be one percent (Coates xii). Non-Aboriginal fishers, reading the erroneous information presented, while already being concerned for their own livelihoods based on the moderate livelihood reference that was now leading many First Nations fishers to fish without constraints, would likely become even more anxious than they already were. It was explained, "in their unease and disappointment, the fishers [non-Aboriginal] erupted in anger and frustration, adding fuel to the controversy and providing First Nations with a unique insight into the thoughts and opinions of their neighbours" (Coates xvii). While it is likely that media reports tending to favour the non-Aboriginal fishers' economic-based arguments against Mi'kmaq rights were not the catalyst for the Marshall crisis, they certainly contributed to the tension and were a reflection of the fears of non-Aboriginal fishers in the Maritimes. This dominant viewpoint in the media likely increased anger and frustration among non-Aboriginal fishers through the expression of viewpoints that resonated with them, but it would have 
also angered First Nations fishers, who likely felt their position was being misrepresented in the media. Media influence on the tensions that arose throughout the Marshall crisis will be described and analyzed at length in Chapters 3, 4, 5 and 6 .

Another reason that the Marshall crisis likely occurred is because it was treated primarily as a legal issue between the Department of Fisheries and Oceans, and First Nations. During the first two months following Marshall 1, the Department of Fisheries and Oceans "had a relationship with First Nations and the Maritime Fishermen's Union and could communicate, but it was initially seen as an issue between two parties (the Department of Fisheries and Oceans and First Nations)" (Jones Interview). It was within the context of the Sparrow decision, as mentioned in the Prologue to the Marshall Crisis section above, that existing relationships already developed with Chiefs and Councils provided an opportunity to hold informal discussions behind closed doors, despite the blatant differences of opinion on how to interpret the meaning of a moderate livelihood in Marshall I (Jones Interview). Interactions behind closed doors point to a couple of public participation techniques that occurred prior to and during the Marshall crisis, which will be further elaborated in Chapters 4 and 6.

The first violent confrontation between First Nations and non-Aboriginal fishers after Marshall 1 occurred on October 3, 1999, near Burnt Church, New Brunswick. The confrontation was described as a pre-dawn attack: On 3 October non-Aboriginal fishers destroyed approximately 3,000 Mi'kmaq lobster traps in Miramichi Bay (Coates 139). This attack was devastating. Additionally, at Burnt Church, non-Aboriginal fishers "temporarily shut down a fish plant that had been buying lobster from the Mi'kmaq, 
wrecking some of the plant's equipment" (Wicken 229). The significant property damage done in this first confrontation demonstrates the immense differences of opinion and tensions that came out of the disagreement over what constituted a moderate livelihood as it relates to the Maritime commercial lobster fishery. It would appear that some of the non-Aboriginal fishers, in the absence of strong enforcement from the Department of Fisheries and Oceans during the first weeks, took matters into their own hands by destroying a significant proportion of the First Nations' traps to cripple the First Nations commercial lobster fishery capacity. However, while the confrontation raged on, the Department of Fisheries and Oceans attempted to intervene by communicating with lobster fishers publicly, as James Jones will describe what was part of his job as Regional Director General.

James Jones recounts the following gathering that he held with non-Aboriginal lobster fishers on the day the traps were destroyed: "On October 2-3, 1999, approximately 10-12 people from Burnt Church and 30-40 from Bay St. Anne were arrested for a variety of mischief charges," such as "cutting traps" (Interview). 450 [nonAboriginal] commercial fishers were present at a public meeting and were very angry about what had occurred (Jones Interview). Jones spoke to the group of angry fishers and the lack of knowledge about Marshall 1 became apparent very quickly: "About an hour into the meeting, there was lots of shouting. One guy gets up and asks 'Why did you do this?"' (Interview). Jones told the individual that it was because of a Supreme Court of Canada decision and the fisher asked, "what's this Supreme Court you're talking about?" (Interview). Jones states that to that point, "all communiqués had mention of the 
Supreme Court of Canada decision on Marshall [Marshall 1], but needed to explain in some manner what the Supreme Court was and where it sat in the Canadian governance structure. We were 'over the heads of some of our audience"" (Interview).

Jones' anecdote is telling of the early efforts that the Department of Fisheries and Oceans made to share information with non-Aboriginal fishers and to keep the lines of communication open among the groups involved in the Maritime commercial lobster fishery, despite not having a contingency plan in place. In addition, an unintended consequence of this public gathering was that the Department came to realize the importance of knowing its audience and tailoring its message to them. Many nonAboriginal fishers were incredibly angry and some did not understand the Supreme Court's role in the context of Canadian society and institutions, let alone why the decision was made and different enforcement regimes were put in place for the First Nations and non-Aboriginal fishers. Changing the communiqués was an important step toward ensuring that everyone had a similar understanding of the situational context involved with Marshall 1. This change may have helped to alter the opinions of some of the fishers toward the Department of Fisheries and Oceans because they could now understand why the Department had to enforce different rules and regulations with each group.

In the immediate aftermath of the pre-dawn attack on Burnt Church traps, Mi'kmaq warriors mobilized on October 4, surrounded and occupied "the wharf at Burnt Church with flags and teepees" to assert their presence and prevent further attacks (Coates 141). When the Mi'kmaq warriors arrived at Burnt Church, they were able to 
ensure that First Nations fishers could continue to land their catch at the wharf, but their presence did little to reduce tensions, as they enabled at least some of the First Nations' catch to be brought on shore, to the ire of some non-Aboriginal fishers. With tensions rising, Herb Dhaliwal, then Minister of Fisheries and Oceans, decided to hold a meeting with First Nations leaders concerning how they would manage their rights according to Marshall 1.

On October 6, 1999, Minister Dhaliwal held a critical meeting in Halifax with the 34 "Atlantic First Nations Chiefs, supported by Aboriginal leaders from across the country" (Coates 144). Coates states the following concerning the outcomes of the meeting: "although discussions were tense and disagreements repeatedly surfaced, they [the Chiefs] did agree to a voluntary thirty-day moratorium"(144). Apparently, Grand Chief Ben Sylliboy of the Mi'kmaq Grand Council convinced the Mi'kmaq Chiefs to agree to the moratorium and avoid further confrontation at the meeting (Coates 144).

Despite the agreement by First Nations Chiefs to hold a voluntary moratorium, there was a significant degree of anger among many First Nations fishers in the region for not having an opportunity to debate such an approach. On October 9-10, 1999, First Nations fishers in Burnt Church were especially indignant about this recent development. They were already "hustling to replace their damaged traps (they ordered 1,000 at $\$ 70$ each), declared their intention to return to the lobster fishery, screaming their defiance at First Nations chiefs who they described as 'sellouts'" (Coates 145). While some First Nations people were likely fine, or at least indifferent to the approach taken by the Mi'kmaq Grand Council at the meeting with Minister Dhaliwal, once again, those who 
stood to gain or lose the most economically from the moratorium decision were not engaged for their input.

When a significant decision, like a voluntary moratorium, is made unilaterally by the leadership of a group, it may be difficult to have some of the members of the group agree with the decision if they feel their concerns were not taken into account. On the one hand, the Department of Fisheries and Oceans would be to blame for this outcome because it did not invite First Nations fishers to the table, but on the other, the Mi'kmaq Chiefs should have gone to the table with a mandate from their members to ensure that their opinions were solid. There was also likely the consideration that there were too many interests and groups to bring to the table to complete such a daunting task in a timely fashion. A balance of sorts, between time available and the degree of involvement to include in these meetings would be necessary.

The Department of Fisheries and Oceans responded to the tensions with Burnt Church and Shubenacadie (Indian Brook) First Nations by imposing regulations and establishing a limited lobster fishery. Minister Dhaliwal announced that a limited Mi'kmaq fishery would be permitted for "Burnt Church (600 traps) and Shubenacadie (Indian Brook) (800 traps)" (Coates 146). This short-term measure of a limited fishery for the First Nations that were not interested in participating in the voluntary moratorium would later backfire. On October 13, 1999, "Maritime Chiefs formally repealed the voluntary moratorium" on the basis that Dhaliwal had imposed legal "limits on the lobster fishery" for Burnt Church and Indian Brook (Coates 147-148).

Another group that worked indirectly toward the voluntary moratorium's demise 
was the non-Aboriginal fishers, who pressured the Department of Fisheries and Oceans to allow their fishing season to continue. They became anxious, especially in Nova Scotia, that their local economy could be jeopardized if they lost a short period of their fishing season (Coates 145). At this point, it appeared that nobody was very supportive of the actions of the Department of Fisheries and Oceans Minister: "Fishers from the Bay of Fundy gathered at a meeting in Nova Scotia on 9 October, cheering calls for the resignation of Herb Dhaliwal" (Coates 145). The non-Aboriginal fishery was permitted to remain open, mostly because Chief Brian Toney of the Annapolis First Nation intervened to ensure that the fishery in Nova Scotia could proceed (Coates 148).

Despite the fact that many First Nations and non-Aboriginal fishers were displeased with Minister Dhaliwal, they did start meeting on how to better integrate First Nations into the commercial lobster fishery: “...to less fanfare, Aboriginal and nonAboriginal fishers gathered to discuss ways of integrating First Nations into the harvest. The most popular idea was for the federal government to purchase existing licences and allocate them to bands" (Coates 148). This approach would enable First Nations to enter the fishery without non-Aboriginal fishers losing their livelihoods (Coates 148). This would prove to be one of the only self-initiated meetings among those with the most to gain or lose, which is likely also symptomatic of the lack of formal public participation with the First Nations and non-Aboriginal fishers by the Department of Fisheries and Oceans.

Considering the intensity of the violent confrontation that occurred on October 6 , 1999, these minor acts of First Nations and non-Aboriginal fishers working together 
helped set the stage for future agreements and co-operation in managing and sustaining the Maritime commercial lobster fishery in a beneficial manner to all groups involved. However, as will be argued in later chapters, it is important to consider how tensions could have been reduced sooner, as in any typical crisis situation, tensions will tend to dissipate over time.

In mid-October, 1999, Minister Dhaliwal focused on negotiations and mediation as a means to resolve the impasse over Marshall 1 (Coates 133). Dhaliwal appointed "a seasoned negotiator, James MacKenzie, the chief federal negotiator for Labrador land claims, to the task of finding a workable solution" (Coates 133). In addition, Robert Nault, Minister of Indian Affairs and Northern Development, appointed a second Chief Negotiator to highlight the two-pronged approach of the federal government. As part of this approach, Indian and Northern Affairs Canada would negotiate long-term treaty rights, while the Department of Fisheries and Oceans would negotiate the buyback of commercial fishing licences. The Department of Fisheries and Oceans would then offer to bring First Nations under the same fishery management regime as a short-term measure to address their treaty rights under Marshall 1 by negotiating commercial fishing licences on a community-by-community basis (Montminy Interview).

Despite the focus on negotiation and mediation, initial negotiations once again left non-Aboriginal fishers out because the whole issue was seen as a First Nations treaty rights issue that had nothing to do with non-Aboriginal interests (Montminy Interview). However, this would later be somewhat remedied with the appointment of Gilles Thériault as Associate Chief Federal Negotiator consult with non-Aboriginal fishers and 
relay their views to James MacKenzie, who would also provide updates to allay their concerns.

James MacKenzie explained his pragmatic negotiation style with each First Nation as he met with them. MacKenzie states that his approach to engaging with the groups was as follows: "I am here, I am going to do this, you may not like what I have to say, but I will never bullshit you" (Interview). MacKenzie indicated that the first round of negotiations was Department of Fisheries and Oceans-only and was primarily concerned with the issuance of "communal licences, resources and training for First Nations fishers" (MacKenzie Interview). In the first round of negotiations, the Department of Fisheries and Oceans was clear that negotiations would pertain to treaty rights, which reflected the short-term nature of the agreements (MacKenzie Interview). James MacKenzie was appointed at an interesting time, as on October 15, 1999, non-Aboriginal fishers gathered in the water near Yarmouth, Nova Scotia, and were "determined to smash Aboriginal lobster traps and threatening to close down the fishery" on the basis of the Mi'kmaq Chiefs repealing their voluntary moratorium (Coates 148). According to Coates, "James MacKenzie rushed to the site, hoping to head off another Burnt Church-type confrontation" (Coates 148). Aside from "a couple of arrests," this protest turned out to be relatively peaceful (Coates 148 ).

The first round of negotiations did not fare well, as the "first offer presented by the federal government was quickly rejected by fishers who gathered in Yarmouth on 19 October to consider their options - but by the end of the month the issue had started to settle down" (Coates 148). 
Information sharing with non-Aboriginal fishers was later addressed with the appointment of Gilles Thériault as an Associate Chief Federal Negotiator to work with the commercial fishing groups. This was largely seen as a very successful approach to informing non-Aboriginal commercial fishers about what was happening with negotiations to sign agreements for the buyback program (Comeau Interview). Thériault was also very attentive to non-Aboriginal commercial fishers' concerns and often relayed them to MacKenzie and other officials at the Department who were involved in negotiations with the Mi'kmaq (MacKenzie Interview). This was especially important for the non-Aboriginal commercial fishers, who at least felt at this point that they had a forum through which to voice their concerns. The use of more than one Chief Federal Negotiator to at least listen and relay all of the particular groups' concerns was wellreceived by all who were interviewed for this thesis. If anything, they would have preferred to see DFO invest additional resources with the negotiators, a point made by John Paul, James MacKenzie, James Jones and Réginald Comeau.

It is important to note that not just anyone could have acted as the Associate Chief Negotiator position and been as effective at communicating with non-Aboriginal commercial lobster fishers. Thériault has had a long career in a variety of roles focused on the Maritime commercial fishery. For example, according to a biographical note on the department of Aboriginal Affairs and Northern Development website, Mr. Theriault began his career as a union organizer with the Association des Pêcheurs Professionels du Sud-Est du Nouveau-Brunswick in 1974-1975, worked as a Research Assistant with the New Brunswick Department of Fisheries in 1975-1976 and then became an Organizer for 
the Association once again in 1976-1977 (http://www.aadnc-aandc.gc.ca/aiarch/mr/nr/sd2005/02721bk-eng.asp). From 1977-1987, Mr. Therriault was the Executive Director of the Maritime Fishermen's Union. According to Wallace Clement, the Maritime Fishermen's Union was turned around during the years in which Thériault was the Executive Director. He was especially adept at getting individuals out for union votes:

In 1984 certification votes were held. On the Caraquet Peninsula 480 fishers were certified, and on the southeastern coast 585 , causing the New Brunswick Fish Buyers' Bargaining Association to be assembled. According to Gilles Thériault, president of the Union, 95 per cent of the fishers who signed were skippers. The species for which prices were to be negotiated included lobster, herring, mackerel, ground-fish, scallops, salmon, gaspereau, and smelt. The average turnout for votes for votes in the three areas was 86 per cent and the average vote in favour of certification was 75 per cent. That was overwhelming support (149). Theriault appeared to be well supported and well respected based on the turnout and support his union received through their certification vote in 1984 . This was just a few short years after it was contemplated that the debt-laden Maritime Fishermen's Union might become extinct in the 1970s (Clement 146). Thériault appeared to exhibit a strong ability to manage union issues and held a decade-long job as the Executive Director/President of the Maritime Fishermen's Union. He was also based out of New Brunswick, the primary hotbed of confrontation during the Marshall crisis. Thériault would have likely been well known by government representatives, First Nations and 
non-Aboriginal commercial fishers alike through his dealings on behalf of the union. Thériault also founded his own consultancy firm on aquaculture issues, GTA Consultants Inc., in 1987, which is based out of Moncton and is still in operation (http://www.aadncaandc.gc.ca/aiarch/mr/nr/s-d2005/02721bk-eng.asp). From 1999 to 2003, Thériault was the Associate Chief Negotiator for the Department of Fisheries and Oceans, alongside James MacKenzie, through the duration of the Marshall crisis. He then moved on to become the Chief Federal Fisheries Negotiator for the Department of Agriculture, Fisheries and Aquaculture for the Government of New Brunswick in 2003-2004 (http://www.aadnc-aandc.gc.ca/aiarch/mr/nr/s-d2005/02721bk-eng.asp).

Considering the long and illustrious career Gilles Thériault held with a variety of organizations, starting with commercial fishing unions, then working for federal and provincial governments, in addition to establishing his own consultancy firm on the fishery, it would appear that he was likely very well known around most circles in the Maritime commercial lobster fishery. As a result of this well-rounded experience, Thériault likely knew how to speak to and manage each individual non-Aboriginal fishing organization with whom he spoke as Associate Chief Negotiator with the Department of Fisheries and Oceans. Indeed, he was likely chosen by the Department for that very reason: He likely had longstanding relationships already established with the unions and other fishery organizations that would enable him to speak to their leadership and effect change.

The two months between Marshall 1 (September 17, 1999) and Marshall 2 (November 17, 1999) demonstrated that despite the Department of Fisheries and Oceans 
being caught somewhat off-guard by the Supreme Court ruling in favour of Donald Marshall Jr., the Department did eventually attempt to resolve the Marshall crisis over the short term through a combination of closed-door meetings, public gatherings and negotiation/mediation. The Department of Fisheries and Oceans was placed in a difficult position, considering the confusion created by the Supreme Court's lack of a definition as to what constituted a moderate livelihood, the influence of external actors, such as the media, and the actions of groups involved in the fishery that took matters into their own hands at times. The Department of Fisheries and Oceans' quick action after the first confrontation on October 5,1999 , focused primarily on stemming the crisis by holding public meetings with non-Aboriginal fishers; by holding Ministerial meetings with the Mi'kmaq Grand Council to seek a voluntary moratorium on the lobster fishery; and then by appointing negotiators - and later Bob Rae as a mediator with Burnt Church and Shubenacadie First Nations, which failed when the two sides could not come together to work with the First Nations to negotiate a means to bring First Nations fishers into the commercial lobster fishery by issuing communal licences.

It remains to be seen if a continual reliance on negotiation and mediation constituted the best way to manage the crisis, especially with so many closed-door meetings held, leaving many First Nations and non-Aboriginal fishers outside of the decision-making process. In addition, the issue was primarily treated as a First Nations treaty rights issue, rather than as a means to address First Nations treaty rights within the context of the commercial fishing industry. This meant leaving out non-Aboriginal fishers entirely for some time, which likely contributed to the violent confrontations that 
ensued. As tensions increased, it appeared that the Department of Fisheries and Oceans began to address some of the outstanding issues or grievances of the people on the ground, but unfortunately, it was a reactionary measure, such as in the case where nonAboriginal fishers were finally provided with Gilles Thériault to voice their concerns and have them included in the overall negotiations process. However, as the following section will demonstrate, history ends up repeating itself until more formal processes are put into place.

\subsection{Events During and After Marshall 2 (November 17, 1999)}

The uniqueness of Marshall 1 , especially in how it led to violent confrontations over one of the primary economic drivers in the coastal Maritimes, led the Supreme Court of Canada to clarify the decision only two months later. The Supreme Court took the opportunity to use the West Nova Fishermen's Coalition application for a rehearing of the case to clarify its decision instead: “...Marshall (No. 1) was no ordinary case. The East Coast was in an uproar, and the Supreme Court of Canada seized upon the West Nova application to comment on their own decision" (Cameron 85). The Standing Committee on Fisheries and Oceans further describes the Supreme Court of Canada's denial of the rehearing and clarification of Marshall 1 :

On November 17, 1999, in a unanimous decision, the Supreme Court denied the Coalition's motion for a rehearing. In doing so, it took the unusual step of providing a written "clarification" of its September 17 decision. In the November 17 ruling, now referred to by some as "Marshall 2," the Supreme Court stated that the scope of its September 17 
[decision] had in fact been limited and that many of the perceived ambiguities had in fact been addressed in the September 17, 1999, decision, had people taken the trouble to read it carefully. This view was not held by a majority of witnesses before the committee (The Marshall Decision and Beyond).

The statement that the majority of those who presented at the Standing Committee did not agree with the Supreme Court's assertion that it had defined a moderate livelihood in Marshall 1 decision is somewhat disconcerting. Had the Supreme Court defined that term in its initial decision, there likely would have not been a need to "clarify" the decision in Marshall 2.

The Standing Committee on Fisheries and Oceans' report of December 1999 also provided an introduction, which laid out a statement of facts that summarized the outcomes of Marshall 1, including that the Supreme Court of Canada "affirmed that the 1760 Treaty provided Mi'kmaq people a right to provide for their own sustenance..." and that "catch limits that could reasonably be expected to produce a moderate livelihood for" individual Mi'kmaq families at present day standards can be established by regulation..." (The Marshall Decision and Beyond). The report also indicated that the Supreme Court of Canada's clarification (Marshall 2) was rendered and while First Nations fishers had the right to fish for a moderate livelihood, their rights could be regulated under certain circumstances, such as conservation (The Marshall Decision and Beyond).

Disagreements continued throughout the fishing season of 2000 with Burnt Church and Shubenacadie (Indian Brook) First Nations, which limited the Marshall crisis 
to those two communities and significantly reduced its scope. However, the reduction in scope may have led to a stronger focus and far more violent consequences. According to the book entitled Permission to Develop, the Department of Fisheries and Oceans confiscated two crab-fishing boats from the members of Indian Brook in February 2000:

In February 2000, the Department of Fisheries and Oceans confiscated two crab-fishing boats from the members of Indian Brook. Seven more Indian Brook fishing vessels were seized later in 2000 and 18 people were charged with illegally fishing lobster. Burnt Church rejected an interim fishing agreement proposed by the Department and the Burnt Church people were raided with 700 traps being seized and four people arrested. Two short-term agreements were negotiated with the Burnt Church people in 2001 to temporarily suppress conflict (White et al. 63).

In addition to the story provided by White et al. above, Ken Coates also provides an indication of the crisis' narrowing focus:

Burnt Church remained the major anomaly into the summer of 2000 ...Both sides were determined to make a point. For Burnt Church, it was the basic argument that First Nations had, under the Marshall decision, the right to fish for commercial purposes and to regulate their harvest. The federal government, also citing the Marshall decision and clarification, asserted that it had an obligation and a duty to enforce the fisheries regulations (174-175).

In June 2000, Fisheries Minister Herb Dhaliwal demonstrated some progress by 
indicating, "24 First Nations have signed interim fishing agreements" (Coates 177). In continual defiance of the Department of Fisheries and Oceans, Burnt Church was the only community that did not sign on to an agreement in the summer of 2000 because it was seeking to manage its own fishery, despite various offers from Minister Dhaliwal (Coates 174).

The Department of Fisheries and Oceans became more aggressive with Burnt Church First Nation, which remained the last holdout that would not sign an interim fishing agreement. On August 13, 2000, Department of Fisheries and Oceans officers moved aggressively at night with powerful spotlights across Miramichi Bay, seizing "700 to 1,000 lobster traps left out the previous day by Burnt Church fishers" (Coates 181). The act of enforcement by the Department led to a new confrontation over the following two days, on October 14 and 15, 2000. Mi'kmaq fishers threw fish guts at Department of Fisheries and Oceans officers. Both sides accused each other of "provoking confrontations on the water, resulting in several near-miss collisions and boat rammings" (Coates 181). Department of Fisheries and Oceans officers used pepper spray on Mi'kmaq fishers. The Mi'kmaq of Burnt Church claimed that Fisheries officers used firearms to intimidate protesters, including firing shots across the bow of one Mi'kmaq boat (Coates 181). The following day, Burnt Church First Nation and the Department of Fisheries and Oceans announced that they had agreed upon a truce and re-opened discussions (Coates 182).

The following month, on September 17, 2000, Donald Marshall Jr. asked the Mi'kmaq Chiefs "to pull the boats from the water" and requested that they "negotiate 
with government officials" (Coates 137).

Minister Dhaliwal issued a "short-term communal licence" to Burnt Church during the week of August 20-27, 2001, which was intended to prevent a recurrence of confrontations in Miramichi Bay during the fall of 2000 (Isaac 152). The communal licence enabled Burnt Church to "set up five hundred lobster traps for food, social and ceremonial purposes in a restricted zone in the vicinity of Burnt Church" (Isaac 152). However, the licence was not established for commercial purposes. The licence was then "renewed from August 27 to October 20, 2001" (Isaac 152). The issuance of this licence to Burnt Church, which came while most other First Nations had signed on to communal licences, likely helped to quell tensions in that community.

Once again relying on negotiation and mediation to resolve the crisis, Minister Dhaliwal appointed Bob Rae as a mediator on September 11, 2000:

On September 11, 2000, former Ontario Premier Bob Rae agreed to act as mediator between the federal government and Burnt Church. Mediation has been used successfully in many situations where parties involved have some apparent misunderstandings and differing perspectives; however, in this situation, the issue of mediation raised deeper questions about its appropriateness and the potential for a long-term resolution. These issues involve many First Nations, are inherently complex, and deal with a scarce resource. In the end, Mr. Rae's involvement did not result in an agreement (Isaac 153).

The theme of addressing short-term conflict continued with the Department of 
Fisheries and Oceans through the Aboriginal Fishing Strategy:

The Department of Fisheries and Oceans promised funds for Aboriginal fishing-related activities. The Department pledged contributions designated to support increased Native participation in commercial fisheries, co-operative fisheries management arrangements and consultations respecting Aboriginal fisheries agreements. The Department committed $\$ 34.7$ million for 2001-2002 and a further $\$ 34.7$ million for 2002-2003 (White et al. 64).

In addition to those numbers, according to the Department of Fisheries and Oceans' website, between 2000 and 2007, the Department invested approximately $\$ 600$ million in the Marshall Response Initiative, which ended on March 31, 2007 (http://www.dfompo.gc.ca/fm-gp/aboriginal-autochtones/marshall/index-eng.htm). The purpose of the initiative was to provide "significant support for increased commercial fisheries access (including vessels and gear, and commercial fisheries infrastructure) and internal governance development, and has become a significant driver for economic development in these communities" (http://www.dfo-mpo.gc.ca/fm-gp/aboriginal- . autochtones/marshall/index-eng.htm). The result of these efforts for the First Nations in the Maritimes and parts of Quebec, according to the Department of Fisheries and Oceans, included the following: they hold approximately 1,300 communal fishing licences, which support 520 First Nations' fishing enterprises; they were "provided with a potential economic return that exceeds $\$ 45$ million annually - a significant increase over the estimated $\$ 15$ million generated in 2000 "; they have "more than 1,000 community 
members earning an income from fishing"; and "have had an estimated 2,000 community members receive training or mentoring that covers a broad range of practical fishing skills," such as basic seamanship and watchman duties (http://www.dfo-mpo.gc.ca/fmgp/aboriginal-autochtones/marshall/index-eng.htm).

The numbers posted by the Department of Fisheries and Oceans are impressive. Those numbers indicate a massive investment in response to Marshall, which has established greater integration of First Nations fishers into the Maritime commercial lobster fishery with the relevant training and supports required to take advantage of their communal licenses. However, they only tell one part of the story. The Summative Evaluation of the Marshall Response Initiative has a section entitled "Negotiations and Consultations Conclusion," which was also generally positive in nature, but indicated that there were some issues with the process. In terms of specific negotiations, the evaluation states the following: "Negotiations of fishing agreements with First Nations took place under difficult circumstances. Nevertheless, agreements were reached with 30 of 34 First Nations in the Initial Marshall Response Initiative and 31 out of 34 in the Longer-term MRI [Marshall Response Initiative]" (Summative Evaluation 11). Generally, the Summative Evaluation found throughout its interviews that First Nations' responses to negotiations were positive (11).

While the Summative Evaluation's conclusion regarding negotiations was positive, it obscured two issues that were identified earlier in this chapter. The first concerned the timeliness of negotiations, including how long it took the Department of Fisheries and Oceans to get organized before Marshall 1 , and the lack of a concrete 
contingency plan for First Nations communities that did not wish to negotiate communal licences, such as Burnt Church and Shubenacadie (Indian Brook). Even though the Department appeared to be unprepared for the fallout of the Marshall 1 decision, through the preceding text, it has become evident that it did mobilize reasonably fast after the first weeks following Marshall 1 in Fall 1999. Informal closed-door meetings with the Mi'kmaq leadership, public consultations with individuals, and a heavy reliance on negotiation/mediation are all proof of that.

The Department of Fisheries and Oceans' lack of a contingency plan to work with First Nations communities that were not interested in negotiating a communal licence was rather evident by the number of limited fisheries agreements that Minister Dhaliwal announced throughout the crisis period for communities like Burnt Church and Shubenacadie (Indian Brook). To this day, Burnt Church has not signed a fisheries agreement.

\subsection{Conclusion}

This chapter has provided a summary of critical events that occurred prior to and during the Marshall crisis, including a Marshall Crisis Timeline for use as a point of reference for the remainder of this thesis. The identified dates and events have served to provide historical context that will support the reader in understanding some of the reasons why the Marshall crisis occurred, such as the lack of communication with concerned First Nations and non-Aboriginal fishers, and the differences of opinion that arose from the vague Supreme Court interpretation of the moderate livelihood reference in Marshall 1. 
Dates and events identified in this chapter have also provided references to some of the public participation techniques and methods used by the Department of Fisheries and Oceans in light of the Marshall crisis, including informal engagement with First Nations leaders, public consultation and negotiation/mediation. In addition, some external factors were identified, such as how the media influenced popular opinion and helped increase tensions during the Marshall crisis. These public participation techniques, methods and external factors will be defined in Chapter 3 , then analyzed in Chapter 4 in terms of their potential to be implemented in a crisis, and in meeting the short- and long-term objectives of this thesis: to reduce tensions during the crisis and to help establish partnerships among the groups involved so they can manage the Maritime commercial lobster fishery over the long term in a manner that benefits all economically and that respects treaty rights. 


\section{Chapter - Public Participation and Policy Making in Canada}

\subsection{Introduction}

This chapter will explain the public participation concepts selected to construct an analytical framework that will be used to: a. conduct a comparative analysis of the techniques and methods of public participation used by the Department of Fisheries and Oceans prior to and during the Marshall crisis, to determine their potential to be implemented in meeting the short- and long-term objectives identified; and b. to recommend possible techniques and methods of engagement, according to the modified public participation spectrum, which could have been used to reduce tensions faster and to establish partnerships to manage the Maritime commercial lobster fishery, while respecting First Nations treaty rights, over the long term.

To provide further context, this chapter will also provide general definitions and an overview of public participation concepts; briefly describe the authors from each body of concepts that will be used, including brief descriptions of their analytical work, its original intent and how it will be applied to analysis in this thesis; and describe external factors, such as time constraints and media influence, which are significant considerations when deciding which public participation techniques and methods should be used in specific contexts.

Finally, this chapter will start with the public participation spectrum, which includes public participation techniques and methods, and then provide a description of each technique and method and how those relate to the other concepts that have been written about, such as traditional public consultation, citizen engagement, and 
representative and deliberative citizen involvement. Finally, external factors will be added. The chapter will end with a modified public participation spectrum that will encompass all components of an analytical framework that will drive analysis in the chapters to follow.

\subsection{Why Public Participation?}

Many scholars have written about the positive benefits of using public participation techniques and methods as tools to engage the public in supporting the development and implementation of policies to address critical societal challenges. Frances Abele, Katherine Graham and several other academics, who wrote in the 1990s and 2000s concerning the need for increased citizen engagement, state that "traditional public consultation" failed because "many participants have complained that consultation as practiced by some government departments was mere window dressing - done as a ritual step to give policies a presumed credibility because they had passed through an exercise in citizen involvement" (Abele, Graham, et al., Talking with Canadians 7). In addition to this, in recent years, many individuals have developed a greater interest in being a part of critical policy making, through techniques and methods of public participation, which provide opportunities to have an impact on policy that is being implemented. This desire on the part of individuals to be involved likely came from general concerns that citizens feel their needs are no longer met adequately through representative democratic processes and groups (Laforest and Phillips, Critical Policy Studies 70-71). An example of representative citizen involvement would include elected politicians, who purport to speak on ordinary citizens' behalf. However, citizens' 
confidence has waned with regard to trusting politicians and public institutions to implement effective policy that meets their needs (Abele, Graham, et al., Talking with

\section{Canadians 4).}

Public attitudes toward elected officials and citizens' desire to be included in public policy discussions are often present in media sound bites, which feature individuals disagreeing with policy decisions made by governments and complaining about their tax dollars being wasted. Public participation techniques and methods may therefore provide an important opportunity for citizens to provide their input into important policy decisions that affect their every day lives, especially regarding economic outcomes to which their livelihoods may depend. In addition, citizens who are engaged in policy discussions and provide their own input feel a sense of ownership of the issue: "Citizen engagement holds out the promise of significant or 'real' influence upon public policy decisions" (Abele, Graham, et al., Talking with Canadians 10).

Individuals will participate in consultative processes and accept their results as legitimate if it appears that they are having an impact on policy outcomes. The academic literature stresses the difference between traditional public consultation and citizen engagement, and between representative and deliberative citizen involvement. It identifies methods of public participation from Inform to Empower. Techniques within the Inform method tend toward the lowest degree of influence that individuals being engaged would have on policy making. For example, information sharing, which is a technique within the Inform method, affords almost no public input into the policy making process, as it refers to the sharing of information from an entity such as the 
federal government to individual who are being engaged (citizens). However, the further one moves toward Empower, the greater the public can affect policy-making through their direct involvement in a process. These ideas provide the analytical framework of this chapter.

To connect the idea of public impact back to First Nations, a prime example of their wanting to be more involved in decisions concerning treaty rights to lands and resources is through the Crown's legal duty to consult and accommodate First Nations' interests. When there is a potential or existing treaty right that may be infringed upon through government or other actions, such as permitting resource extraction on traditional territories without the consent of those First Nations that stake claim to the land or the resources on which it sits, the Supreme Court of Canada has established the legal duty to consult and accommodate First Nations' interests through its judgements in the Haida and Taku cases (Morellato 27-32).

The legal duty to consult and accommodate was the initial subject of research for this thesis because of the potential effects such a legislative requirement could present for policy makers seeking to resolve treaty rights issues. However, there were two primary considerations that led to the selection of public participation as the subject of research, instead of the legal duty to consult and accommodate. The first reason was that while the legal duty to consult and accommodate First Nations' treaty rights established a legal precedent that forces the Crown to consult with First Nations possessing treaty rights to lands and natural resources, it also establishes, in some cases, highly prescriptive requirements for the Crown to conclude that it has fulfilled its legal duty. While this 
approach to engagement can be beneficial in terms of forcing governments and other actors to discuss accommodation of First Nations' treaty rights, it may also be an overly rigid process that could, in some cases, generate perverse results. For example, the government may be forced to consult with First Nations only, without considering the surrounding Métis or non-Aboriginal communities that may also have vested economic interests in the area's lands and/or natural resources.

The circumstance above is similar to what happened during the Marshall crisis with non-Aboriginal fishers, as described in Chapter 2. After the Supreme Court rendered Marshall 1, non-Aboriginal commercial fishers were left out of initial discussions concerning the Maritime commercial lobster fishery, which led them to take matters into their own hands because they were afraid to lose their economic livelihoods. Considering the potential implications of leaving a group out of consultations, the legal duty to consult and accommodate will not necessarily improve upon what had already occurred during the Marshall crisis, especially if the process becomes too rigid or drawn out.

In contrast to the potential for rigidity with the legal duty to consult and accommodate First Nations' treaty rights, public participation techniques and methods present a variety of options to conduct a comparative analysis of engagements that did occur before and during the crisis, while also considering new options at varying levels of involvement and cost, which could have helped reduce tensions quicker. By using public participation concepts to analyze the Marshall crisis, this thesis will have a greater variety of options to demonstrate that the crisis was a missed opportunity for public 
participation, which may have reduced tensions earlier and supported the establishment of partnerships among the groups involved to manage the Maritime commercial lobster fishery over the long term.

Studies of public participation and citizen engagement have been chosen to provide the analytical framework for this thesis because many academics in these two traditions are in agreement that engaging with the general public in a manner that permits increased public impact on decisions generally leads to better public policy making. Improved public policy making, in turn, can then help address difficult issues, such as the dispute over treaty rights to the Maritime commercial lobster fishery in the case of the Marshall decisions because citizen engagement with those actively working and seeking to work in the Maritime commercial lobster fishery could have reduced tensions sooner. Individuals would have likely taken ownership of the issues if they had an active role in the policy making, on how to respect First Nations' treaty rights within the fishery. These ideas are discussed in the next section of this chapter. In addition, external factors that can influence public participation will also be considered to help construct an analytical framework for the Marshall crisis case study.

\subsection{Toward A Public Participation Analytical Framework}

The terms citizen engagement and public participation take many forms in literature on how to engage with citizens and groups in policy and legislative development. To develop an analytical framework to assess public participation techniques and methods undertaken by the Department of Fisheries and Oceans prior to and during the Marshall crisis, it is imperative to define and briefly elaborate on the use 
of these two terms, including the authors and the concepts they espouse that will be used in this thesis. This description will determine how elements of an analytical framework, namely how to categorize the concepts as techniques to be included under the five methods identified within the public participation spectrum, which will form the basis of the said framework.

The term citizen engagement is primarily derived from the works of Frances Abele, Katherine Graham, Susan Phillips, Michael Orisini and other academics in several documents that span the 1990s and 2000s. One of the major foundational documents of citizen engagement scholars stems from the work of Frances Abele, Katherine Graham, Alex Ker, Antonia Maioni and Susan Phillips, and is entitled Talking with Canadians: Citizen Engagement and the Social Union, which they prepared for the Canadian Council on Social Development in July 1998.

In Talking with Canadians, the authors attempt to "contribute to the ongoing construction of Canada's social union by considering how citizens can be effectively engaged in this process" (Abele, Graham, et al., Talking with Canadians 41). This is the result of social, cultural and economic changes afoot in Canada in the late 1990s. During this time, Canada was undergoing a "critical economic, political and social" transformation: "In the wake of an intense debate about the reconfiguration of the country's key trading relationships, and the most severe reductions in government spending in many decades, consideration has turned to the pace and regulation of internal economic growth in the new environment" (Abele, Graham, et al., Talking with Canadians 3). The authors argue that in the face of new pressures, there needs to be a 
focus on the social relationships that underlie the "set of relationships, among government of the federation and between governments and citizens, [which] is referred to as the social union" (Abele, Graham, et al., Talking with Canadians 3). At the centre of the social union is citizen engagement: "Central to the social union is a recognition that democratic participation and citizen engagement are important ingredients in building a consensus on our social future" (Abele, Graham, et al., Talking with Canadians 3). The work of Abele, Graham, et al., in Talking with Canadians provides several reasons why citizen engagement is important to the critical policy debates in Canadian society, including how relationships should be configured among the federal government and the citizenry. These configurations are especially pertinent in light of the changing role of institutions and the increasingly complex and diverse issues facing the country, while government budgets are reduced. As a result, governments have come to rely more on the citizenry to support their in-house capacity to formulate policy and implement it on the ground (Phillips and Orsini, Mapping the Links 5).

Katherine Graham and Susan Phillips have written about citizen engagement at the local/municipal government level for the Intergovernmental Committee on Urban and Regional Research, which provides "Canadian local governments with the latest information on the how-to of problem solving and on the trends and developments that arise in the planning and management of communities" (v). Graham and Phillips describe the increasing importance of public participation to individuals in the first chapter of the book: "Citizens no longer see public participation as an 'opportunity,' graciously granted by the council and administration; it is regarded as a basic service and 
an integral part of local governance" (Citizen Engagement 2). They further describe that while the expectations of local citizens have changed, local governments also expect that the public should increase its ability to contribute to policy discussions by providing informed opinions: "Rather than simply offering personal opinions, regardless of whether these opinions have been well thought out, participants are now expected to offer informed opinions and to be willing to make tough choices" (Graham and Phillips, Citizen Engagement 2). Graham and Phillips make similar assertions to what is written in Talking with Canadians, namely that significant government budget constraints and other, demographic, cultural and socio-economic factors have changed the way that governments and the general public relate to resolve critical policy issues.

The importance of Graham and Phillips' work in Citizen Engagement is how their chapter contemplates the writing on local government public participation and considers the potential external factors that present constraints on the design and implementation of public participation processes. Such constraints and external factors will be further elaborated later in this chapter as external factors in the modified public participation spectrum.

Another significant contribution to citizen engagement analysis is a Canadian Policy Research Networks discussion paper entitled Mapping the Links: Citizen Involvement in Policy Processes, written by Susan Phillips and Michael Orsini in April 2002. In this discussion paper, Phillips and Orsini "map the links among eight dimensions of citizen involvement, three key political institutions, and six stages of the policy process" to determine the "adequacy of existing institutions, including 
parliamentary committees, elected representatives, and political parties" (Mapping the Links i). They then argue that "multiple routes for representation and participation remain one of the strengths of liberal democracy" and "make a number of suggestions for reform to improve existing institutions, to strengthen the capacity of government and civil society to engage on policy issues, and to create new processes or institutions to support a stronger role for citizens at the appropriate times in the policy process" (Phillips and Orsini, Mapping the Links i).

Phillips and Orsini note that the public values its political rights above other policy domains surveyed in the paper. One of the questions asked in the foreword of the paper in response is: "Why, then, do so many studies also find that citizens are ambivalent, some would say apathetic, about their possibilities for being involved in the parliamentary system and in decisions that affect their lives?" (Phillips and Orsini, Mapping the Links i). This particular question ties into what was stated in the previous two articles concerning the changing landscape and relationships in Canadian policy making, as a result of the changing socio-economic and cultural factors playing out in the late-1990s and early-2000s. Phillips and Orsini find that the public may have become apathetic about traditional forms of representation through government institutions and elected politics, yet they are no less engaged on other fronts. This establishes a requirement for various forms of citizen involvement, including citizen engagement, and other public participation techniques and methods.

The contribution of Phillips and Orsini's work to this thesis will be their argument that it is crucial to the democratic process to make a variety of means available to citizens 
who wish to be engaged in public policy debates, as the traditional, representative means of providing input to governments, such as traditional public consultation, do not work as well as they once did. Phillips and Orsini's actual mapping of the different ways citizens can become involved in public policy processes will also be used to connect some of the techniques of citizen engagement with public participation techniques and methods, according to the public participation spectrum.

Rachel Laforest and Susan Phillips advance the argument that citizen engagement in policy processes has been present for some time, but that citizens have to be "plugged in" to the process for it to be worthwhile:

The wiring may exist, but the power is not always on. The point of this chapter is not to argue against continued efforts at achieving more truly deliberative forms of dialogue as a means of enhancing a meaningful role for citizens in policy development. Rather, it suggests the need to ensure that the new deliberative wiring is effectively plugged into decision making (Laforest and Phillips, Critical Policy Studies 83).

In this chapter, the authors are mostly concerned with the need to ensure that as new deliberative forms of citizen involvement are established to seek their input, these new forms of involvement will be relatively worthless unless they are connected to actual policy-making processes. As the public participation spectrum will demonstrate later in this chapter, Laforest and Phillips are pointing to the importance of increased public impact on policy making, which can lead to improved outcomes.

Another contribution of Laforest and Phillips' chapter to the analytical framework 
being developed in this chapter is the distinction between representative and deliberative forms of citizen involvement, which mirrors the level of public impact citizens have in the policy making process, which also ties into the methods included in the public participation spectrum. In addition to their spectrum of representative versus deliberative forms of citizen involvement, Laforest and Phillips' article will also contribute some examples of different techniques of citizen involvement that will be analyzed in future chapters, in connection with the techniques and methods of the public participation spectrum.

Coming full circle, the terms traditional public consultation and citizen engagement can be seen as opposing ends of a spectrum that includes increased public impact in policy making, much the same as representative and deliberative citizen involvement, and the five methods of public participation move along the same spectrum. The term citizen engagement is also contrasted with what Abele, Graham et al. define as traditional public consultation, which affords less influence in decision making among the citizenry:

The first approach, 'consultation,' fails to fully engage citizens in a decision making process. 'Engagement,' on the other hand, simulates some of the conditions of public decision making, providing participants with information and confronting them with difficult choices. Equipped with an understanding of issues, relationships among issues, policy options and tradeoffs...participants are able to form...a consensus about the future. As a consequence of learning, deeper dialogue and the 
formation of 'public judgment,' these types [techniques] of citizen engagement realize a qualitatively and democratically superior outcome than is otherwise achievable through traditional public consultation forums (Abele, Graham, et al., Talking with Canadians 9).

The distinction between traditional public consultation and citizen engagement is an important one. Traditional public consultation can imply almost no public influence in decision-making concerning an issue that affects everyone, while citizen engagement suggests reliance to a significant degree on the public for help in solving some of society's most complex issues. Citizen engagement can be seen as being near to the end of the public participation spectrum.

Citizen engagement, as a concept, was meant to address a number of changes in state-society relationships: increasing diversity amongst the population; decline in confidence in public institutions; rising citizen intervention in politics; difficulties experienced by institutions in resolving complex issues on their own; and diminished political support for intermediary groups. In addition, while citizen groups have increased in number and scope, there has been a greater need on the part of citizens to provide input to fill the government's policy capacity gaps, and new communication technologies have created new opportunities for citizens to become engaged (Abele, Graham, et al., Talking with Canadians 3-7). These reasons and benefits also help to explain the changing dynamics of how governments attempt to address some of society's complex issues with the help of the citizenry and to demonstrate that today's problems require a variety of tools, techniques and methods of engagement to achieve the best 
possible policy making to address these increasingly complex issues.

The definition of citizen engagement provided by Abele, Graham, et al., provides an understanding of the differing levels of influence, involvement or public impact that can be accorded to citizens when they are engaged using specific techniques and methods of engagement. However, it does not specifically define a full spectrum of those techniques and methods, in a practical administrative manner, according to the level of public impact citizens have on the policy-making process. The next section will focus on the International Association for Public Participation's public participation spectrum and some authors who write on issues concerning public participation as part of the International Association's journal, most often from a practitioner's perspective.

The International Association for Public Participation defines itself as an international association seeking to promote the practice of public participation "in relation to individuals, governments, institutions and other entities that affect the public interest in nations throughout the world" (http://iap2canada.ca). The International Association for Public Participation delivers activities to promote public participation by training its members in a variety of ways, acting as an "advocate for public participation throughout the world," promoting a results-oriented research agenda and use research to support education and advocacy goals; and providing "technical assistance to improve public participation" (http://iap2canada.ca).

The International Association for Public Participation takes a non-academic approach to public participation to help practitioners implement public participation processes on a practical, administrative level. The purpose of their alignment with 
analytical concepts, such as citizen engagement, is to help determine their feasibility during a crisis. Additionally, aligning these concepts along the degree of public impact also helps to show how much the public can influence policy-making processes through the implementation of a specific method. However, what these methods are not intended to do is make specific pronouncements, such as commentary on power dynamics of a particular approach to public participation. Moreover, it should not be construed that the alignment of an analytical concept (e.g. citizen engagement) and a practical administrative method (e.g. Involve) would mean that they mean the same thing. In other words, the methods and their associated techniques in the public participation spectrum will only be used to review whether a specific analytical concept can be implemented in a practical sense. The modified version of the International Association's public participation spectrum introduced in this chapter is the primary tool that will be used as the analytical framework for the remaining chapters.

The public participation spectrum was taken from the International Association for Public Participation. In addition, two articles from the IAP2's journal also support some of the issues raised during the Marshall crisis. Renee A. Irvin and John Stansbury begin their article, "Citizen Engagement: Is it Worth the Effort?," with the idea that few argue against the following statement: "It is widely argued that increased community participation in government decision-making produces many important benefits" (Irvin and Stansbury 1). Rather than agree entirely with this assertion, the authors consider what potential problems might arise by studying the U.S. Environmental Protection Agency's watershed management initiative's citizen participation meetings (Irvin and 
Stansbury 1).

Irvin and Stansbury's major contribution in this thesis is to provide some concerns with respect to the external factor of participant legitimacy. They argue that citizen participation initiatives permit special interests to dominate because when participants in such an initiative are not paid to be there, generally speaking, "committees may be dominated by strongly partisan participants - whose livelihood or values are strongly affected by the decisions being made - or by those who live comfortably enough to allow them to participate regularly (Irvin and Stansbury 9). Irvin and Stansbury's work will be further elaborated later in this chapter.

J. H. Snider defines fake public participation as the following:

Fake public participation is an element of the much larger and more troublesome phenomenon of fake democracy. The basic logic behind fake democracy is quite simple. In the contemporary world, democratic rule has more public legitimacy than authoritarian rule, so it is generally in the interest of rulers to present themselves as democrats rather than autocrats (Snider 91).

Snider makes the point that democratic rule is the only form of legitimate rule, which means that any politicians and institutions of government that are perceived to be undemocratic in making decisions lose legitimacy. As a result, governments often tend to design public participation processes that seek public input, but as Laforest and Phillips state earlier, fail to "plug in" the public to the policy-making process. While the level of public impact on policy making is low in fake public participation, government 
officials continue to tout their due diligence in holding traditional public consultation sessions and indicating that they have received a mandate from the public as a result.

The International Association for Public Participation defines public participation as the following:

"Public participation" means to involve those who are affected by a decision in the decision-making process. It promotes sustainable decisions by providing participants with the information they need to be involved in a meaningful way, and it communicates to participants how their input affects the decision (http://www.iap2.org).

The International Association for Public Participation's definition of public participation is broad, but it provides opportunities to include the practical application of a variety of engagement techniques and methods that have been elaborated under traditional public consultation, citizen engagement, as well as representative and deliberative citizen involvement. Chapter 5 will elaborate on some of these practical techniques and methods through its description of a proposed policy summit:

Table 1 below is a reproduction of the original public participation spectrum provided by the International Association for Public Participation: 
Table 1: International Association for Public Participation (IAP2) Public Participation Spectrum Increasinq Level of Public Impact

\begin{tabular}{|c|c|c|c|c|c|}
\hline & Inform & Consult & Involve & Collaborate & Empower \\
\hline $\begin{array}{r}\text { Public } \\
\text { participation } \\
\text { gatoal }\end{array}$ & $\begin{array}{l}\text { To provide the } \\
\text { public with } \\
\text { balanced and } \\
\text { objective } \\
\text { information to } \\
\text { assist them in } \\
\text { understanding } \\
\text { the problem, } \\
\text { alternatives, } \\
\text { opportunities } \\
\text { and/or solutions. }\end{array}$ & $\begin{array}{l}\text { To obtain public } \\
\text { feedback on } \\
\text { analysis, } \\
\text { altematives } \\
\text { and/or solutions. }\end{array}$ & $\begin{array}{l}\text { To work directly with } \\
\text { the public throughout } \\
\text { the process to ensure } \\
\text { that public concerns } \\
\text { and aspirations are } \\
\text { consistently } \\
\text { understood and } \\
\text { considered. }\end{array}$ & $\begin{array}{l}\text { To partner with the } \\
\text { public in each aspect } \\
\text { of the decision } \\
\text { including the } \\
\text { development of } \\
\text { alternatives and the } \\
\text { identification of the } \\
\text { preferred solution. }\end{array}$ & $\begin{array}{l}\text { To place final } \\
\text { decision-making in } \\
\text { the hands of the } \\
\text { public. }\end{array}$ \\
\hline $\begin{array}{l}\text { Prounive to" } \\
\text { lhe l'ululic }\end{array}$ & $\begin{array}{l}\text { We will keep } \\
\text { you informed. }\end{array}$ & $\begin{array}{l}\text { We will keep you } \\
\text { informed, listen } \\
\text { to and } \\
\text { acknowledge } \\
\text { concerns and } \\
\text { aspirations, and } \\
\text { provide feedback } \\
\text { on how the } \\
\text { public input } \\
\text { influenced the } \\
\text { decision. }\end{array}$ & $\begin{array}{l}\text { We will work with } \\
\text { you to ensure that } \\
\text { your concerns and } \\
\text { aspirations are } \\
\text { directly reflected in } \\
\text { the alternatives } \\
\text { developed and } \\
\text { provide feedback on } \\
\text { how public input } \\
\text { influenced the } \\
\text { decision. }\end{array}$ & $\begin{array}{l}\text { We will look to you } \\
\text { for advice and } \\
\text { innovation in } \\
\text { formulating solutions } \\
\text { and incorporate your } \\
\text { advice and } \\
\text { recommendations into } \\
\text { the decisions to the } \\
\text { maximum extent } \\
\text { possible. }\end{array}$ & $\begin{array}{l}\text { We will implement } \\
\text { what you decide. }\end{array}$ \\
\hline $\begin{array}{l}\text { I samples } \\
\text { technifyuses }\end{array}$ & $\begin{array}{ll}- & \text { Fact sheets } \\
-\quad & \text { Web sites } \\
\text { - } & \text { Open } \\
\text { houses }\end{array}$ & $\begin{array}{ll} & \text { Public } \\
\text { comment } \\
\text { - } & \text { Focus } \\
\text { groups } \\
\text { - } & \text { Surveys } \\
\text { - } & \text { Public } \\
\text { meetings }\end{array}$ & $\begin{array}{ll} & \text { Workshops } \\
\text { Deliberative } \\
\text { polling }\end{array}$ & 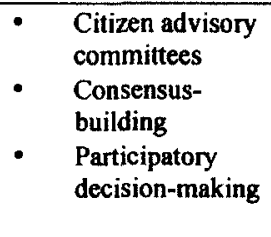 & $\begin{array}{ll}- & \text { Citizen juries } \\
-\quad & \text { Ballots } \\
- & \text { Delegated } \\
\text { decision }\end{array}$ \\
\hline
\end{tabular}

Table 1 provides five methods, including Inform, Consult, Involve, Collaborate and

Empower, which are arranged according to an ascending degree of public impact on the policy-making process, which is represented by the arrow above the table. The further the arrow moves to the right, the greater degree of public impact is provided by the particular method falling under it, and its associated techniques. The methods should be considered separate and apart from each other, meaning that one does not have to implement the lower-level methods (e.g. Inform and Consult) to attain the public impact 
accorded by a higher-level method (e.g. Involve). However, more than one method can be implemented in the same public participation process (e.g. Involve could be implemented with Inform). The public participation spectrum reproduced in Table 1 will form the basis for the modified public participation spectrum, which will follow at the end of this chapter as Table 3.

The modified public participation spectrum highlighted in Table 2 will demonstrate how the public participation methods help to further sub-divide and compartmentalize the increasing levels of public impact among the continua of concepts into five specific methods. This sub-division will allow for greater depth of analysis in targeting the most feasible public participation method and associated techniques to implement during a crisis, especially considering that increasing public impact improves the chances of resolving disputes by involving individuals directly in the policy-making process. However, external factors, such as time and financial/human resource constraints, also must be considered and taken into account, as increasing public impact also requires greater time and resources to enable participation from greater numbers of people. Stemming from the five methods identified above are specific techniques of engagement. For example, deliberative polling and workshops would be encompassed within the Involve method of engagement, which aligns with citizen engagement and deliberative citizen involvement (democracy).

This thesis will make significant use of the modified public participation spectrum to identify the specific techniques and methods that were implemented during the Marshall crisis. The techniques and methods, based on the ascending degree of public 
impact in policy-making in Table 1, will then incorporate the definitions of traditional public consultation and citizen engagement, as well as representative / deliberative citizen involvement written about by Abele, Graham, Phillips, Orsini and other academic authors. All of these features will be included in Table 3 .

For the purposes of this thesis, the following four external factors will form the crux of the analytical framework, in addition to the techniques and methods of public participation: time constraints; financial and human resource availability; participant legitimacy; and media influence. Little has been written about time constraints and resource availability, but they do play an important role in decision-making as to how to engage during a crisis, and as such, have been included in the analytical framework. There has been some writing on key considerations for determining the legitimacy of participants in public participation processes, especially in a context such as the Marshall crisis, which had several layers of First Nations and non-Aboriginal organizations vying for the right to speak on behalf of their constituents. Media influence can also play a crucial role as to whether a public participation initiative is successful or fails. In sum, these four factors can adversely affect the scope and outcomes of public participation processes.

The following section of this chapter, which will focus on the five public participation methods, will define and outline the various techniques of public participation and provide examples of techniques that could be encompassed under each method. It will then incorporate the four external factors into its analysis of each technique's suitability for implementation in a crisis situation. Once this analytical 
framework has been scoped out, specific analysis will be conducted on the techniques and methods of public participation that were used prior to and during the Marshall crisis to review their approaches to crisis management in terms of reducing tensions over the short term and establishing partnerships to manage the Maritime commercial lobster fishery over the long term.

\subsection{Public Participation Methods}

The International Association for Public Participation (IAP2) has developed a chart to highlight the varying degrees of public participation (see Table 1). Each method of public participation is organized according to how much direct impact the public has through its contributions to the public policy-making process. Methods include the following: Inform, Consult ${ }^{14}$, Involve, Collaborate, and Empower. Considering the context of the policy or legislative issue that is being developed, the level of public impact in a process becomes increasingly important to the process. However, varying levels of impact may be required at different times when addressing a particular issue or series of issues. The following sections describe each method in turn.

\subsubsection{Inform}

Information sharing is an important part of any public participation process. The Inform method of public participation includes various techniques that an entity, such as a government, can use to share information with the public, as well as seek their information in an ad hoc manner. Fact sheets and websites are listed above as some of

\footnotetext{
${ }^{14}$ This form of consultation does not refer to the "Legal Duty to Consult and Accommodate" First Nations, which was set out by the Supreme Court of Canada.
} 
the ways that an entity may work to inform the public about decisions that may have had an effect on them. In addition, most communications materials developed by an entity such as a private corporation or government (e.g. press releases, backgrounders, frequently asked questions, etc.) could also be seen as techniques encompassed within this method. While Inform does not provide opportunities for individuals to have an influence on specific public policy-making activities, it can be combined with other methods of public participation to ensure individuals have the necessary information to participate with informed opinions, as Graham and Phillips have pointed out earlier in this chapter.

\subsubsection{Consult}

Consultation provides the public with a greater degree of involvement in the sense that government officials will develop options in draft form to respond to a crisis. The federal government will then seek to consult with the public on whether a specific course of action is on a correct trajectory through a variety of means, such as public meetings (http://www.iap2.org). This method and its techniques afford individuals an opportunity to review the overall policy or initiative being developed and to provide their input. However, there are variations to how much time, resources and openness are involved in this technique of public participation. This is similar to what Abele, Graham, et al., define as traditional public consultation in the sense that there is little empowerment or public impact for the people and key policy decisions are already developed prior to engaging with the public.

One of the main issues with consultation processes is the management of 
participant expectations, as some participants often feel that their input will not be taken seriously. Individuals in a consultation process can sometimes feel that at most, their commentary could lead to tweaking a policy or initiative that is already in an advanced stage of development. Sometimes this is the fault of the government department or agency that designed the consultation process by raising expectations of real change when it only seeks to receive a "rubber stamp" endorsement from the public or technical experts on the subject matter in order to move forward with its agenda and seek legitimation through the democratic process. This is also known as fake public participation, as per the definition provided by J.H. Snider that is provided in the previous section. Fake participation will also be elaborated in the Consult section below.

Other times, it is very difficult to convince participants that anything except wholly integrating their input into a new policy or initiative is a satisfactory outcome in such a process. In this case, it is difficult to know how to ensure a particular individual or group does not become disenfranchised with the promise of limited consultative input being incorporated in its entirety. Add to this the stress and tension of a crisis situation and it may not be the most feasible method of bringing groups to the table, especially when they have opposing interpretations of the same concept, which in the Marshall case was the vaguely-defined moderate livelihood clause in the treaties. First Nations fishers thought it meant they had a right to earn a moderate livelihood in the Maritime commercial lobster fishery, while non-Aboriginal fishers felt otherwise, as stated in Chapter 2.

Another issue with the Consult method of public participation occurs when an 
initiative or policy is proposed to address a major issue that polarizes public opinion. Not only is Consult (e.g. a public meeting or town hall) perceived by many as being inadequate for seeking public opinions (the public often wish to participate in citizen engagement processes from beginning to end, as stated in many of the works by scholars of citizen engagement), it can also force groups to organize and attempt to force their own agendas in focus groups or public meetings.

A prime example of groups "hijacking" a consultation or series of consultations occurred in 2009 with U.S. President Barack Obama's Healthcare town hall meetings. Throughout several of the town halls, many individuals came forward and expressed their vehement opposition to the proposed approach of nationalizing health insurance and attempted to stifle any opinions that favoured Obama's health care plan (Obama ready). In fact, some Democrat party members were concerned that Republicans had put some of the outspoken individuals against the health care plan in the town halls to derail any real discussion (Obama ready). However, regardless of the reason for individuals disrupting the town halls, the point is that public participation techniques under the Consult can further polarize public opinion and the stances taken by groups with a stake in an issue, at least in part, because it appears that a particular approach to a problem has already been developed. Consultations, as an approach to bringing groups together during a crisis, could potentially contribute more tension to a crisis, as has and will be seen with the public participation initiatives implemented by the Department of Fisheries and Oceans with groups as part of the short-term plan to address the Marshall decisions in Chapter 2 and Chapter 4. 
A final concern with the Consult method of public participation lies in what is considered to be fake participation. The term is defined as follows: "Fake participation occurs when governments seek the democratic legitimacy but not the accountability that comes with public participation. Fake participation allows politicians to say, 'I gave you an opportunity to speak on this legislation-and you didn't take it" (Snider 90). This technique of public participation would likely fall within the Consult method because a politician can present a policy or legislation in a public participation process, seek input and then indicate that individuals had the opportunity to provide input, even if there is no chance that participants' input would be incorporated in a serious manner. Snider indicates that this occurs because democracy is the only legitimate form of rule, so to appear legitimate, politicians and governments must present themselves as being democratic in the way they develop policy and initiatives (91). Fake participation can eat away at the public mistrust of representative forms of citizen involvement, such as politicians and institutions of government, to actually take their concerns into account and address them. This can lead to significant tensions and frustration among groups in dispute because they sense that governments and other private entities are not taking their concerns seriously.

\subsubsection{Involve}

Involving the public from the beginning in a policy-making process through public participation initiatives, such as workshops and deliberate polling, can be a very helpful means to connect with the public and receive its support for a policy initiative in response to a crisis. The public would likely place more trust in an Involve public 
participation process because their provision of input would have more impact on policy making, it would ensure additional accountability because of this increased impact over Inform and Consult methods, and the public would take greater ownership of the issue. If conducted as promised, policy considerations would have to be developed and reported to demonstrate that the government seeking input is serious concerning citizens' knowledge of an issue. As Graham and Phillips note in Citizen Engagement, citizens would also be required to be educated on the subject matter and would then need to possess informed opinions (2). Openness and transparency are crucial during a crisis to bring opposing groups to the table, especially if the government facilitating a public participation process has already developed the said process to reduce tensions as quickly as possible. In a Consult public participation process, an already tense group could become even angrier that the government is not taking it seriously. The group may perceive that the government is only seeking to provide "lip service" to its requirements, or seeking "buyin" for a particular way in which the government sees the crisis should be addressed.

In terms of time considerations, techniques of public participation in the Involve method would likely take more time to establish than Inform or Consult. However, in a way, time constraints could be offset by the promise of involving the different groups acting in a crisis period through the establishment of a new process of policy making to reduce tensions and establish long-term partnerships.

\subsubsection{Collaborate}

Collaboration takes the idea of Involve techniques a step further and enables publics that are being engaged to develop responses to crises in conjunction with other 
groups, as well as the government. Essentially, collaboration is a joint-management approach to developing policies and initiatives to respond to issues. The empowerment accorded to citizen advisory committees and other similar entities has the potential to enable the public to affect real change in policy and/or initiative development and implementation (http://www.iap2.org). However, depending on who is placed a committee or advisory panel, there is a significant chance for fake participation to occur. Much like politicians can stack a town hall meeting with supporters of a policy to indicate that they have done their due diligence in engaging with the public, Ministers and/or senior bureaucrats can appoint key people to a committee or panel who will do their bidding. It is important to recognize that while collaboration holds the promise of real decision-making for the public, the appointments that are made can sometimes reign that promise in, especially if those who are appointed tend to push their agenda, which could represent fringe groups and/or those who are affluent enough to participate without much concern, as was raised by Irvin and Stansbury as an issue with such initiatives (9).

Another issue with collaboration is that those chosen to act on committees and/or advisory panels often already have the ear of those who appoint them and are among the elites in society. Sometimes, this can be okay, if the person is an important expert on the subject of the committee to which one is appointed, but sometimes the lack of a fresh perspective from individuals who work at the ground level can be detrimental to developing the best ideas to respond to a crisis. This is especially important if the opposing groups that cause a crisis are mostly at the ground level and they are left out of public participation. 
Time constraints are likely the greatest barrier toward implementing techniques under the Collaborate method. Collaboration can sometimes take a long time to produce a significant policy or resolution, especially if those appointed to a committee or panel tend to debate a lot of issues and take opposing viewpoints. This would likely not be ideal in a crisis situation, unless the groups involved could be convinced that they must attempt to broker a consensus within a reasonable time frame.

\subsubsection{Empower}

Empowering individuals, while a significant and important technique of public participation in some cases, would not likely work, at least initially, during a crisis involving more than two groups of actors because it would take too long to establish a comanagement type of role for policy-making processes or industrial management. In addition, if there were any legislative requirements to managing a resource industry, for example, governments would likely not abdicate their legislative drafting authority to other organizations. The Empower method would likely be better situated as an option in the long term to follow up from another method of public participation that stems from a crisis and commences the establishment of long-term partnerships. Once those initial partnerships are established, they may be easier to build into a co-management type of approach.

\subsection{Time Constraints}

The amount of time available to stem an impending crisis, or to manage an existing one is dependent on a number of key factors. These include the method of public participation that is selected and the specific technique(s) chosen from that 
method, the financial resources required to implement the proposed process, and the determination of legitimate groups. It is important to note that the amount of time required establishing these factors could stretch far beyond that which is available. Reducing tensions as soon as possible is very important because in so doing, relations among groups involved will not likely suffer as much as if the crisis were allowed to continue for a longer period of time. In addition, public participation processes can aid in airing grievances and help create a situation that will enable all parties involved to establish partnerships to manage lands and resources that are subject to section 35 rights over the long term.

Despite the benefit of reducing tensions as soon as possible, doing so sooner rather than later requires a quick turnaround time for public participation, which can vary from being feasible, to plausible, to impossible, depending on the circumstances. Graham and Phillips state the importance of governments choosing when and how to engage with the public: "In general, the literature concludes that conducting public participation is legitimate only if it can actually make a difference to the policy decision at hand and only if the sponsoring government is prepared to commit the requisite time and resources to make it effective" (Citizen Engagement 7). In the context of a crisis, the amount of time available to hold a public participation process becomes even more limited. However, depending on the techniques, method and stakes involved, tensions can be reduced while enabling a greater public impact on the policy-making process.

\subsection{Financial and Human Resource Availability}

Resources, be they fiscal or human, can often be difficult for governments to 
access for a specific public participation process. Competing demands draw on financial resources, which can be in short supply in the federal government, not to mention the number of federal officials that are often required to coordinate some public participation processes. For example, the 2008-2009 Indian and Northern Affairs Canada Summative Evaluation of Consultation and Policy Development ${ }^{15}$ and Basic Organizational Capacity Funding provides data that demonstrates significant variations in funding for Aboriginal public participation over several years. The Evaluation indicates that from $2003-2004$ to $2007-2008$ fiscal years, a total of $\$ 231,069,218.49$ was spent on consultations and policy development (Summative Evaluation ii). While approximately $\$ 231$ million is a significant amount of funding, when it is compared with Indian and Northern Affairs Canada's total actual expenditures of \$6,992.7 million in 2007-2008, it would not appear to be a significant priority overall (2008-2009 Departmental Performance Report). However, despite the relatively low amounts budgeted for public participation at Indian and Northern Affairs Canada, there were several subject-specific public participation initiatives that received significant amounts of funding, which pushed expenditures in particular years far beyond the initial budgeted amounts.

Total funding for Indian and Northern Affairs Canada's Consultation and Policy Development authority varies significantly between actual and estimated funding. Table 2 below, reproduced from the Evaluation provides a year-to-year snapshot of variances:

\footnotetext{
${ }^{15}$ The "Consultation and Policy Development" funding authority has many eligibility categories and can be used to fund several variations of public participation.
} 


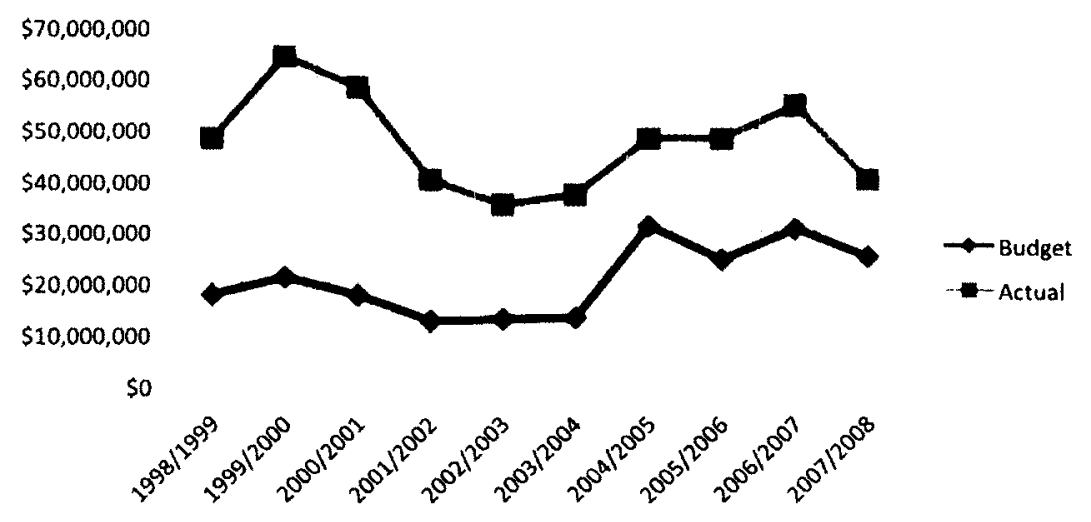

The Evaluation states that "actual expenditure has varied from a low of $\$ 34.6$ million in $2002 / 2003$ to a high of $\$ 64.4$ million in $1999 / 2000$. The variance in total funding is primarily due to the number and size of subject-specific consultations that are funded in any year" (Summative Evaluation 23). The trend of having widely varying total funding amounts for Consultation and Policy Development every year would appear to demonstrate that Indian and Northern Affairs Canada has a significant number of targeted, annual public participation processes for which it contributes funding on an adhoc basis. In addition, budgeted versus actual expenditures also vary by a significant margin every year (1999-2000 has the highest budget to actual variance at approximately $\$ 40$ million, while $2007-2008$ has the smallest variance at approximately $\$ 15$ million). These variances provide more evidence that resources (financial and human) tend to only be invested when the Department appears forced to provide them, yet despite the seemingly ad-hoc basis through which Indian and Northern Affairs Canada provides funds for public participation processes every year, there is also the possibility that when ${ }^{16}$ Note: This graph was reproduced from the Summative Evaluation of C\&PD and BOC Funding, Page 24. 
a major issue presents itself (these would include crises), resources can be sourced from within the Department to address such an issue. It is important to consider the ramifications of these subject-specific public participation processes have on departmental resources. Despite there being little funding budgeted annually for engagement, it would appear that an important issue will enable Indian and Northern Affairs Canada to clear a path to a significant amount of resources to address it. From this perspective, it could be surmised that significant resources could be made readily available to engage with the public in a crisis situation.

Considering that Indian and Northern Affairs Canada has a trend of investing heavily in subject-specific engagement initiatives that involve millions of dollars depending on the crisis, it is likely that generally, the federal government could plausibly spend significant amounts of funding during a crisis situation involving First Nations, such as Marshall, depending on how quickly a situation is deemed to require immediate action.

\subsection{Media Influence}

The media can play a significant role in influencing public opinion and contributing to increasing tensions among groups during a crisis. Depending on how the media decide to filter information for a story, who they decide to interview and which angle they choose to investigate, there can be significant repercussions, especially if the owners of a particular media outlet, or series of media outlets, decide to go forward with stories that favour one group or series of groups heavily. That is exactly why the media's approach to stories must be monitored and considered when the federal government 
attempts to bring different partners to the table. If false information is reported, or if an idea expressed by a group leader is presented incorrectly, a whole public participation process could be derailed based on some participants not feeling like another side is engaging in an honest dialogue.

A prime example of how the media can contribute to increasing tensions during a crisis is derived from the debate between Mi'kmaq and non-Aboriginal fishers concerning the moderate livelihood clause of the historic treaties that were at the centre of the Marshall decisions. When the Supreme Court of Canada rendered Marshall 1 , it indicated that Mi' $\mathrm{kmaq}$ fishers had a right to fish for a moderate livelihood, but what it failed to do was pronounce on whether a moderate livelihood constituted fishing for sustenance, or whether it included the commercial fishery (Coates 11). Newspapers publishing stories on the "Marshall case" during the crisis focused significantly on nonAboriginal perspectives, which in turn led to the following:

Numerous reports represented the 'threat' posed to the east coast lobster fishery by expanded First Nations harvesting, but recent arguments by fishers that the harvest could be enlarged substantially were rarely reported, and little attention was given to the very small cumulative size of the total planned First Nations fishery (according to several estimates, the planned Aboriginal harvest represented a meagre 1 per cent of the total east coast lobster fishery, an amount hardly likely to destroy the resource) (Coates xii).

For non-Aboriginal fishers, reading the erroneous information presented, as the dominant voice in the local media, such as newspapers, would create the potential for widespread 
panic and increased tensions. Further, "in their unease and disappointment, the fishers [non-Aboriginal] erupted in anger and frustration, adding fuel to the controversy and providing First Nations with a unique insight into the thoughts and opinions of their neighbours" (Coates xvii). While it is likely that media reports that tended to favour the non-Aboriginal fishers' economic-based arguments against Mi'kmaq rights were not the catalyst for the Marshall crisis, they certainly contributed to and were a reflection of the fears of non-Aboriginal fishers in the Maritimes. This dominant viewpoint in the media likely increased anger and frustration among non-Aboriginal fishers through the expression of viewpoints that resonated with them, but it would have also angered First Nations fishers, who likely felt their position was being misrepresented in the media.

It is precisely because the media can take the side of one group over another during a crisis that the federal government, and other groups involved, must monitor how their interests are being represented in the public eye. It is important to monitor and adjust messaging accordingly to ensure participant groups can be trusted to engage with each other on the basis of openness and trust with the most accurate information on hand.

There are two ways that this thesis will analyze the media's impact on tensions among the involved groups throughout the Marshall crisis. The first is to conduct a simple agenda-setting analysis, which, according to Robert $\mathrm{S}$. Hanczor presumes that the media plays the role of agenda setter by placing emphasis on a specific topic and to influence public thinking:

These [agenda-setting] relationships are assumed to be causal; in other words, media coverage of certain issues is assumed to have certain effects 
on the audience that can be measured quantitatively through hypothesis testing. Put simply, this perspective assumes that the media sets the agenda and ways of thinking for the audience (2).

While agenda setting is a very basic form of media analysis, there is evidence in the secondary sources researched for this thesis, such as the news analysis conducted by Coates in his book, which highlights the media's one-sided approach to the Marshall crisis. The influence of the media by virtue of its one-sided reporting will be further elaborated in the proceeding chapters.

In addition to agenda setting, another angle that is of specific use in analyzing the Marshall crisis is the political economy theory of media analysis, which is similar to agenda-setting, but analyzes how the media filters information based on who owns the media and where the money and power flow:

Like the agenda-setting perspective, political economy assumes a powerful and influential media system. However, this approach goes beyond assumptions of direct causal linkages and analyzes controversial issues by tracing the routes through which money and power are able to filter out undesirable news, marginalize dissent and allow both the public and private spheres to present their dominant messages to the public (Hanczor 3).

One of the major works written about the political economy of the mass media in the United States is the 1988 book Manufacturing Consent: The Political Economy of the Mass Media, by Edward S. Herman and Noam Chomsky. In their book, they establish a 
propaganda model based on manufactured information that seeks to influence public opinion to the agendas of those who own the media, namely large corporate conglomerates (1-3). Herman and Chomsky indicate that "the elite domination of the media and marginalization of dissidents that results from the operation of these filters occurs so naturally that media news people, frequently operating with complete integrity and goodwill, are able to convince themselves that they choose and interpret the news 'objectively' and on the basis of professional news values" (2). There is an economic element among media outlets that can filter news stories to reflect a dominant perspective, being that of the elites who own the media, especially if the same conglomerate or individual owns all of the media in a particular geographical area where a crisis is occurring.

\subsection{Participant Legitimacy}

One of the key questions concerning those in charge of developing and implementing public participation processes is the determination of what individuals, leaders, institutions and/or organizations legitimately represent a group. This is an especially poignant and sensitive question as it relates to First Nations because there are many ways to divide their interests among geographic, socio-economic, cultural, community and tribal lines. This can become problematic, because if too many individuals and groups with different agendas participate, they can confuse the priority messages that participants want to express to governments in a public participation process. In addition, fringe groups and others from a "higher socio-economic status" can often pursue their own agendas and dominate a public participation process, obscuring 
the majority perspective on an issue (Irvin and Stansbury 9).

The Marshall crisis case study provides an excellent series of examples to demonstrate the complexities that can arise when attempts are made to decide who should legitimately represent First Nations' interests. The federal government, when it decided to engage with First Nations fishers and communities after Marshall 1, had to decide the scope and extent of who should legitimately represent the interests of First Nations in the Maritimes, who had suddenly found themselves in possession of a newly defined treaty right to fish. Geography was key in defining legitimacy in terms of scope. For example, Indian and Northern Affairs Canada officials, who were responsible for the longer term outcomes of negotiating treaty rights to natural resources in relation to the Marshall decisions, simply expanded the existing negotiating table to engage on the fishing rights issues with Nova Scotia First Nations, while attempting to develop other forms of engagement with different provincial groups of Mi'kmaq from New Brunswick, Prince Edward Island and Quebec ${ }^{17}$ (Montminy Interview). Already, the Mi'kmaq were divided along provincial lines when engagements were to occur, despite representing the same tribe with many similar customs. Department of Fisheries and Oceans officials met with First Nations community members to discuss short-term aspects of how to manage the lobster fishery in light of the Marshall decisions through informal engagement meetings (Montminy Interview). Department of Fisheries and Oceans officials held these engagements with each Maritime First Nations community to discuss short-term

\footnotetext{
${ }^{17}$ The Mi'kmaq of Newfoundland and Labrador were not considered in this process because they were not considered to possess hunting and fishing rights in the same way as the Maritime Provinces and Quebec.
} 
approaches to managing the lobster fishery in light of the Marshall decisions (MacKenzie Interview). While the Mi'kmaq formed the majority of First Nations involved in the Maritime commercial lobster fishery, the Maliseet and Passamaquoddy people were involved as well, but the issue was largely viewed as a Mi'kmaq rights issue.

Finally, the political leadership of the First Nations were engaged in different ways, including through meetings where the Minister of Fisheries and Oceans at the time, Herb Dhaliwal, met with the $34 \mathrm{Mi}$ 'kmaq Chiefs to seek a voluntary 30-day fishing moratorium (Coates 144). While that occurred, departmental officials met with the Atlantic Policy Congress of First Nations Chiefs (APC) and other regional organizations (Montminy Interview). In sum, throughout the crisis period, many individuals, organizations and institutions were engaged by a variety of representatives from the federal government to determine the best means to move forward in responding to the Marshall crisis. However, as Chapter 2 demonstrated, many of those who did not have the time or were not permitted to participate initially, including First Nations and nonAboriginal fishers, should have been permitted, at least through some form of representation at the ground level, to provide their input in the policy-making process. By leaving those groups out of the process, the Department of Fisheries and Oceans likely missed out on a significant opportunity to reduce tensions, and may have instead contributed to them by keeping those who had the most to gain or lose out of the loop. Had the Department implemented a public participation process with a higher public impact on policy making and a more deliberative form of citizen involvement, there would likely have been more participant legitimacy among those who were confronting 
each other and they may have favoured a calmer discussion on how to manage the Maritime commercial lobster fishery while respecting treaty rights as a result.

\subsection{Conclusion}

This chapter has defined and illustrated several concepts, then compiled them to establish a modified public participation spectrum. Public participation methods (Inform, Consult, Involve, Collaborate and Empower) and their respective techniques have been combined with additional concepts along a continuum of increasing public impact. The additional concepts include dichotomies between traditional public consultation / citizen engagement, and representative / deliberative citizen involvement.

In addition to the concepts identified above, the modified public participation spectrum also includes four external factors that must be taken into consideration when choosing an appropriate technique and method of public participation to resolve a crisis. The first two external factors, time constraints, and financial/human resource constraints, must be considered when determining the method of public participation to be implemented, as these two factors increase when methods that afford a higher public impact on the policy-making process are chosen. The last two external factors, media influence and the participant legitimacy, present potential means to improve, or derail, a public participation process during a crisis. 
Table 3: Modified Public Participation Spectrum

Increasing Level of Public Impact

Increasing Time Requirements

Increasing Financial/Human Resource Requirements

\begin{tabular}{|c|c|c|c|c|c|}
\hline & Inform & Consult & Involve & Collaborate & Empower \\
\hline $\begin{array}{l}\text { Public } \\
\text { participations } \\
\text { guals }\end{array}$ & $\begin{array}{l}\text { To provide the } \\
\text { public with } \\
\text { balanced and } \\
\text { objective } \\
\text { information to } \\
\text { assist them in } \\
\text { understanding the } \\
\text { problem, } \\
\text { alternatives, } \\
\text { opportunities } \\
\text { and/or solutions. }\end{array}$ & $\begin{array}{l}\text { To obtain public } \\
\text { feedback on } \\
\text { analysis, } \\
\text { alternatives } \\
\text { and/or solutions. }\end{array}$ & $\begin{array}{l}\text { To work directly with } \\
\text { the public throughout } \\
\text { the process to ensure } \\
\text { that public concerns } \\
\text { and aspirations are } \\
\text { consistently } \\
\text { understood and } \\
\text { considered. }\end{array}$ & $\begin{array}{l}\text { To partner with the } \\
\text { public in each aspect } \\
\text { of the decision } \\
\text { including the } \\
\text { development of } \\
\text { alternatives and the } \\
\text { identification of the } \\
\text { preferred solution. }\end{array}$ & $\begin{array}{l}\text { To place final } \\
\text { decision-making in } \\
\text { the hands of the } \\
\text { public. }\end{array}$ \\
\hline Inall ficial & \multicolumn{2}{|c|}{ Traditional Public Consultation } & \multicolumn{2}{|c|}{ Citizen Engagement } & Empower \\
\hline 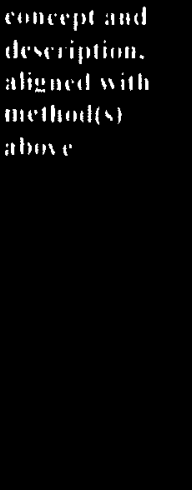 & \multicolumn{2}{|c|}{$\begin{array}{l}\text { Provides "citizens with information } \\
\text { about programs, results, options and } \\
\text { recommendations, then ask for } \\
\text { feedback...the first approach... fails to } \\
\text { fully engage citizens in a decision } \\
\text { making process" (Abele, Graham, et } \\
\text { al., Talking with Canadians 9). }\end{array}$} & \multicolumn{2}{|c|}{$\begin{array}{l}\text { "Citizens are asked to reflect on choices and } \\
\text { tradeoffs involving conflicts in values or } \\
\text { difficult resource allocation } \\
\text { decisions... Engagement, on the other hand, } \\
\text { simulates one of the conditions of public } \\
\text { decision making, providing participants with } \\
\text { information and confronting them with difficult } \\
\text { choices. Equipped with an understanding of } \\
\text { the issues, relationships among issues, policy } \\
\text { options and tradeoffs, as well divergent and } \\
\text { convergent perspectives, participants are able } \\
\text { to form a considered or enlightened judgement } \\
\text { about an issue or set of issues, and in some } \\
\text { instances a consensus about the future" (Abele, } \\
\text { Graham, et al., Talking with Canadians 9). }\end{array}$} & $\begin{array}{l}\text { To place final } \\
\text { decision-making in } \\
\text { the hands of the } \\
\text { public. }\end{array}$ \\
\hline $\begin{array}{l}\text { Inalytical } \\
\text { (mintept and }\end{array}$ & \multicolumn{2}{|c|}{$\begin{array}{l}\text { Representative Citizen Involvement } \\
\text { (Democracy) }\end{array}$} & \multicolumn{2}{|c|}{$\begin{array}{c}\text { Deliberative Citizen Involvement } \\
\text { (Democrecy) }\end{array}$} & Empower \\
\hline 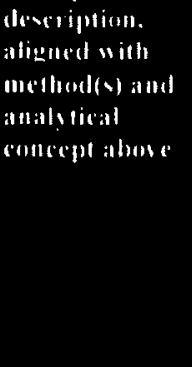 & $\begin{array}{l}\text { Accountability: Opposition parties, } \\
\text { interest groups } \\
\text { (Laforest and Phillips, Critical Policy } \\
\text { Studies 72). }\end{array}$ & $\begin{array}{l}\text { al parties, interest } \\
\text {, interest groups, } \\
\text { osition parties, } \\
\text { s, Critical Policy }\end{array}$ & $\begin{array}{l}\text { Aggregation: Public se } \\
\text { consultants } \\
\text { Accountability: Citizen } \\
\text { legislators } \\
\text { (Laforest and Phillips, } \\
\text { 72). }\end{array}$ & $\begin{array}{l}\text { vice, legislators, } \\
\text { public service, } \\
\text { ritical Policy Studies }\end{array}$ & $\begin{array}{l}\text { To place final } \\
\text { decision-making in } \\
\text { the hands of the } \\
\text { public. }\end{array}$ \\
\hline $\begin{array}{l}\text { PVlerial } \\
\text { lacture }\end{array}$ & \multicolumn{4}{|c|}{$\begin{array}{l}\text { - } \quad \text { Media Influence } \\
\text { - } \quad \text { Participant Legitimacy }\end{array}$} & \\
\hline
\end{tabular}

Note: Methods row and Public Impact arrow reproduced from http://www. iap2.org 
The modified public participation spectrum presented in Table 3 above uses the methods highlighted in Table 1 and aligns them with the analytical concepts presented earlier along the spectrum to suggest the concepts' feasibility for implementation during a crisis management. The additional two arrows at the top highlight ascending requirements for time and financial/human resources, which are both in short supply during a crisis. These arrows follow in parallel to the original public impact arrow to demonstrate that a greater degree of public impact on the policy-making process will lead to additional requirements of time and financial/human resources. Two external factors are also featured on the bottom, namely media influence and participant legitimacy, which can wreak havoc on any process if they are not kept in check.

To provide an example, if a citizen engagement process were implemented, its feasibility in terms of time and resource constraints could in part be determined by considering whether such time and resources would permit the practical implementation of techniques under the Involve method. Since they are aligned along the spectrum, if Involve techniques could be implemented on a practical level, it is likely that similar techniques under citizen engagement could potentially be as well.

The modified public participation spectrum featured in Table 3 will be used in the following chapters as the analytical framework to help assess what public participation method and its related techniques could be the most useful to achieve the short- and long-term goals of reducing tensions and establishing partnerships among the groups involved to manage the Maritime commercial lobster fishery over the long term. While some techniques and methods of public participation could be useful in some 
circumstances, generally speaking, the closer one draws to the centre of Table 3 , at the Involve method of public participation, I argue that will be better to implement a public participation method that will meet the aforementioned objectives, while managing potential barriers arising from the four external factors. I believe that individuals and groups in conflict may wish to present their perspectives to influence policy making. However, at the same time, there are time and financial/human resource constraints to consider.

Chapter 3 has presented an analytical framework through which to choose a public participation method to implement during a crisis, along with external factors to consider when choosing such a method. Chapter 4 will take this foundational work and use it as a means to analyze the techniques and methods of public participation that were implemented prior to and during the Marshall crisis for their usefulness in meeting the short- and long-term objectives of reducing tensions and establishing partnerships over the long term. Chapter 5 will continue to build on the analysis of Chapter 4 and recommend that the Involve method of public participation would have likely provided the likeliest approach to meet the short- and long-term objectives. 


\section{Chapter - Public Participation Prior to and During the Marshall Crisis}

\subsection{Introduction}

This chapter will focus on the few instances prior to and during the Marshall crisis where public participation techniques and methods were attempted by the Department of Fisheries and Oceans, primarily with the leaders of various groups through the use of unofficial meetings, negotiations and ad hoc public consultations.

Comparative analysis will demonstrate that while the public participation techniques that were implemented by the Department of Fisheries and Oceans leading to and during the Marshall crisis changed and increased in intensity, no technique that was used came from a method other than Inform or Consult, thus leaving little opportunity for increased public impact in policy making to achieve the stated short- and long-term objectives of this thesis. This analysis will set the stage for Chapter 5, which will draw from the modified public participation spectrum and propose new techniques and methods with which to engage with groups during a crisis in a manner that is both respectful of potential barriers, such as time, while also considering the importance of public impact to reduce tensions and contribute to improved policy making.

Public participation, which is defined in Chapter 3, encompasses a spectrum of public participation techniques, encompassed in five methods with increasing levels of public impact in government decision-making concerning policy and other related issues affecting the citizenry or electorate. Public participation methods can be identified, such as Inform, Consult, and Involve, specific techniques (e.g. deliberative polling and 
workshops) and then be sorted according to the degree of public impact they enable in the policy-making process during a crisis. Moreover, external factors, such as media influence and participant legitimacy, are to be considered for their influence on the outcomes of public participation processes. This analytical framework will be used to assess the relative feasibility and usefulness of techniques and methods implemented before and during the Marshall crisis.

To provide a brief recap of the longer description in Chapter 2, the Marshall crisis was precipitated when, a few days following Marshall 1, some First Nations and nonAboriginal fishers faced off on land and water in violent confrontations as a result of the Supreme Court's decision, which First Nations thought allowed them to the right to fish commercially out of season and without a quota. The violent confrontations were largely blamed on differences of opinion concerning what constituted a "moderate livelihood and whether it applied to the Maritime commercial lobster fishery, among others, as per the Supreme Court of Canada ruling in Marshall I, and through the later clarification, known as Marshall 2, both of which occurred in Fall 1999. The Marshall crisis continued well into 2000, when the Department of Fisheries and Oceans engaged with First Nations bands on an individual basis to provide them with communal fishing licences as a shortterm measure to bring them into the fishing regime. While this initiative was largely successful, the Department of Fisheries and Oceans, Burnt Church and Shubenacadie (Indian Brook) First Nations faced off in the summer of 2000 on land and water because the First Nations rejected the notion of having to be regulated by the Department.

To analyze the potential of public participation techniques and methods 
implemented by the Department of Fisheries and Oceans during the Marshall crisis, it may be helpful to compare and contrast techniques that were implemented with the various groups that were involved with the Maritime commercial lobster fishery prior to the crisis. This chapter will begin by focusing on public participation techniques and methods that were implemented by the Department of Fisheries and Oceans with First Nations and non-Aboriginal fishers prior to the crisis. The section and sub-sections to follow will focus on the broadening public participation techniques and methods ${ }^{18}$ that were implemented during the Marshall crisis, with a specific focus on three major techniques: community and group engagements, federal negotiations and mediation, and legislative and parliamentary committee hearings. In addition, external factors that may have an impact on public participation outcomes, including time constraints, financial/human resource constraints, media influence, and participant legitimacy, will be analyzed to determine their level of impact during the Marshall crisis.

\subsection{Public Participation Prior to the Marshall crisis}

There was significant debate among those interviewed for this thesis as to whether any public participation actually occurred with First Nations and non-Aboriginal fishers prior to the Marshall crisis. John Paul, Executive Director of the Atlantic Policy Congress of First Nations Chiefs, states that the "federal government did not want to discuss" treaty rights to fish for lobster commercially because "they thought they would win the case [Marshall I]" (Interview). In addition, James MacKenzie, who was the

\footnotetext{
${ }^{18}$ Please see Chapter 3 for an explanatory typology of the differences between public participation techniques and methods.
} 
Chief Federal Negotiator appointed by the Minister of Fisheries and Oceans to negotiate with First Nations fishers during the crisis, felt that "there was not much engagement prior to Marshall" (Interview). MacKenzie guessed that the public participation that did occur prior to Marshall was on "an issue by issue basis," which had an effect on the "200 plus existing fisheries organizations, including the Maritime Fishermen's Union, [which] was grassroots, hourly paid, and small operations" (Interview). Considering the many fisheries organizations in the Maritimes and the many varied, competing interests that fish packers and commercial fishers would have, it is not surprising that public participation would occur on an issue by issue basis with the different fishing organizations because the Department of Fisheries and Oceans likely did not have the financial/human resources to continually hold public participation sessions. Despite the sporadic engagement that occurred with the fishing organizations, the Department did have some organizations and groups with which it had already established regular relations, especially after the Sparrow decision.

James Jones states:

Prior to Marshall, the Department of Fisheries and Oceans developed a fair relationship with Chiefs and Councils, which helped considerably in managing engagement [with groups]. You have to have a relationship with the different groups, including the commercial fishery...You develop relationships and interaction with First Nations. Relations and contacts helped [throughout the crisis] (Interview).

The relationships to which Jones is referring include informal engagements to address the 
outcomes of the Sparrow decision with "most First Nations Chiefs around New Brunswick, Prince Edward Island and Nova Scotia" (Interview). Engagements spurred by the outcomes of Sparrow were ad hoc and led to the establishment of informal relationships that enabled the lines of communication to open during the Marshall crisis.

The $R v$. Sparrow ${ }^{19}$ case, which concerns the "Indian food fishery," is considered a precursor to the Marshall decisions. In the Sparrow decision, the Supreme Court of Canada overturned a previous conviction of an Aboriginal individual that was fishing with a "longer than permitted by the terms of his Band's Indian food fishing licence," under the Fisheries Act in 1984 (R. v. Sparrow [1990] 1 S.C.R. 1075.). The Supreme Court indicated the following:

The Crown failed to discharge its burden of proving extinguishment. An aboriginal right is not extinguished merely by its being controlled in great detail by the regulations under the Fisheries Act. Nothing in the Fisheries Act or its detailed regulations demonstrated a clear and plain intention to extinguish the Indian...aboriginal right to fish. These fishing permits were simply a manner of controlling the fisheries, not of defining underlying rights...Historical policy on the part of the Crown can neither extinguish the existing aboriginal right without clear intention nor, in itself, delineate that right. The nature of government regulations cannot be determinative of the content and scope of an existing aboriginal right. Government

${ }^{19} R$ v. Sparrow [1990] 1 S.C.R. 1075. 
policy can, however, regulate the exercise of that right but such regulation must be in keeping with s. 35(1) (R v. Sparrow).

The Supreme Court Justices handed a significant victory to Aboriginal peoples possessing a treaty right to fish for food, social and ceremonial purposes by stating that provincial fishing regulations cannot take away from an Aboriginal right to fish. Sparrow provided an onus for the Department of Fisheries and Oceans to develop policy that was more conducive to respecting Aboriginal treaty and natural resource rights. The end result of the Supreme Court decision was that a significant paradigm shift occurred in which the Department began to support First Nations fishers' treaty rights.

The difference between Sparrow and the Marshall decisions is that the Marshall decisions involved the commercial fishery, which posed a significantly greater real or imagined threat to non-Aboriginal fishers economic prospects in Atlantic Canada. As one could likely predict, the lack of public participation with non-Aboriginal fishers concerning the Aboriginal treaty right to fish became a far more substantial matter once they perceived the potential of economic fallout accompanying the Supreme Court decisions.

The informal development of relations prior to a crisis could potentially help ease tensions or reduce them once the crisis begins. This is because the lines of communication could remain open behind the scenes among individuals and/or group leaders. This technique of public participation would likely fall under Consult in the public participation spectrum. Although the relationships that developed between the Department of Fisheries and Oceans and First Nations fishers were mainly the result of 
the Sparrow case, they tended to be about the federal government "imposing its will" on the fishery for food, social and ceremonial purposes, rather than seeking input on how to manage the fishery with First Nations. Regardless, these relations did carry on into the Marshall crisis and helped to maintain communication while violent confrontations exacerbated matters in public.

In Chapter 3, it was argued that the Consult method of public participation has less of a public impact on the policy-making process, as it affords little opportunity for the affected public, in this case First Nations fishers, to provide input on how to manage the crisis. Federal policy-making concerning the future of the Maritime commercial lobster fishery without First Nations' input could serve to alienate and disempower them as a group. Yet, while First Nations leaders had somewhat tangible relations with the Department of Fisheries and Oceans, non-Aboriginal fishers were entirely left out of public participation discussions.

A major issue arising from the interviews concerning pre-Marshall crisis engagement is the notable absence of non-Aboriginal fishing organizations, such as the Maritime Fishermen's Union. These organizations could have contributed to discussions on how to integrate First Nations into the Maritime commercial lobster fishery. Additionally, non-Aboriginal fishing organizations could have also benefitted from information sharing under the Inform method of public participation. In such a scenario, the Department of Fisheries and Oceans could have engaged the non-Aboriginal fishing organizations in information sharing to allay fears associated with the requirements of the Sparrow decision. 
Réginald Comeau, a full-time employee of the Maritime Fishermen's Union in the Gulf Region prior to and during the Marshall crisis, states that after Sparrow, but before Marshall 1, First Nations were afforded "the right to fish lobster in the summer time for food and ceremonial purposes, [while] the Department of Fisheries and Oceans call[ed] the shots from Ottawa and they didn't involve the commercial fishermen in their decision, [and] by doing so, they indeed set the table for [the] dispute[s] that took place during Marshall $[I]$ decision" (Interview). He also says that First Nations were fishing out of season as a result of the Sparrow decision, and they would often sell lobster at lower prices than non-Aboriginal fishers from the roadside, which undercut alreadyestablished market prices designed to keep the commercial lobster fishery sustainable (Comeau Interview).

The lack of any formal or informal public participation with non-Aboriginal fishers by the Department of Fisheries and Oceans after the Sparrow decision demonstrates that the Department of Fisheries and Oceans perhaps did not perceive the need to address anyone else's concerns. This approach could be seen as shortsighted in terms of preventing the Marshall crisis, especially since the government could still regulate the fishery with First Nations through negotiations, and facilitate partnerships with non-Aboriginal fishers to manage the Maritime commercial lobster fishery over the long term, while respecting First Nations' treaty rights.

Overall, the Department of Fisheries and Oceans could have likely improved outcomes or reduced tensions, if it chose to engage with non-Aboriginal commercial lobster fishers. The Department could have held information sharing discussions, based 
on the Inform method of public participation, which could have clarified why the rules would be different for First Nations fishers versus non-Aboriginal fishers. This is an error that would later be repeated, at least during the initial few days after Marshall 1.

Overall, the Department of Fisheries and Oceans' approach to public participation with First Nations and non-Aboriginal fishers prior to the Marshall crisis, where actual engagement did occur, was lacking in opportunities to empower each of the groups that had an interest in the Maritime commercial lobster fishery, as per the lower level of public impact involved in the techniques and methods that were used. The lack of such empowering public participation methods, like Involve, could be seen as a contributing factor in the precipitation of the Marshall crisis, as groups felt their concerns were not being taken seriously. This ties back to several of the concerns written about by the citizen engagement scholars in Chapter 3, most importantly to Phillips and Orsini, who state that there need to be many ways in which to engage with the public, as the traditional means, such as leaving the policy making to political leaders, does not work anymore (Mapping the Links i).

The definite lack of public participation in a manner with higher public impact that included the ground level groups highlights some complacency on the Department of Fisheries and Ocean's part, especially as some have stated that the Department had no action plan to address Marshall (Coates ix). However, this issue occurred in the late 1990s, around the same time that the citizen engagement scholars were writing about the changing policy-making landscape and how the public became interested in having a greater impact on policy decisions, as government budgets and capacity were being 
significantly cut (Abele, Graham, et al., Talking with Canadians 5). The Department of Fisheries and Oceans' lack of public participation initiatives that would enable increased public impact by the First Nations and non-Aboriginal fishers may have been because the Department had not yet become versed in the new techniques and methods of public participation, such as citizen engagement.

Regardless of whether the perception that the Department of Fisheries and Oceans was complacent in implementing public participation techniques and methods was actually correct, a significant increase in the variety and use of techniques did occur throughout the Marshall crisis. However, as the next section will demonstrate, the methods of public participation did not change, which led to similar challenges as the pre-Marshall phase with regard to public frustration concerning the lack of engagement and the same methods that provided little public impact on policy making.

\subsection{Public Participation During the Marshall Crisis}

The events that occurred immediately after the Supreme Court of Canada rendered Marshall 1 , up to and past the Marshall 2 clarification required drastic action in terms of engaging quickly and meaningfully with all of the groups involved. One of the most notable reasons for the need to engage was that First Nations fishers, who held one interpretation of Marshall 1 . They perceived that their treaty rights allowed them the right to fish for lobster without any constraints, any time of the year (Coates 11). Additionally, non-Aboriginal fishers increasingly called on the Department of Fisheries and Oceans to regulate the Maritime commercial lobster fishery because they feared First Nations would deplete the stock and destroy everyone's livelihoods while the "federal 
government did nothing" (Coates xvii). While it was described in the Chapter 2 that the Department of Fisheries and Oceans did become active behind the scenes after the first couple of weeks following Marshall 1, the public perception, further exacerbated by the media, was that nothing was being done by the Department while First Nations fishers were fishing every day without the same constraints of everyone else.

As if debate arising from the many of interpretations of Marshall $I$ was not enough, tensions increased further through external factors, such as media influence over the public. Local newspapers and television often published and broadcasted stories that favoured non-Aboriginal perspectives and focused on the plight of non-Aboriginal commercial fishing interests. As an example, while news stories indicated a significant proportion of the Maritime commercial lobster fishery would go to First Nations fishers based on Marshall 1 and 2, the actual percentage of the First Nations' interests in the Maritime commercial lobster fishery only constituted one percent overall (Coates xii). Politicians, various fishing organizations, and the media all spoke for and against the different groups with a vested interest in the Maritime commercial lobster fishery. When progress was too slow, disputes, vandalism and violence ensued. When tensions became more pronounced through violent confrontations the Department of Fisheries and Oceans attempted to engage individuals using several public participation techniques to reduce tensions over the short term.

The Department of Fisheries and Oceans implemented public participation techniques throughout the Marshall crisis that could reasonably fall within the Inform 
and Consult ${ }^{20}$ methods of the public participation spectrum that were elaborated in Chapter 3. Instead of attempting to highlight every public participation technique that occurred, this thesis will instead focus on three of the most prominent and common techniques, including: community and group engagements; federal negotiations; and legislative and parliamentary hearings. These three techniques of public participation were chosen because they represent an important cross-section of what was implemented by the Department of Fisheries and Oceans, along with all of the positive and negative aspects of Inform and Consult that were highlighted in the interviews with primary and secondary sources.

\subsubsection{Community and Group Engagements}

As previously stated in Chapter 2, many questions remained to be answered after Marshall 1 was rendered due to the ambiguity surrounding what constituted a moderate livelihood (Jones Interview). The Supreme Court of Canada's vagueness in addressing some of the questions surrounding Marshall created a problem for some groups, such as non-Aboriginal communities who were adversely affected by the discussions: "We should have made it an issue involving all of the communities (First Nations and nonFirst Nations). Communities that were involved had nowhere to turn and were stuck in the middle [of the disputes and violence]" (Jones Interview). At this point, the nonAboriginal community-by-community engagements that occurred concerning the buyback of commercial fishing licences appeared to have been no more useful than the

\footnotetext{
${ }^{20}$ Note: The other methods of public participation are not identified in the rest of this chapter because Inform and Consult were the only methods identified in all of the research conducted for this thesis. The fact that no other methods were employed throughout the crisis will be elaborated throughout this chapter.
} 
techniques under the Consult method that were implemented prior to the crisis. This is because the Department of Fisheries and Oceans afforded no opportunity for communities that were affected by the Supreme Court decisions and the Marshall crisis to provide input into how the crisis, and more importantly the question of managing the fishery, should be resolved. Instead, the Department decided that a buyback of fishing licences, which was initially rejected by most First Nations, would be the quickest and simplest means to address the issue (Montminy Interview). However, a valid point in these communities' favour is the fact that their residents bore the brunt of the confrontations, regardless of whether they were fishers. The school was vandalized in Burnt Church and there were roadblocks that prevented community members from easily passing to and from their homes in First Nations and non-Aboriginal communities alike (Obomsawin). Another example of an affected community was Nacuac, New Brunswick: "Engaging the communities earlier would have been better. Not just engaging the non-Native commercial fishery industry. For example, Nacuac, which is located next to Burnt Church, was significantly affected by the crisis. We have families affected and people could have contributed to helping resolve it" (Jones Interview). While many in the community were not necessarily reliant on the lobster fishery for their livelihoods, they were at the centre of where First Nations and non-Aboriginal fishers faced off on land by virtue of their close proximity to Burnt Church.

The examples provided above help to explain why it is important to involve the broader citizenry in public participation initiatives, as the complexity of the issues, including the indirect effects on one group on the basis of an issue over another, can be 
quite significant. When entire communities, not just those that are directly involved in a public participation initiative, can come together and provide input that will have an impact on policy making, there is the possibility of receiving robust advice, where everyone can potentially own their issues: "better public policy requires better public participation processes. Involving stakeholders at the beginning of policy development helps to distribute and promote ownership and commitment. This is essential, considering resource constraints, fiscal pressures and the complexity of issues" (Sterne 2). Add short time frames in a crisis to the list above and there are many reasons why one should engage with more than just the few groups to increase the impact of the techniques and methods being used. The issues become too complex, too timely and simply cannot be addressed with a heavy-handed consultative approach that already has a pre-conceived response developed. If individuals and communities are not permitted an opportunity to provide input from the beginning, they often have little faith in the decisions that are made by politicians and other governance structures in society (Abele, Graham, et al., Talking with Canadians 7).

Another issue with public participation that was not addressed in the Department of Fisheries and Oceans's community-by-community negotiations was whether those with an interest had enough of an understanding of the issues involved. A case in point from James Jones, which was provided in Chapter 2, will be recounted here for ease of reference: "On October 2-3, 1999, approximately 10-12 people from Burnt Church and 30-40 from Bay St. Anne were arrested for a variety of mischief charges," such as cutting traps (Interview). 450 commercial fishers were present at a public meeting and were very 
angry about what had occurred (Jones Interview). Jones spoke to the group of angry fishers and the lack of knowledge about Marshall I very quickly became apparent: "About an hour into the meeting, there was lots of shouting. One guy gets up and asks "Why did you do this?"' (Jones Interview). Jones told the individual that it was because of a Supreme Court of Canada decision and the fisher asked, "what's this Supreme Court you're talking about?" (Interview). Jones then stopped everyone and proceeded to provide as brief an explanation as possible on how the governance structure of the Government of Canada worked, including the specific role of the Supreme Court of Canada in making decisions (Interview). At that point, "all communiqués had mention of the Supreme Court of Canada decision on Marshall [Marshall 1], but needed to explain in some manner what the Supreme Court was and where it sat in the Canadian governance structure. We were 'over the heads of some of our audience"' (Jones Interview). Jones' anecdote highlights an issue that can be managed by implementing two methods of public participation at one time. While one method is being implemented (Consult), sometimes it also helps to implement another method (Inform) to help ensure the target audience understands the issues prior to being engaged. Of course, this is also seen as being a part of educating participants prior to engaging with them, so they can provide the most informed opinions possible (Graham and Phillips, Citizen Engagement 2). Public participation techniques under the Inform method tend to complement others in terms of enabling the facilitating body (e.g. the Department of Fisheries and Oceans) to share information with target audiences to prepare them to provide the best input possible and to alleviate any concerns about the issues on which they are being engaged. For 
example, had the Department of Fisheries and Oceans understood that there was poor general knowledge concerning the Supreme Court of Canada's role as an institution among non-Aboriginal commercial lobster fishers, pamphlets, an information website and/or other means of sharing general information could have been developed to impart a basic working knowledge of the federal governance structure in preparation for everyone who was interested in providing input to federal representatives. This would have enabled non-Aboriginal fishers participating in an engagement initiative to make informed decisions concerning how to manage the Maritime commercial lobster fishery while respecting First Nations' treaty rights.

\subsubsection{Federal Negotiations}

Two types of federal negotiations were underway during the Marshall crisis. The first type involved treaty negotiation tables with First Nations in the Maritimes and Quebec, which were headed by Indian and Northern Affairs Canada. ${ }^{21}$ These negotiation tables were a long-term endeavour to negotiate treaty rights and land claims, which are outside of the parameters of this thesis. In addition, short-term negotiations were mostly handled by the Department of Fisheries and Oceans, which was the federal department responsible for enforcement relating to the commercial lobster fishery, and as a result, had to directly manage the immediate aftermath of the Marshall decisions.

One of the key negotiators for the Department of Fisheries and Oceans was James MacKenzie, who was appointed by then Minister Herb Dhaliwal prior to Marshall 2

\footnotetext{
${ }^{21}$ While long-term negotiations are important to the recognition of Aboriginal treaty rights and can potentially carry many economic benefits, they will not be highlighted in this thesis, as the focus is more specifically on public participation techniques and methods that are implemented during a crisis.
} 
(Montminy Interview). In addition, Robert Nault, Minister of Indian Affairs and Northern Development at the time, appointed a Chief Negotiator to highlight the twopronged approach of the federal government, entitled the Marshall Response Initiative. As part of this approach, Indian and Northern Affairs Canada would negotiate long-term treaty rights, while the Department of Fisheries and Oceans would negotiate the buyback of commercial fishing licences. The Department of Fisheries and Oceans would then offer to bring First Nations under the same fishery management regime as a short-term measure to address Marshall 1 as part of fishing licence negotiations (Montminy Interview). According to Montminy, this approach did create some confusion as to which federal department was responsible for negotiating with the different groups involved, including First Nations and non-Aboriginal commercial fishers (Interview). However, the initial negotiations left non-Aboriginal fishers out of the loop, as it was once again seen as a First Nations treaty rights issue that had nothing to do with nonAboriginal interests.

Information sharing with non-Aboriginal fishers was later remedied with the appointment of Gilles Thériault as an Associate Chief Federal Negotiator to work with the commercial fishing groups. As previously stated in Chapter 2, Thériault's appointment was largely seen as a very successful approach to informing non-Aboriginal commercial fishers on progress with negotiations to sign agreements for the buyback program (Comeau Interview). Thériault was also very attentive to non-Aboriginal commercial fishers' concerns and often relayed them to MacKenzie and other officials in the federal government, who were involved in negotiations with the Mi'kmaq 
(MacKenzie Interview). This was especially important for the non-Aboriginal commercial fishers, who felt at this point that they had a forum through which to voice their concerns. Once again, the use of more than one Chief Federal Negotiator to listen and relay all of the particular groups' concerns was well received by all who were interviewed for this thesis. The desires of non-Aboriginal fishers did not appear to surpass the Consult method of public participation, even though the use of separate Chief Negotiators was a good idea to reduce tensions throughout the short-term public participation process. The Department of Fisheries and Oceans did eventually seek the opinions of non-Aboriginal commercial fishers through Gilles Thériault, but the Department was not the most sincere in its approach, as it already had a plan in place to negotiate the buyback of commercial lobster fishing licences and ask First Nations to adopt them as communal licences as an immediate measure to ensure their treaty rights were addressed over the short term. Department of Fisheries and Oceans officials could have announced that they were planning to engage with First Nations, non-Aboriginal fishers and others to help reduce immediate tensions and resolve the question of how to integrate First Nations interests on the basis of their treaty rights into the Maritime commercial lobster fishery. This may not have worked, but it was nonetheless an option that could have been implemented.

On the other hand, Thériault's appointment was especially important for maintaining an Inform method of public participation, as one of the key issues with the non-Aboriginal groups is that there were many news stories in the media skewed toward the non-Aboriginal interpretation of the decision (Coates xii). The media was especially 
negative toward First Nations fishers, who were often ignored in favour of nonAboriginal perspectives in the papers and on radio stations in New Brunswick owned by the J.D. Irving family (Coates xi).

At the time of the Marshall crisis, most, if not all of New Brunswick's regional newspapers and radio stations were owned by the Irving family, who also own the J.D. Irving Oil company (Coates xi). In the prelude to Marshall, Thomas Peter Paul, a Mi'kmaw logger, was embroiled in a commercial logging dispute that involved J.D. Irving Corporation, in which the New Brunswick court of appeal ruled on a third appeal that the Mi'kmaq had no right to go logging for commercial purposes (Coates 98-99). This is important because the Irving family's business likely suffered initially because the Mi'kmaq were initially allowed to harvest timber commercially in this case. The Irvings were likely concerned that a victory with Marshall could become a catalyst to open up other natural resource areas, such as logging, to the Mi'kmaq based on their newly found treaty rights:

Although scholars in general have been uneasy about the relationship between news reporting and corporate ownership, the issue is particularly strong in this part of Canada [the Maritimes]. The Irving group of companies, in addition to formidable holdings in logging, pulp and paper, transportation and other industries, publishes all the major newspapers in New Brunswick, control many radio stations, and exerts tremendous power throughout the Maritimes. Observers are sceptical about the independence of Irving newspapers and about the media generally (Coates 
xi-xii).

The Irving family's possession of most media in New Brunswick at the time would have afforded them a very strong position to draw public attention against the Marshall decisions. As further analysis will demonstrate in Chapter 4, it is highly likely that they used that influence to have the media producing more stories in favour of the nonAboriginal fishers, while obscuring the position of the Mi'kmaq people.

In addition to focusing on non-Aboriginal fishers' perspectives in the majority of news stories featured throughout the Marshall crisis, there was also a significant focus on Aboriginal stereotypes, especially when it came to the centre of violence, Burnt Church. In his article entitled "Fishing for Stories at Burnt Church: The Media, The Marshall Decision and Aboriginal Representation," Paul Fitzgerald states:

Burnt Church became the site of a vast fishing expedition, an expedition for quick and easily digested stories. The stories were familiar ones: Eurocentric or ethnocentric stories told by governmental actors, which were eagerly learned and repeated by reporters who seemed to lack even a rudimentary understanding of the core issues and precepts governing legal decisions they had been dispatched to cover (29).

In addition to the lacklustre reporting that is commented on above, Fitzgerald further argues that the federal government was able to use the media "as a conduit to inflame public opinion - directly associating the acts of First Nations people at Burnt Church with criminality. For the most part, the media accepted such characterizations without qualification" (Fitzgerald 30). In addition, Fitzgerald asserts that news stories routinely 
omitted First Nations' perspectives, and in one case, it was omitted that Burnt Church, "have themselves established a limit of four traps per person," which only represented " 0.5 percent of the total 950,000 traps in the Gulf Region" (32). Obviously, not all news omissions can be directly attributed to a political economy analysis of the media. Yes, J.D. Irving did own the media in New Brunswick, which mostly took an unfavourable view of the First Nations' positions, when it took one at all. However, there were enough news stories that omitted First Nations opinions and facts, which, when coupled with non-Aboriginal fishers' serious concerns about the future of their livelihoods, could produce serious damage and potentially derail engagements/negotiations.

John Paul, Executive Director of the Atlantic Policy Congress of First Nations Chiefs states, "everyone was under significant scrutiny in the media and in communities [First Nations and non-Aboriginal]. Whatever anyone said or did created a reaction from another group involved. There was a void of uncertainty...everyone tried to fill it" (Interview). Paul's take on the situation demonstrates the immense pressure that the media was placing on the different groups that were trying to negotiate with the Department of Fisheries and Oceans precisely because they were meeting behind closed doors. In addition, non-Aboriginal commercial fishers were not involved in the negotiations, which likely increased their anxiety even further when media reports were published.

Considering the impact that the media likely had on increasing tensions during the federal negotiation process, it may have been more beneficial to bring non-Aboriginal commercial fishers to the table and provide them with an opportunity to provide input 
that would be taken into consideration in developing a response to resolve the impasse concerning the Marshall decisions. In this respect, while the Inform and Consult approaches taken by the Department of Fisheries and Oceans helped to address the nonAboriginal fishers' request to be informed on negotiations and to provide input through the Associate Chief Negotiator, the Department of Fisheries and Oceans also appeared to be undertaking fake participation.

Fake participation is a subset of fake democracy, which has arisen out of the need for autocratic rulers [or leaders] to seek legitimacy in the present, where democracy is acceptable as the only true form of legitimate governance. According to the scholar J. H. Snider:

Fake participation is an element of the much larger and more troublesome phenomenon of fake democracy. The basic logic behind fake democracy is quite simple. In the contemporary world, democratic rule has more public legitimacy than authoritarian rule, so it is generally in the interest of rulers to present themselves as democrats rather than autocrats (91).

As an element of fake democracy, fake participation occurs even in liberal democracies as a form of legitimation exercise to enable governments to state that the public supports unpopular ideas through some sort of participatory process where their input was sought (Snider 91). How many times has a Minister or other public official indicated in the media that a seemingly unpopular policy or initiative was "consulted on" and "accepted" by the "stakeholder groups" involved? Who are the groups that accepted the public figure's policy? Why are they not in the public eye to show their support? Were these 
groups provided with an opportunity to provide real input, or were they simply asked to place a "rubber stamp" on an existing idea? Snider also indicates that the higher the stakes become concerning a particular issue, the greater the pressure increases to engage in fake participation (92). As the next example will demonstrate, the Marshall crisis presented significant pressure for politicians and negotiators to engage in fake participation, which is problematic because the opportunity for groups to affect change becomes subdued in this type of context.

The way the Department of Fisheries and Oceans managed its relationship with non-Aboriginal commercial fishers presents an example of what could be seen as a high stakes issue, namely how to allocate, regulate and manage Maritime commercial lobster quotas. These quotas represented the primary income and economic livelihood of many people in the coastal regions of the Maritimes, when the Supreme Court of Canada issued a vague court decision stating that First Nations have a legal right to part of that fishery. Non-Aboriginal commercial fishers were very concerned that their livelihoods could literally be handed over to First Nations, or that the entrance of First Nations into the commercial fishery could compromise lobster stocks in the Maritimes.

The assignment of an Associate Federal Negotiator may have helped to calm tensions among the First Nations and non-Aboriginal fishers, but it also helped to obscure the fact that what was happening was a very unpopular legislative initiative among the majority of the population, which was consistently highlighted in the media. The one difference in this instance is that it was the Supreme Court of Canada, which made the decision that First Nations had a treaty right to fish for a moderate livelihood, as was 
stated in the original treaties (Wicken 232-233). As such, fake public participation that occurred among the negotiations with non-Aboriginal fishers may not be so much construed as a means to a political end, as the decision was already made for the government by virtue of the Supreme Court of Canada rendering Marshall $l$ and its clarification in Marshall 2. Yet, while it may be true that the decision had already been made by the Supreme Court of Canada concerning First Nations rights to fish when it came to how to proceed with the licence buyback, there could have been broader attempts at engaging First Nations and non-Aboriginal fishers, who it appeared would now both become dependent on the Maritime commercial lobster fishery for their livelihoods. Potential broader attempts at public participation will be elaborated further in Chapter 5 .

\subsubsection{Legislative and Parliamentary Hearings}

Legislative and Parliamentary hearings are one traditional method that the federal government has used in the past to engage with a variety of citizens and experts on key issues facing the Canadian populace: "Legislative or Parliamentary hearings, generally conducted by special or standing committees composed of members of a legislative assembly, are a long standing feature of the Canadian political landscape" (Abele, Graham, et al., Talking with Canadians 14). Parliamentary hearings are positive in many respects, but have their drawbacks:

In terms of allowing a focus on a particular issue or set of issues (generally reflected in draft legislation); providing a forum for the airing of informed opinion (although this is generally by experts and those most affected); and potentially having an impact on outcomes. Legislative hearings are weaker in terms of 
ensuring broad representation and allowing for the introduction of new options. Because they are Ottawa-based, they are seen by many as inaccessible, formalized and, in some instances, intimidating. They permit dialogue, reflection and the modification of views, but often this remains exclusively the purview of members of the legislative committee conducting the hearings (Abele, Graham, et al., Talking with Canadians 14-15).

The inaccessibility of this type of forum to the general public, especially those residing outside of Ottawa, is a cause for concern, especially in terms of identifying how to address an impending crisis. There is also the intimidation factor, which can be significant if one has ever seen how Members of Parliament and Senators can crossexamine a participant at one of these meetings. These constraints make it incredibly difficult for standing committees to select someone average, who would be willing to speak on behalf of their communities or organizations. For example, would a political representative from a reserve such as a Chief, a political representative from a broader umbrella Aboriginal representative organization, a fishing scientist, or a fisher from a Mi'kmaq community be best suited to represent the First Nations communities involved in the Maritime commercial lobster fishery? This is a very difficult question to answer and as will be further elaborated, there are few individuals who are not from a political or technical background that are called to appear in front of standing committees, which likely reduce a significant number of perspectives that could provide additional insights. This also relates to what happened during the Marshall crisis, where every day fishers were not initially asked for their opinions on how to successfully integrate First Nations 
into the Maritime commercial lobster fishery on the basis of their affirmed treaty rights.

Time constraints play into the usefulness of this public participation technique because during a crisis, events will not await a Parliamentary hearing and deliberations in the form of a report with recommendations. However, despite these many negatives, there may be some benefit to Parliamentary hearings, as they are focused and provide an opportunity after the fact to summarize the overall time line of events as a means of lessons learned for the future.

The Standing Committee on Fisheries and Oceans issued a report in December 1999 entitled "The Marshall Decision and Beyond: Implications for Management of the Atlantic Fisheries," which fell within the crisis period, being a month after the Supreme Court of Canada released the clarification of its initial decision (Marshall l), known as Marshall 2. In its report, the Standing Committee provided an introduction, which laid out a statement of facts that summarized the outcomes of Marshall 1 , including that the Supreme Court of Canada "affirmed that the 1760 Treaty provided Mi'kmaq people a right to provide for their own sustenance..." and that "catch limits that could reasonably be expected to produce a moderate livelihood for individual Mi'kmaq families at present day standards can be established by regulation..." (The Marshall Decision and Beyond). The report also indicated that the Department of Fisheries and Oceans did not issue orders and that it was caught off guard by the decision. Other statements of facts followed, including that non-Aboriginal fishers were angry, violence occurred, the Supreme Court of Canada issued its clarification (Marshall 2), and while First Nations fishers had the right to fish for a moderate livelihood, their rights could be regulated 
under certain circumstances, such as conservation (The Marshall Decision and Beyond). The introductory statement of facts helped to set the stage for statements that would follow from individuals who were invited to speak in front of the Standing Committee. Yet they provide little merit for addressing the present crisis because they are simply a statement of what occurred, as opposed to what should occur, or what individuals think could help improve the situation in a pragmatic way.

After the introduction, several individuals were called forward to speak to the issues of Accommodation of Treaty Rights; Conservation; Fisheries Management; Food Fishery; Localized Fishing Pressure; First Nations; Process; and Remaining Issues. Of those who were invited to speak, one person was a non-Aboriginal fisher, while the remaining 15 were provincial Ministers, First Nations Chiefs, representatives of First Nations, Wildlife or Fisheries advocacy organizations, or lawyers. As can be seen by the roster of individuals called forward, unless you were a politician, non-governmental organization representative or some other form of technical expert, generally speaking, you were not permitted to provide recommendations to the Standing Committee on how to resolve the Marshall crisis or manage the Maritime commercial lobster fishery.

Standing committee hearings and reports would likely be included under the Consult method (or traditional public consultation), as the report did seek the opinions of individuals speaking before the Standing Committee on Fisheries and Oceans. However, this method would likely be worse than the informal relations that characterized the preMarshall crisis period, as the individuals called to appear before the Standing Committee and make recommendations were mostly political or technical experts, not the individuals 
who have the greatest interest in these processes, namely the Maritime First Nations and non-Aboriginal fishers and the communities in which they live.

While some could argue that their Chiefs and advocacy organizations would represent First Nations communities, there could be some disagreement among those within the affected reserve communities on the basis of the front line experience that some community members have and the opinions that follow such experiences. This ties back to the work of Laforest and Phillips on representative versus deliberative citizen involvement.

The way that the Standing Committee heard from political and technical representatives is characteristic of representative democratic process, which is not enough anymore: "The model of deliberative democracy that emerged in the 1990s starts from the premise that political representation is not enough: active participation by citizens is as important as having their interests represented by third parties" (Laforest and Phillips, Critical Policy Studies 71). One of the main pieces of information that is often lost in standing committee appearances with few individuals is the experiential knowledge that someone like a First Nations fisher could provide in addition to the technical and political aspects of an issue: "The trend of the 1990s toward a preference for the involvement of individuals signaled a shift in the purpose of public input: to add experiential knowledge, often through the sharing of personal stories, rather than to provide technical expertise" (Laforest and Phillips, Critical Policy Studies 75).

The same issues with standing committee rosters could be applied to Maritime non-Aboriginal commercial fishers. In late 1999, the Maritime Fishermen's Union had to 
often intervene with its members to plead for calm during the tense negotiations that occurred among representatives of each group (Comeau Interview). It is this difference of opinions among those on the ground and those who represent them politically, or on an advocacy basis, which makes legislative and Parliamentary committee hearings one of the less desirable techniques of public participation through which to seek public input during a crisis. It is also through strong citizen engagement that citizens can bring their experiential and technical expertise to the table that can really help governments can solve complex issues.

As Abele, Graham, et al. have noted in Talking with Canadians, there are several reasons that citizen engagement is more important now than traditional public consultation, such as the rise of "citizen intervention in politics," the difficulties institutions face in resolving complex issues, and how political support for intermediary institutions has waned overall in recent years, while there has been an increase in the formation of citizen groups (Talking with Canadians 5). Additionally, individual citizens have become angry with decisions that governments make after having consulted with them: "At a deeper level, the disrepute of consultation arises from a sense that governments have not taken it seriously" (Abele, Graham, et al., Talking with Canadians 7). The narrow focus of Parliamentary Committees in a public consultation process generally serves to further alienate a public that was enraged by the uncertainty of events following Marshall 1.

\subsection{Conclusion}

There are several conclusions to be drawn from analyses of the public 
participation techniques and methods that were applied prior to and during the Marshall crisis. The first is that the Department of Fisheries and Oceans implemented more public participation techniques throughout the crisis with greater intensity than prior, but they all tended to fall under the Inform and Consult methods. The fact that the methods implemented were the same before and during the crisis likely meant that the new public participation techniques that were implemented were no more useful than they were before. This is because the level of involvement afforded to each group through the various techniques did not really change, despite the extra investment of time and financial/human resources, because the response to the crisis was already pre-determined through the buyback program. However, there were some improvements in the overall public participation throughout the crisis period. This was especially true in terms of Associate Chief Federal Negotiator Gilles Thériault, who was appointed by the Department of Fisheries and Oceans, who acted as a point of contact for non-Aboriginal fishers to receive information on negotiations and provide their own perspectives for the first time since the Sparrow decision. Unfortunately; the degree of public impact with this technique, encompassed within the Inform method, was very low.

Time and financial/human resource constraints created barriers to those who wanted to know what was happening with negotiations. For example, most primary interviewees indicated that there were not enough human resources committed to each Chief Federal Negotiator to meet the needs of the people. In addition, time constraints, while reducing the opportunities for broader engagement during the crisis, did not prevent the additional techniques and intensities of engagement from occurring. 
Media influence contributed in a significant manner to the tensions that occurred among the different groups with an interest in the Maritime commercial lobster fishery. In addition, while media influence was significantly skewed away from Aboriginal interests in the crisis, it did provide a certain counter-balance for the non-Aboriginal commercial fishers, who up to a certain point had been entirely excluded from being engaged during the negotiation period.

Overall, the public participation techniques of information sharing, community and group engagements, federal negotiations and Parliamentary and legislative hearings all tended to keep those with the most to gain or lose, First Nations and non-Aboriginal fishers, out of the policy making process. This is unfortunate, because including them would have likely reduced tensions and allowed for better public policy to resolve the issue over the long term, as their contributions of experiential knowledge and taking ownership of the issues could have contributed to the establishment of partnerships to manage the Maritime commercial lobster fishery over the long term, while taking First Nations treaty rights into account. This could likely occur through techniques under the Involve method, as the groups could be educated on the issues, made to face the realities and then be asked to contribute informed opinions.

Having conducted an analysis of the techniques and methods of public participation that were implemented prior to and during the Marshall crisis, Chapter 5 will draw from the conceptual outline of the public participation spectrum and analyze what opportunities other techniques under new methods of public participation could have presented to achieve reduced tensions and to help establish future relationships. The 
second part of Chapter 5 will review these new techniques and methods according to similar common problems that arise during crises, which could render many public participation approaches unfeasible to implement, or stem any positive outcomes (e.g. time constraints, financial/human resource constraints). 


\section{Chapter - New Possibilities for Crisis Management Through Public Participation}

\subsection{Introduction}

This chapter builds on the developments in Chapters 2, 3 and 4, and considers new possibilities for public participation in crises, based on the modified public participation spectrum. With new perspectives on forms of public participation brought in to construct a modified narrative of the Marshall crisis (Chapter 2), and the development of the modified public participation spectrum (Chapter 3), in Chapter 4 we were able to look at the few instances prior to and during the Marshall crisis where a limited form of public participation was attempted by the Department of Fisheries and Oceans. The analysis in Chapter 4 set the stage for this chapter, which will draw from the modified public participation spectrum and propose new possibilities for public participation that will enable an increase in public participation and public impact in the policy-making process. Such an approach may provide new possibilities for reducing tensions in the short term and help to establish partnerships among the groups involved to manage natural resources while respecting treaty rights over the long term.

It will be argued in this chapter that Involve (aligned with citizen engagement) is likely the most feasible method to implement during a crisis that would allow for greater public impact in the policy-making process. This is because the Collaborate and Empower public participation methods and their related techniques would likely require significant time and financial/human resources to implement.

Prior to discussing techniques that could be implemented under the Involve 
method, the exclusion of Collaborate and Empower methods on the basis of time and financial/human resource constraints merits further elaboration.

Collaborate and Empower encompass techniques such as consensus building, citizen juries and delegated decisions. While both methods are very useful in many circumstances, attempting to implement their associated techniques, such as consensus building, could pose a significant drain on time and financial/human resources, as negotiations that require consensus building can often hinge on one or two points of discussion that cannot seem to be rectified, thus leading to a stalemate in trying to achieve consensus. During the Marshall crisis, the fact that the different groups involved had engaged in violent confrontations at various points would lead one to consider that perhaps consensus would be out of reach in the short term.

Another technique under Empower would be to establish a board for delegated decisions, which would see representatives from the groups involved in a natural resource issue coming together and to decisions on behalf of the government, concerning the management of a natural resource. This would be another difficult technique to implement without significant time and financial/human resources invested at the beginning. Individuals need to be nominated, budgets established, meetings held and schedules coordinated. These challenges are further compounded by the special circumstance of a crisis, where those chosen to work on the board would likely be the leaders of the same groups that have engaged in violent confrontations in a crisis. It would obviously make sense then that most of the individuals would not want to be in the same room, let alone making decisions together in the short term. As a result of the brief 
explanations provided above, Collaborate and Empower methods and their associated techniques will not be discussed in this chapter, but will be elaborated in Chapter 6 as a possibility for future research to build on the long-term objective of establishing partnerships by determining how co-management structures and institutions could be achieved to manage the Maritime commercial lobster fishery over the long term.

Involve presents the only public participation method remaining to possibly meet both the short- and long-term objectives identified in this thesis without presenting significant time and financial/human resource challenges. The Involve method will enable a rapid response to a crisis, while ensuring the general public can provide input and reasonably expect to have an impact on important policy decisions in a government response.

The second section of this chapter will draw on primary source interviews featured in Chapter 2 to determine what they felt might have been done differently to improve public participation during the Marshall crisis. The third section will elaborate the techniques to be used as part of the summit. The final section of this chapter will use perspectives from the interviews to argue that Involve/citizen engagement/deliberative democracy techniques, if arranged efficiently in a summit format, could hypothetically hold the greatest potential to include everyone affected by the Marshall crisis in such a summit without incurring significant time or financial/human resource increases. In addition, it will be argued that the techniques would help deliver the key changes that the officials who were interviewed would have made, while affording greater public impact on the policy-making process. Involve presents deliberative polling and workshops as 
two of its primary techniques. These two techniques, along with others emphasized by Abele, Graham, and other scholars of citizen engagement will be developed as components of a crisis summit, which would include a cross section of citizens and groups affected by the Marshall crisis as participants. The summit will then be examined according to its component parts to determine how Involve techniques may have contributed to greater public impacts on the policy-making process to address the shortand long-term objectives of reducing tensions and establishing partnerships.

\subsection{New Possibilities: Primary Source Interviews}

Individuals interviewed for this thesis expressed three important changes they would have considered making during the Marshall crisis that fall within the Involve method. Some of those individuals who were interviewed would have engaged with a broader cross-section of those affected by the crisis from the beginning; some recommended having community types of meetings to repair relationships between the First Nations and non-Aboriginal communities and have outside intermediaries present; and some would have sought a more systemic, proactive approach to engaging with communities, rather than the one-by-one approach that occurred with the licence buyout program. The following three sub-sections of this chapter outline what was stated during interviews concerning these three recommendations. The third section of this chapter will relate what was stated to a summit using the Involve techniques highlighted.

\subsubsection{Broader Engagement from the Beginning}

Some of the individuals interviewed for this thesis indicated that the Department of Fisheries and Oceans may have fared better in managing the crisis had its 
representatives held public participation with a broader cross-section of individuals from the beginning of the crisis. James Jones said that the Marshall crisis was "treated initially as an issue between two parties (Department of Fisheries and Oceans, and First Nations)" (Interview). However, he felt that the Department "should have made it an issue involving all of the communities (First Nations and non-First Nations)" (Jones Interview). He later stated, "engaging with communities earlier would have been better. Not just engaging with the non-native commercial fishery industry" (Jones Interview). Jones then provided the example of Nacuac, a non-Aboriginal community located next to Burnt Church, which was affected by the crisis and its people could have helped contribute to a resolution (Jones Interview). Jones' statements indicate that had more individuals been involved from the beginning, they could have contributed their concerns and solutions to resolving the crisis.

Réginald Comeau provided another argument for engaging with a broader crosssection of the public from the beginning of the Marshall crisis: "[The Department of Fisheries and Oceans] would have avoided problems with Natives if you [non-Aboriginal fishers] were included in the beginning of negotiations. Lack of keeping in the loop led to panic. People need to be engaged" (Interview). He then described the frustration of non-Aboriginal fishers initially with the Department of Fisheries and Oceans: "When you have to put [a] foot in the door to have a meeting, you know something is wrong. DFO [Department of Fisheries and Oceans] had no problem with having [the] fishery out of season in Ottawa" (Comeau Interview). Comeau's argument appears to support that of Jones, but adds that an additional benefit would have been reduced tensions if broader 
engagement had occurred with non-Aboriginal fishers supported by his organization.

\subsubsection{Community Meetings}

James Jones was the only person interviewed who could recall that community meetings were held in an attempt to rebuild the relationships between First Nations and non-Aboriginal peoples after the crisis unfolded. He describes that for a couple of years after the Marshall crisis, there was still some unrest in the Miramichi Bay area, which included Burnt Church and Nacuac. This unrest in the news was making it exceedingly difficult to promote the Miramichi area as a good place to invest (Jones Interview). As a result, the Miramichi Bay Panel was established and the members of the Panel "were asked to examine some of the ways to rebuild the social fabric among the communities" (Jones Interview). The Panel's report included a community conference that was held: The community conference looked at community relationships with community leaders such as those of Nacuac and Burnt Church were there. [The conference] looked at how to rebuild community relations and recognize that in a crisis, there are a whole bunch of other community interactions that get affected. Department of Fisheries and Oceans could solve the fisheries issue, but others remained. Rebuilding those relationships was just as important (Jones Interview).

Had the community meeting occurred at the beginning of the crisis with a broader cross section of the population affected by the Marshall decisions, there may have been a greater opportunity to reduce tensions over the short term by informing everyone of the issues and attempting to ensure relationships would remain strong among First Nations 
and non-Aboriginal communities. As Jones rightly points out in this case, the community meeting was held to rebuild relationships. However, if such a meeting was held at the beginning of the Marshall crisis, and techniques under the Involve method were included in the meeting, it might have afforded an opportunity to reduce tensions, as individual perspectives would be sought on how to resolve the impasse. If successful in reducing tensions, such a meeting might also help maintain existing relationships among the First Nations and non-Aboriginal communities, thus contributing to the long-term objective of establishing partnerships to manage the Maritime commercial lobster fishery.

\subsubsection{Systemic Public Participation}

Some of those interviewed for this thesis felt that a significant opportunity was squandered through the Department of Fisheries and Oceans' community-by-community approach to the fishing licence buyback as an interim measure, while others felt is was entirely justified as a means of crisis management. In terms of those who saw an opportunity squandered, John Paul stated: "There was no systemic method to engage with groups, not proactive, and [the process] was dictated. As many people were involved as there were interpretations of the case [Marshall 1]" (Interview). He felt that such an approach to negotiating the buyback of fisheries licences and signing First Nations communities onto them as an interim measure missed a real opportunity for meeting a long-term positive outcome:

The federal government had a substantial opportunity to play out First Nations' inclusion in the fishery. An incremental approach (i.e. buyouts) led to a failure to bring communities together [in a more holistic manner]. 
Instead, every community wanted to make a deal once the first one was struck. Viger was the first community to sign a fisheries agreement. Today, they are trying to sort out what the long-term involvement of First Nations will be in the Atlantic fishery... How do you develop the fishery as an inter-community enterprise instead of a one-by-one approach? First Nations would have had more benefits that way (Paul Interview).

Paul's quotes above demonstrate a frustration with the lack of integration of First Nations in the Maritime commercial lobster fishery as a result of the way that the Department of Fisheries and Oceans engaged on a community-by-community basis with First Nations and non-Aboriginal fishers to issue buyback licences as an interim measure. One consequence of this approach is that First Nations are still somewhat separated from the rest of the commercial fishery insofar through the separate approaches that are taken today. Such an approach to the negotiation of licence buybacks has had unintended consequences as well, according to Réginald Comeau. Comeau felt that while the licence buyback program was a good idea, the consequence is that First Nations do not appear to be any better off economically today than they were prior to the Marshall crisis and that many have leased their commercial licences back to non-Aboriginal commercial fishers (Interview). Additionally, he stated that the "vast majority of commercial fishers are not fishing anymore" (Comeau Interview).

James MacKenzie had yet a different perspective on the engagement process for the buyback program. MacKenzie felt the interim approach worked because he had signing authority on the spot to purchase the licences from non-Aboriginal fishers and 
then sign agreements with the First Nations communities (Interview). He also felt that this interim measure did what it was intended to do, to bring "peace and order to the East Coast," because " 30 of 34 agreements [were signed] and nobody died" (MacKenzie Interview). While MacKenzie felt the process worked for what was intended, he also indicated that they had barriers. One such barrier was "marrying the new system with the old. Fishers had to renew their [commercial] licences annually, they were not a right and were issued to individuals. Aboriginal [commercial] licences were community-based in perpetuity and were a right" (MacKenzie Interview). While it would appear that all can agree that there were consequences to the community-by-community approach taken to the buyback of commercial fishing licences and the signing of agreements with First Nations, MacKenzie's quotes appear to demonstrate more than others that there was a real concern that someone could be killed during the violent confrontations, which he felt justified the approach taken to resolve the crisis.

Joëlle Montminy felt that the interim negotiations on a community-by-community basis helped, especially since Indian and Northern Affairs Canada was negotiating the long-term treaty rights with First Nations on a separate track (Interview). She felt that the engagement done on the ground started a more standardized process for negotiating longterm treaty rights through aggregated negotiation tables. According to Montminy, "there was too much at stake to rush into an agreement on long-term treaty rights. Department of Fisheries and Oceans tables were different because less was at stake. Indian and Northern Affairs Canada tables were slower" (Interview).

The negotiation of treaty rights may have been a little too hasty when the 
Marshall crisis began, and community-by-community engagements to buy back commercial fishing licences and assign them to First Nations communities may have been good to meet the short-term objective of reducing tensions, but terrible for meeting long-term objective of establishing partnerships. However, techniques under the Involve method may still present the best potential approach to public participation that can address potentially lost opportunities and the other recommended changes highlighted in this section. The third section will include analysis of the Involve method, citizen engagement and deliberative democracy concepts to analyze how a crisis summit may prove useful to balance the short- and long-term objectives identified. It will then include description of a crisis summit, as if it occurred during the onset of the Marshall crisis, to demonstrate how the response might have been different.

\subsection{Involve, Citizen Engagement and Deliberative Democracy Techniques}

The implementation of Inform and Consult methods, as outlined in Chapter 4, was constraining at the beginning for the groups involved. Mi'kmaq fishers, non-Aboriginal commercial fishers and the communities that were directly or inadvertently affected by the increasing tensions that followed, frequently complained that they had no means of expressing their concerns or providing input throughout the public participation process with the Department of Fisheries and Oceans.

Involve techniques can be more costly in time and financial/human resources than traditional public consultation (i.e. Involve more so than Inform or Consult). They can pay significant dividends in terms of maintaining good existing relationships to help reduce tensions through open communication, determining strong policy solutions for the 
issues that caused the crisis, which will present the likeliest possibility, hypothetically speaking, to meet the short- and long-term objectives identified.

As described in Chapter 3, Renee A. Irwin and John Stansbury cite several shortterm benefits that the implementation of citizen participation might provide:

With citizen participation, formulated policies might be more realistically grounded in citizen preferences, the public might become more sympathetic evaluators of the tough decisions that government administrators have to make, and the improved support from the public might create a less divisive, combative populace to govern and regulate (2).

Based on the reasoning presented above, the Department of Fisheries and Oceans' implementation of an interim traditional public consultation technique under Consult the licence buyback program - could be seen as flawed over the short term, as it may have contributed to increasing tensions between First Nations and non-Aboriginal commercial fishers as the crisis was developing. Frustrated groups of non-Aboriginal fishers who feared for their livelihoods, and Mi'kmaq fishers, who felt they had a right to fish for lobster commercially, eventually raised their concerns in public (through the media) and then confronted each other because it appeared no one in the Department of Fisheries and Oceans would listen to them (Coates 9).

Another unforeseen weakness in the Department of Fisheries and Oceans' public participation process for non-Aboriginal fishers was the lack of education prior to a public consultation. In the case of some angry non-Aboriginal fishers who were present 
on October 3, 1999 when several men were arrested for mischief and other charges, they did not know what the Supreme Court of Canada was, nor why the Department of Fisheries and Oceans had to implement its decision (Jones Interview).

Educating groups on complex policy issues can be a positive by-product of a public participation process. Education can help reduce tensions by dispelling misguided anger among the groups involved, despite it being a very informal public participation meeting. Participants develop an understanding of the important considerations that must be balanced when the federal government has to make a policy decision or implement a legal ruling. Educating participants prior to a citizen engagement process is also essential to their contributing input based on informed opinions, which Graham and Phillips have noted are an expectation of local governments that hold citizen engagement processes (Citizen Engagement 2).

While the short-term objective of reducing tensions during the Marshall crisis was likely somewhat affected by the licence buyback program, the long-term objective of establishing partnerships among the groups involved to manage the fishery was likely lost in the Marshall case. While the Department of Fisheries and Oceans may not have entirely understood the implications of its chosen engagement techniques and methods with groups during the Marshall crisis, it is important to note that a delicate balance could and should have been struck between short-and long-term objectives to ensure that positive outcomes from a difficult situation could be realized. The Inform and Consult methods of public participation highlighted in Chapter 4 will manage short-term results to a degree. Yet the long-term objective of establishing partnerships to integrate First 
Nations fishers into the Maritime commercial lobster fishery is just as important.

The Involve method of public participation would likely have posed the most potential for meeting the short- and long-term objectives, primarily because had Involve techniques been implemented at the beginning with the broadest group of affected citizens, their impact on the policy-making process would have been substantial without any significant increases in time or financial/human resources. Involve techniques provide an opportunity for individuals and groups to become educated and actively influence public policy issues through a citizen engagement process. Involve techniques would also provide an ample opportunity for participants to work together and learn about the complexities of the issues, posing additional opportunities to educate about the issues and address any concerns in a meaningful way. The public could potentially develop a common understanding of the issues as they contribute to them, and they can own the issues through an Involve process, which is an important benefit of citizen engagement over traditional public participation.

Deliberative democracy is a concept developed in the 1990s, which is premised on the desire to receive public input on critical policy issues, in addition to being represented by government bureaucracies and elected officials. Laforest and Phillips indicate that "the model of deliberative democracy that emerged in the 1990s starts from the premise that political representation is not enough: active participation by citizens is as important as having their interests represented by third parties" (71). Deliberative democracy can provide an opportunity for individuals, especially those with experiential knowledge, to contribute their specific understanding of an issue and point to barriers and 
solutions that may be missed by other officials.

In the book Talking with Canadians, Abele, Graham, et al. provide the following description of deliberative democracy (citizen involvement) and some of the techniques involved:

The Canada West Foundation describes deliberative democracy as a democratic consultation process that combines the opinion poll, policy conference and policy roundtable. Participants are chosen at random, and their opinions are surveyed both prior to and after the conference or roundtable. The group spends time in both conference and plenary settings, and in workshop, small discussion and focus groups. The process generally takes place over several days. Participants are provided with an opportunity to learn about issues and increase their knowledge of issue complexity, interrelationships, tensions, options and trade-offs (Talking with Canadians 17).

Spanning and bridging is an additional technique (also known as a dimension) of citizen involvement in public policy processes. It is defined as follows:

[Spanning and bridging] taps into a breadth of knowledge and facilitates participation across a broad span of society. The breadth that comes from convening and hearing from different networks of citizens and communities may also enable the parties to better learn from each other and to cultivate allies (and, possibly, to better identify opponents as well). There may be a tradeoff, however, between acquiring depth and breadth of 
participation (Abele, Graham, et al., Talking with Canadians 9).

The description of deliberative democracy presented above provides some critical ideas that could be implementable within a shortened time frame and conceivably at almost as low a cost as traditional public consultation approaches (Inform and Consult methods). Many of the techniques indicated in deliberative democracy - which are also argued to form part of the Involve method of engagement because they enable participants to comment and provide input and have an impact on policy decisions - could enable participant perspectives to be heard and considered, while ensuring a good "cross-section of the population" is involved, rather than political leaders and technical advisors, as is often the case.

Deliberative democracy provides improved opportunities to structure and manage agenda issues in a summit type of setting, rather than having participants bring their personal agendas to the table. Abele, Graham, et al. state in that "the critical dynamic of deliberative democracy is in how discussion of agenda issues is managed and structured. Sufficient focus must be achieved to move dialogue towards a meaningful conclusion" (Talking with Canadians 17). Policy roundtables, and spanning and bridging would be useful in a crisis situation insofar as providing a specific agenda to follow and structuring the means through which to identify critical issues to discuss that all participants can agree on. This technique could also focus on the technical questions that would need to be raised to ensure more individuals understand what is at stake and how they will have to work together to manage crisis outcomes to everyone's mutual benefit.

Deliberative democracy techniques have unique strengths for crisis engagements 
and despite some minor drawbacks, could likely be very beneficial. Abele, Graham, et al., define deliberative democracy's strengths as the following:

The main strengths of this approach [deliberative democracy] are its representativeness, its ability to encompass learning, education, dialogue, debate, reflection, option and opinion development, individual influence and participation and, depending on how results are organized and reported, a degree of closure. The drawback of deliberative democracy forums is in their expense and logistical organization (Talking with

\section{Canadians 17).}

Some of the strengths listed above, such as representativeness, learning, education, dialogue, debate, as well as option and opinion development have already been raised as considerations in some of the interviews conducted for this thesis. For example, education has already been discussed at length as an important by-product and requirement of citizen engagement when it is conducted prior to the commencement of a citizen engagement process, especially because it can become a means to gather further depth on the issues when everyone is contributing. Representativeness is beneficial because it affords individuals within groups a random opportunity to participate, instead of only those who are in positions of leadership or technical experts in an organization.

Finally, debate, and option and opinion development are important positive steps because they enable groups that are in diametric opposition to examine individual issues more carefully, develop an informed opinion and debate the relative merits of specific policy solutions. Education, option and opinion formation, and debates support all 
individuals and groups involved to come to common ground and develop a greater understanding of the complexities and compromises that may be required to help reduce tensions and establish boundaries for new partnerships over the long term.

The drawbacks of deliberative democracy techniques indicated above include how expensive they can be and the logistical organization required to pull off such an event. These may be drawbacks, but they tend to be relatively minor insofar as the availability of financial/human resources can improve during a crisis, as targeted funds for consultation/engagement can be found, as argued in Chapter 3 .

There is also the relative weight of the costs of doing nothing during a crisis, which could eventually require varying degrees of intervention by police and/or military force to maintain order. Finding the human resources available to manage the logistical organization of a deliberative democracy event may be a little more difficult, but as indicated in Chapter 4, one of the main complaints of the non-Aboriginal fishers throughout the informal engagements that occurred was that Gilles Thériault was helpful as an Associate Chief Federal Negotiator, yet he did not appear to have any staff to support him, which frustrated many (Comeau Interview).

Deliberative democracy citizen engagement processes also present opportunities to reduce costs and burdensome logistics through the use of new technologies that have been developed since the Marshall crisis. For example, electronic voting services that tabulate votes and project them back to participants instantaneously could reduce time and cost requirements to manage deliberative polling. In sum, the techniques that align under the Involve/citizen engagement/deliberative democracy rubric may be somewhat 
more difficult to implement, but there can be time and cost savings achieved if processes are designed accordingly.

To analyze the potential of Involve techniques, they will be reviewed according to how they might have been implemented during a summit at the beginning of the Marshall crisis. The following section will analyze the potential of three important techniques including workshops (policy conference and roundtable), deliberative polling (or opinion poll) and spanning and bridging - to be implemented and to increase public impact in the policy-making process to the meet short- and long-term objectives. These techniques will be bundled into a critical summit of several days to achieve economies of scale.

\subsection{Crisis Summit}

This section will state the Involve techniques identified in the previous section on an individual basis and as part of a broader policy summit. The section will then demonstrate the potential of these techniques to address the changes recommended by the individuals interviewed to balance the objectives of reducing tensions and contribute to the establishment of long-term partnerships in the management of Maritime commercial lobster fishery, while respecting treaty rights.

An alternative option to the Department of Fisheries and Oceans' implementation of a lobster licence buyback program would have been to host a three-day summit to bring together a cross section of federal and provincial government officials; First Nations leadership and fishers; and non-Aboriginal fishers and members from First Nations and non-Aboriginal communities. The techniques to be implemented throughout the summit follow in the sections below. 


\subsubsection{Spanning and Bridging}

The purpose of randomizing the participants through a spanning and bridging process would be to receive input from the broadest cross-section of the public in all roles, who were directly or indirectly effected by of the Marshall decisions in the region. The cross-section would include those who possess experiential knowledge (fishers), those who are often left out of such engagements (community members) and their organizations' leaders (e.g. federal and provincial representatives, Chiefs and Councils, non-governmental organizations and union leaders). A significant breadth of knowledge would come from drawing upon all of the individuals and organizations involved, while enabling participants to "better learn from each other and cultivate allies," as well as learn who their opponents will be (Abele, Graham, et al., Talking with Canadians 9). This approach aligns with the concern raised by James Jones that outside communities should have been involved in engagements (Interview). This would be an improvement on informal relations established prior to the Marshall decisions, as alliances could be formed on a vertical, as well as horizontal basis, enabling individuals from all walks of life to work together and learn more. The relationships established prior to Marshall were primarily with the leadership of various organizations. However, with this technique, the leadership and others could meet and discuss the issues, presenting further opportunities for educating individuals and ensuring everyone is aware of the issues presented.

The only risk associated with spanning and bridging could be that individuals might not identify priorities as easily in their varied groups. However, using key 
priorities identified in entrance polls as a driver for discussion could mitigate this risk.

\subsubsection{Pre-Workshop Sessions}

The first step in the summit would be to prepare participants by holding presummit sessions to educate them about the Supreme Court of Canada's decisions and the issues that must be addressed, such as how First Nations and non-Aboriginal fishers could co-exist in the Maritime commercial lobster fishery over the interim period, while also working to determine a long-term vision for management of the natural resource.

Pre-workshop sessions would equip individuals to own the issues by being informed from the beginning, instead of entering the summit with pre-conceived notions. These sessions, through the education they provide, could also help reduce tensions among those involved in the Marshall crisis over the short term, as all participants would be involved in discussions and brought up to date on the issues. Educating participants in advance would also help reduce the media's influence, which was seen to have contributed significantly to increasing tensions during the Marshall crisis. Pre-workshop sessions might also cultivate respect for the process if someone like Gilles Thériault were made responsible for leading them, as individuals appreciated being informed by him during the Marshall crisis. The time and financial/human resources required implementing this technique, as part of a summit would likely not increase the requirements of the Department of Fisheries and Oceans, as this session could be packaged within the entire summit.

\subsubsection{Deliberative Poll (Entrance)}

A deliberative entrance poll should be held prior to the beginning of policy 
opinion and option formation to ensure all participants identify their main priorities. A deliberative poll would help set the overall agenda for the summit to ensure options are developed at the end. Such a poll could also help identify any concerns that individuals have, which could be used to determine what types of discussions would need to occur to ensure positive relationships are maintained. Another benefit of an entrance poll is to determine where priorities are at the beginning of the summit and compare and contrast where the priorities are at the end of it. This would show participants how their perceptions of the issues have changed, not to mention the potential for impacting the policy-making process to address the short- and long-term objectives identified.

\subsubsection{Workshop (Policy Conference)}

A workshop would be held to enable individuals selected from a cross-section of the affected public (based on spanning and bridging) to meet and form policy options for debate, as part of the key priorities identified in the entrance poll. Discussions could be broken into short- and long-term objectives and how to achieve them to everyone's reasonable satisfaction. These types of policy options can be very helpful if they are well developed and encompass perspectives from all groups involved, as few individuals would likely dissent against a solution they helped to establish. The workshop process might help to reduce tensions over the short term by virtue of enabling individuals to contribute to and have an impact on key policy recommendations to address the crisis.

The smaller groups might then meet to discuss the policy options and challenges to the broader plenary group. Options could then be debated and re-organized according to priority and individuals could also take an opportunity to discuss relationships among 
their communities and how they might benefit from a specific option over another. Such discussion would be helpful, especially if leaders were present, to ensure calmness and mutual support could be achieved. This approach might also address the idea raised by James Jones about holding a community meeting to discuss how to develop, or maintain positive relationships and to keep the lines of communication open.

The beginnings of improved relationships among some First Nations and nonAboriginal groups could help establish partnerships over the long term and help both sides manage the Maritime commercial lobster fishery in a manner that would be economically beneficial to all. Such an approach could help alleviate adverse long-term outcomes presented by the interim buyback program and the community-by-community negotiations that occurred. While such an opportunity might benefit First Nations in some ways, there may have been a greater opportunity for improved integration had more flexible options been made available as part of the Department of Fisheries and Oceans' response to the Marshall decisions. The presentation of a flexible policy option that could be debated and agreed upon as an interim measure, such as the establishment of partnerships for those who wish to enter into them, could have led to the possibility that future public participation processes involving techniques under Collaborate and Empower might also not be squandered for a short-term solution.

The Marshall crisis was precipitated in part because most citizens were unsure what the Supreme Court decisions meant when referring to a moderate livelihood. First Nations and non-Aboriginal fishing groups, among others, felt their concerns were being ignored. The outcomes of the Marshall decisions led to the establishment of a separate 
system for First Nations fishers through the licence buyback program, but the difference between that and the development of flexible policy options is that individuals were forced into it, which led to division and dissention in some First Nations communities. Enabling groups to work together on possible solutions that they feel reasonably comfortable with can help with the formation of partnerships down the road.

\subsubsection{Workshop (Policy Roundtable)}

A policy roundtable would be the final element to lead decisions on the policy options presented, in which the strongest policy options, decided on by the majority of participants, would be put forth for leaders, such as Ministers, Chiefs, Presidents of organizations and other key officials, to ultimately decide a course of action on behalf of the people. This approach would address participant legitimacy because all leaders are being called together to quickly agree on flexible policy options and next steps, while also being accorded the power in their roles as representatives of their constituent groups. In addition, representatives holding significant sway with a variety of organizations with a stake in the commercial lobster fishery (e.g. Gilles Thériault as Associate Chief Negotiator) might also act as a focal point to approve recommendations because they are generally respected and known by most organizations.

A potential drawback is that leadership at the roundtable could reject all of the options presented and provide their own prescription to resolve the issue, which could pose the possibility of completely undermining the deliberative democracy process. Yet if the participants are educated enough in the beginning and receive appropriate direction on the issues that need to be considered when formulating their policy options to meet the 
short and long-term objectives, this would not likely become an issue. It would also likely be untenable, politically, to host a summit and reject the recommendations outright, as the public could see it as a colossal waste of taxpayer funds.

Holding a policy roundtable could add another minor amount of time and financial/human resource requirements, but such needs would likely be justified in a crisis, which could end up costing far more if the status quo were left to stand.

\subsubsection{Deliberative Polling (Exit)}

Finally, once all has been completed, a deliberative exit poll might determine how participants' attitudes have changed since the beginning of the summit. This technique is especially important to demonstrate whether the groups have come together on some issues and solutions, and/or grown apart on others, which would present a direct impact on priority setting and the establishment of policy options. Demonstrating how opinions have changed is important because participants will also realize how they have not only contributed to the debate and development of options, but they have also learned from the process and each other. The possibility for the development of long-term partnerships would likely be helped by this technique as a result.

\subsection{Conclusion}

This chapter has presented the argument that the public participation techniques and methods with the most potential to be implemented during a crisis tend to fall under the Involve/citizen engagement/deliberative democracy rubric. This is because these techniques provide maximum public impact on the policy-making process with minor adjustments in time and financial/human resource requirements if a process is designed 
properly. In other words, a moderate approach to public participation that allows for some public impact in policy-making processes to develop a response to a crisis can help resolve it, and prepare groups for future discussions on how partner and manage natural resources while respecting treaty rights.

The Involve method of public participation, with its many techniques drawn from deliberative democracy analysis (i.e. spanning and bridging, deliberative polling and workshops), likely provides a strong balance between achieving the short- and long-term objectives. Through these techniques, participants from broad swaths of the public are educated on the issues and encouraged to develop the best possible short-term policy options to respond to those issues, which are then validated by leadership. Long-term policy options are also established to address the development of long-term partnerships, which can begin through the action of participating in the summit. This approach sets the stage without alienating anyone, but also ensures that participants realize that a crisis is incredibly complex and that there is no time to lose when increasing tensions need to be addressed. 


\section{Chapter - Conclusion: New Possibilities?}

\subsection{Introduction}

Following this introduction, the first section of the chapter presents a summary of the research and the three intended areas of contribution. The second section presents a review of the analysis of the methods of public participation undertaken prior to and during the Marshall crisis. The second section will then focus on new possibilities in crisis management based on the modified public participation spectrum. The argument in favour of the Involve method will then be briefly reviewed. The third section of this chapter will then focus on the Atlantic Lobster Summit, held in 2007, which led to the establishment of the Lobster Council of Canada. I will then briefly review the short-term strategies of the Summit and the long-term impacts of establishing the Council through use of the modified public participation spectrum as a means of analysis. The fourth section of this chapter will focus on recommended areas for further research. The chapter will then conclude with a brief summary of findings indicating that the Involve public participation method has the potential to engage with citizens in a manner that provides more genuine public involvement and impact on the policy-making process during a crisis.

\subsection{Summary of Research Plan and its Three Contributions}

The aim of this thesis has been to answer two questions: what public participation methods did the federal government implement prior to and during the Marshall crisis, and are there possibilities for strengthening public participation in crisis management over the short and long term? Chapter 1 laid out a research plan to address these two 
questions in the hope of making contributions in three main ways. The first of the three contributions, presented in Chapter 2, was the construction and presentation of a revised narrative concerning events that occurred prior to and during the Marshall crisis. This narrative of events adds to the body of knowledge on the subject of the Marshall crisis because it included primary source interviews that offered unique perspectives from important individuals involved on all sides of the fishing dispute over commercial access to the Maritime lobster fishery.

The perspectives provided by the five individuals who were interviewed were compared and contrasted to each other, and to the secondary source literature on the Marshall crisis. The revised narrative provided a significant degree of insight into how key individuals identify strengths and weaknesses in how public participation was and was not incorporated. The additional information presented in the Marshall narrative provided further examples of crucial points to analyze using the analytical concepts, techniques and methods identified in the modified participation spectrum.

Chapter 3 focused primarily on the development of the modified public participation spectrum, which used an orienting dichotomy constrasting traditional public participation and citizen engagement. The primary difference between these two concepts was cited as the varying degree to which each method enables public impact on the policy-making process, with citizen engagement presenting a higher degree of public impact than traditional public consultation.

Traditional public consultation and citizen engagement were then aligned with the concepts of representative and deliberative democracy, respectively. These two concepts 
were seen to fall in line with traditional public participation and citizen engagement in terms of the degree of public impact they afford to citizens in the policy-making process. Representative democratic processes tended to focus on traditional forms of democratic representation, such as having an elected official represent one's interests as a citizen, which many citizens feel is inadequate (Abele, Graham, et al., Talking with Canadians 4). Deliberative democracy, which closely aligns with citizen engagement, permits individual citizens to participate more actively in expressing their concerns on public policy issues. It was likely derived as a response to the viewpoint that representative democracy became inadequate for many citizens, who sought additional means to express their perspectives on policy issues (Laforest and Phillips, Critical Policy Studies 71). The alignment of these concepts along an increasing level of public impact placed traditional public consultation in line with representative democracy and citizen engagement with deliberative democracy. These concepts formed the basis for the modified public participation spectrum, from an academic perspective and set the stage for their merging with the five methods provided by the International Association for Public Participation's public participation spectrum.

Five practical administrative methods of the International Association for Public Participations' public participation spectrum were aligned along the same lines as the four previous analytical concepts. The five methods, including Inform, Consult, Involve, Collaborate and Empower, were arranged according to an ascending level of public impact on the policy-making process, coupled with the orienting dichotomy and representative/deliberative democracy. This led to the second contribution, which was 
the alignment of academic and practical administrative approaches to analyzing public participation. By aligning the methods identified with the already-aligned orienting dichotomy of traditional public consultation/representative democracy and citizen engagement/deliberative democracy, the five methods provided even more depth from which to analyze smaller differences in the possibility, development and implementation of public participation during a crisis with increased precision.

The final element of the modified public participation spectrum was the consideration of four external factors when deciding which method of public participation to use in a crisis management situation. Two of the external factors related to the feasibility of using methods that increase public impact on policy making. Time and financial/human resource constraints were understood as rising in proportion with the level of public impact on policy-making processes when considering a method along the modified public participation spectrum. It was important to determine if methods that enable greater public impact during a crisis were even hypothetically possible, as at a certain point, the implementation of some methods would be too time consuming and costly to be feasible.

The final two external factors, media influence and participant legitimacy, were considered more in terms of their ability to influence the outcome of a public participation process during a crisis.

All of the elements cited above helped establish the modified public participation spectrum, which ties into the third contribution of this thesis. The modified spectrum presented additional insights into the narrative of the Marshall crisis when considering 
public participation methods used and their outcomes, prior to and during the crisis; the short- and long-term consequences of what happened; and possibilities presented for new techniques and methods of public participation in a similar crisis management context. Further description of my analysis using the modified public participation spectrum is presented below.

\subsubsection{Analysis of Public Participation Prior to the Marshall Crisis}

Analysis of public participation techniques and methods that were applied prior to the Marshall crisis indicated that informal relationships established among the Department of Fisheries and Oceans and First Nations as a result of the Sparrow decision helped the Department maintain communication with First Nations communities at the height of the crisis.

Another outcome of pre-Marshall public participation was the notable absence of non-Aboriginal fishing organizations, such as the Maritime Fishermen's Union, in discussions regarding the Maritime commercial lobster fishery. Such groups and/or organizations, had they been involved, might have provided helpful insights during discussions on how to integrate First Nations into the lobster fishery for food, social and ceremonial purposes, as a result of Sparrow. The development of such partnerships, if established prior to Marshall 1 and 2, could have contributed to an improved response to the crisis, as the groups would already be in regular contact and sharing information with each other. Non-Aboriginal fishing organizations might have potentially benefitted from information sharing, especially in terms of being educated about the Sparrow decision's implications for their fishery, had they been included in discussions with the Department 
of Fisheries and Oceans and First Nations.

The Department of Fisheries and Oceans' approaches to public participation with First Nations and non-Aboriginal fishers prior to the Marshall crisis appeared to be lacking in techniques and methods that could enable greater public input into and impact on the policy-making process. The Department also excluded most non-Aboriginal fishers from even knowing what the food, social and ceremonial fishery was about, which might have been one of the contributing factors to the Marshall crisis. Food, social and ceremonial fishing was one thing, but First Nations' involvement in the commercial lobster fishery prove to be a significant threat to non-Aboriginal fishers' livelihoods.

\subsubsection{Analysis of Outcomes During the Marshall Crisis}

The most notable outcome of public participation conducted during the Marshall crisis was a greater intensity of focus traditional public consultation (Inform and Consult methods) when contrasted with the pre-crisis period. New techniques, such as negotiation and mediation (primarily with leadership of organizations and groups) were implemented, while informal relationships included communication with greater intensity. However, while the variety and intensity of the techniques implemented during the crisis increased, the methods, namely Inform and Consult, appeared to have remained the same, affording no more public impact on the policy-making process to manage the crisis. The three most important techniques undertaken during the crisis were focused on in Chapter 3, including: Community and Groups Engagements; Federal Negotiations; and Legislative and Parliamentary Hearings. Outcomes for each of the three are presented below. 


\subsubsection{Community and Group Engagements}

The Department of Fisheries and Oceans managed community and group engagements during the Marshall crisis, building on the informal relations that it held with First Nations leaders, as a result of the prior Sparrow decision. It was within the context of Sparrow that existing relationships appeared to provide at least some opportunity to hold open and informal discussions behind closed doors, despite the blatant differences of opinion on what the Marshall decisions really meant in terms of commercial fishing constituting a moderate livelihood. This technique was highly similar to what occurred pre-Marshall.

Another outcome was that the Department of Fisheries and Oceans' buyback of commercial fishing licences on a community-by-community basis afforded no greater opportunity for public impact through public participation than prior to the crisis. The Department of Fisheries and Oceans afforded no opportunity for communities that were affected by the Supreme Court decisions and the ensuing crisis to provide input into how the crisis should be addressed. Instead, it bought back commercial fishing licences from non-Aboriginal commercial fishers to provide to First Nations communities as a shortterm measure. There was no discussion or input sought from the public as to whether this would have been the best option in the short term, nor was there any education of nonAboriginal fishers as to why this had to be done, which infuriated many.

\subsubsection{Federal Negotiations}

Federal negotiations during the Marshall crisis pointed to the importance of sharing information with affected groups who are not a part of direct negotiations, but 
who are involved/affected through other means, such as their geographic proximity to the site of a crisis. Regardless of whether the method used generated greater public impact on the policy-making process, sharing information and keeping the public in the loop on the progression of negotiations is an important step for reducing tensions and educating them for future public participation exercises.

Another consideration during the Marshall crisis was that the media posed a significant threat to negotiations. As discussed in Chapter 3, most of the media stories were significantly skewed toward non-Aboriginal perspectives (Coates xii). Such stories, while they may not have been the catalyst for the Marshall crisis, certainly did little to help reduce tensions and often caused tempers to flare.

The media was especially negative toward First Nations fishers, who were often ignored in favour of non-Aboriginal fishers' perspectives in the papers and on radio stations in New Brunswick, owned by the J.D. Irving family (Coates xi). In addition to focusing on non-Aboriginal fishers' perspectives in the majority of news stories featured throughout the Marshall crisis, there was also a significant focus on Aboriginal stereotypes, especially when it came to the centre of violence, Burnt Church. All of these factors are attributable to political economy and agenda-setting analyses of the media, both of which were present throughout the Marshall crisis and had a significant role to play in increasing tensions among First Nations and non-Aboriginal fishers. The potential for significant media influence during a crisis situation increases the need for improved communication among the groups involved to filter the content that is disseminated in the media. 
The government's desire for legitimation in modern democracies has also given rise to an issue of participant legitimacy known as fake participation. The way the Department of Fisheries and Oceans managed its relationship with non-Aboriginal fishers presents an example of what might potentially be seen as a high stakes issue, namely how to allocate, regulate and manage Maritime commercial lobster quotas. The assignment of an Associate Federal Negotiator, Gilles Thériault, may have helped to reduce tensions among the First Nations and non-Aboriginal fishers, and could only do so by virtue of his network of contacts from his long career. However, his appointment also helped to obscure the fact that the Department of Fisheries and Oceans did not necessarily engage many concerned groups in the first place. The one difference in this instance is that the crisis was the result of a Supreme Court ruling. As such, fake participation occurring in negotiations with non-Aboriginal fishers may not be so much construed as a means to a political end, as another institution, the Supreme Court, already made the decision. However, the outcome in this case is that fake participation can occur when there are high stakes involved to attempt to resolve a crisis quickly for political expediency.

\subsubsection{Legislative and Parliamentary Hearings}

Legislative and Parliamentary hearings are a traditional method that the federal government has used in the past to engage with a variety of citizens and experts on key issues facing Canadians. The outcome of this public participation technique is that committees are not particularly expedient in holding meetings, which runs counter to the time constraints in a crisis situation. In addition, it is often leaders, politicians and technical experts who are chosen to testify at committees, rather than those who are 
usually the most affected, such as the First Nations and non-Aboriginal fishers in the Marshall case. This approach can skew perspectives and obscure important testimony that could help support the resolution of a crisis. There is depth but often very little breadth. It is important to also consider the legitimacy of those who are called on to provide feedback to Parliamentarians. Are they really the true representatives of their constituent groups? Generally speaking, the aforementioned shortcomings of standing committees can hinder the push to achieve the goals of reducing tensions in a crisis. However, despite these many negatives, there may be some benefit to hearings, as they are focused and provide an opportunity after the fact to summarize the overall time line of events as a means of summarizing lessons learned and next steps for managing an issue into the future. Yet, this approach would probably be better placed after the resolution of a crisis as a means of summarizing key outcomes.

\subsubsection{Involve as a Possible Public Participation Method}

The Involve public participation method, located alongside Collaborate under citizen engagement in the modified public participation spectrum, may very well present a possibility for implementation as part of crisis management. Involve can accomplish this because its techniques might, in theory, enable greater public impact on the policymaking process without drawing too much time and financial/human resources. This is because there are no formal governing bodies that have to be established, like in the Collaborate and Empower methods in the modified public participation spectrum.

As specified in Chapter 5, one potential approach for implementing Involve techniques, without a significant gain in time and financial/human resource constraints, 
could be through a summit. Such an event could incorporate several Involve techniques into a three-day setup to enable individuals from a cross-section of society to work together, form opinions, debate priorities and future work. Pre-summit education sessions might help participants establish informed opinions prior to holding discussions. Entrance and exit polls could provide a means to demonstrate how priorities have changed through the duration of the summit and act as a measurement tool. Workshops, including a policy conference, might present an opportunity for opposing groups to come together and consider their options, then decide priority options. Finally, through a policy roundtable, leaders of the different organizations may be brought in to ratify the options presented.

In sum, while there is no hard evidence to prove whether the Involve method and its associated techniques might have been the most effective in the context of the federal response to the Marshall crisis, Involve does present the most likely possibility as a feasible method that would afford greater public impact in the policy-making process. Individuals interviewed for this thesis mostly indicated that more people should have been afforded the opportunity to contribute to the conversation concerning how they would be impacted by the Marshall decisions, which did not appear to be the case with the Inform and Consult techniques identified earlier. In addition, Collaborate and Empower methods of public participation appear to be too time consuming and costly to implement during a crisis. However, these are only appearances and only future research will truly determine if the theory developed here will stand true in reality. 


\subsection{Atlantic Lobster Summit and the Lobster Council of Canada}

In Chapter 5, I presented the possibility that implementation of the Involve method in the form of a three-day policy summit likely presents the most feasible opportunity in a crisis to increase public impacts on the policy-making process. Elements of the summit, including specific citizen engagement techniques to be implemented, have been summarized in the previous section. The analysis need not remain hypothetical, since an actual summit was held concerning the Atlantic commercial lobster fishery (including the Maritimes Gulf region).

In October 2007, nine years after the Marshall crisis began, an Atlantic Lobster Summit was held. The purpose of the two-day summit was to address industry challenges (Atlantic Lobster Summit 1). The summary states that "among these [industry challenges] include issues on: sustainability, quality, supply, price, human resources, marketing, communication and industry coordination" (Atlantic Lobster Summit 1). All of these challenges tend to be linked to the key objective of the Summit, which was the following:

The key objective of the Lobster Summit was the development of approaches to maximize the value of the resource for all participants in the Atlantic Lobster fishery. The Summit aimed to identify the barriers and difficulties that impede industry's ability to maximize its potential and establish a follow-up process to address these obstacles (Atlantic Lobster Summit 1).

Judging by the objectives of this Summit, it would appear that the primary purpose was to 
maximize profits for the resource industry by bringing groups together to discuss any key issues and barriers the industry is facing. The Summit was held almost nine years after the Marshall crisis and presumably, would not entail the same concerns and issues that might be addressed during a crisis. In addition, based on the composition of participants in the Summit that will be elaborated below, it would appear that the Summit was held among government and industry representatives only, which raises questions about whether it was meant for a significant proportion of the population of citizens at all. In addition to having the objective of maximizing the value of the commercial lobster fishery and ensuring any obstacles to that were addressed, the participation at the Summit was quite telling: "The Summit attracted leaders of the Atlantic Lobster Industry and speakers ranged from fish harvesters to processors to market experts and scientists" (Atlantic Lobster Summit 1). Based on the roster of participants, representation at the Summit was widespread across various organizations among governments (Members of Parliament, provincially-elected members, and federal and provincial departments that manage the lobster fishery); and industry (representatives of various fishery unions, cooperatives, Lobster Fishing Areas, lobster processors, lobster retailers, college fisheries programs, and non-governmental organizations) (Atlantic Lobster Summit 48-53). The Summit participants list, while enormous with representation from the aforementioned government and industry organizations, does not appear to have formal representation from First Nations organizations or communities involved in the Atlantic commercial lobster fishery, as was the case with organizations and communities affected by the Marshall crisis. In the meantime, there was some representation of non-Aboriginal 
fishers from specific Lobster Fishing Areas by actual non-Aboriginal fishers, rather than only union representatives. It is understood that the purpose of the Atlantic Lobster Summit was the maximization of profits. It was not held during a crisis with First Nations, but they certainly had an active stake in the Maritime commercial lobster fishery after the Marshall decisions of 1999. Nine years following the Marshall crisis, it would appear that First Nations were once again being left out of, or abstaining from participation in, the commercial side of the fishery.

The Atlantic Lobster Summit was a two-day event, which included several sessions with titles such as "What do Buyers and Consumers Want? A Reality Check," and "Breakout Session: Meeting Market Requirements" (Atlantic Lobster Summit 9-25). Considering the Atlantic Lobster Summit in terms of the practical administrative methods outlined in the modified public participation spectrum, as well as analytical concepts outlined throughout this thesis, it would appear that this Summit does not move very much further beyond what was undertaken in terms of negotiations and mediation during the Marshall crisis. The Atlantic Lobster Summit appeared to use techniques under Inform, Consult, traditional public consultation and representative democracy, which are all connected in terms of the degree to which citizens have an impact on policy-making processes. The Summit included a significant component of representation from elected officials and federal and provincial bureaucrats, meaning that individual citizens with a stake in the lobster fishery were not significantly involved. There appeared to be little opportunity for the public to comment on the Atlantic commercial lobster fishery, as participation was limited to government and industry. First Nations organizations were 
not in attendance at all. The composition of participants was sorely lacking if the federal and provincial governments were seeking comprehensive input. In addition, the scope of the Summit was already set on maximizing profits for the industry and most of the events (e.g. breakout sessions and plenary speeches) were already focused on sharing information with industry leaders, and/or seeking input to respond to barriers to profits. Information sharing is important, but as Chapter 5 elaborated, the hypothetical summit would use information sharing as a vehicle to seek informed opinions from citizens wanting to participate. Additionally, seeking input from individuals on the narrow topics defined for the Atlantic Lobster Summit appeared to go no further than Consult on the modified public participation spectrum because the barriers were already developed and questions were being asked on how to address those barriers, rather than asking a broader audience comprising citizens what he barriers really were.

In terms of external factors, time and financial/human resources appeared to not be an issue, as there was no crisis present. Media coverage of the Summit appeared to be minor, with local newspapers in the Atlantic region filing stories. The lack of national coverage could mean that the Summit was kept relatively quiet, or that national media outlets felt the story was not compelling enough to cover. Finally, while participant legitimacy was definitely addressed with the elected representatives, bureaucrats and industry leaders that were present, it may not have gone far enough because there were too few members of the public (especially First Nations) invited to attend. Overall, citizens' potential impact on public policy making in this case would have been significantly low, as the Summit only included representatives of specific industry 
organizations. By appearing to be engaged in Involve and Consult only, this Summit, which did not occur during a crisis period, likely went no further than negotiations held between Department of Fisheries and Oceans representatives and First Nations leaders immediately after Marshall 1 and through negotiations for communal licencing. That is fine if the purpose of the Atlantic Lobster Summit was to have an industry convention concerning the Atlantic commercial lobster fishery. The Atlantic Lobster Summit may have been a missed opportunity for ordinary citizens from all areas affected by this industry to provide input that could possibly affect overall policy development.

One of the outcomes that did appear somewhat promising from the Atlantic Lobster Summit was the establishment of the Lobster Council of Canada. According to its website, the Lobster Council was established based on the outcomes of the 2007 Atlantic Lobster Summit:

The Lobster Summit held in October 2007 recognized the value and importance of the lobster industry in Atlantic Canada, and provided a clear mandate to establish a mechanism to address key issues identified in both the earlier lobster benchmarking study and the Summit (http://lobstercouncilcanada.ca/about).

The Lobster Council's mandate is "to enhance the value of the Canadian Lobster Sector in a sustainable fashion by addressing the issues of importance to the industry" (http://lobstercouncilcanada.ca/about). According to the website, the Lobster Council of Canada has a similar scope of concerns as those highlighted in the Atlantic Lobster Summit of 2007. For example, one of the organization's primary aims is to "lead market 
access issues, including but not limited to sustainability certification, food safety, traceability requirements, etc." (http://lobstercouncilcanada.ca/about). One area where the Lobster Council deviates from the Lobster Summit is that composition of its membership. For example, it is noted that John Paul of the Atlantic Policy Congress of First Nations Chiefs, and Réginald Comeau, who works for the Maritime Fishermen's Union, are both members. While there does not appear to be significant public participation in the Lobster Council, those who are in leadership positions throughout the industry and other areas, such as First Nations policy, are involved, which represents a slight step forward from the composition of participants at the Atlantic Lobster Summit.

A common theme throughout this thesis has been the possibility of implementing a public participation method that could address both the short-term objective of reducing tensions during a crisis, while also setting the stage to address a long-term objective of establishing partnerships to manage the resource for everyone's benefit, while respecting Aboriginal treaty rights. While the short-term objective cannot be analyzed in terms of the Summit and Council because they were established way after the Marshall crisis, there is certainly room to consider the long-term objective of establishing partnerships. In the case of the Lobster Council of Canada, it would appear that at least some partnerships are being formed to maximize profits in the commercial lobster industry, while respecting principles of sustainability. This is evident through the stated mandate, objectives and composition of the Lobster Council. However, where the Lobster Council of Canada would appear to fall short of the long-term objective I have identified is that it is an advocacy organization only. It does not purport to act with delegated decision- 
making from the federal and/or provincial governments, as in Collaborate, nor does it constitute joint management of the resource, which public participation under Empower might do. The Lobster Council also does not include any significant participation beyond those present at the Atlantic Lobster Summit. As a result, I would consider the Lobster Council to fall short of the stated long-term objective of this thesis because at best, its approaches would constitute Involve public participation, and that would only occur if the public were invited to provide their input to affect policy-making concerning the commercial lobster fishery.

\subsection{Recommendations for Further Research}

There are three areas recommended for further research. The first is to use the modified public participation spectrum to analyze a similar case study to Marshall, where it may be possible to evaluate the effectiveness of the Involve method among others in crisis management. Possible metrics of effectiveness could include measuring the time it would take to resolve a crisis, a determination of the positive long-term outcomes of a government's response to a crisis, and/or by surveying those involved to seek their satisfaction with crisis management.

A second area of consideration for future research would be an evaluation of opportunities to develop and implement techniques under the Collaborate and Empower methods of the modified public participation spectrum over the long term. As previously stated, both methods might not be feasible during a crisis due to time and financial/human resource constraints. However, the best time and place to implement these public participation methods may be after a crisis has been resolved. Collaborate 
and Empower methods may present a feasible option for establishing long-term partnerships and joint management of natural resources. Such partnerships might also help reduce the risk of future crises. Such research might also focus on existing models of co-management that are currently working well and analyze them to determine their applicability in other contexts.

A third area of future research would be to consider other section 35 treaty rights cases where no crisis occurred after the court decisions. The modified public participation spectrum could then be used to determine if public participation methods that enabled greater public impact on the policy-making process led to the prevention of another crisis. The Powley decision of 2003 regarding Métis harvesting rights is one example of a case where the Supreme Court of Canada decision was not followed by protests and violence.

\subsection{Conclusion}

This chapter has summarized all of the outcomes from analyses of public participation techniques and methods implemented prior to and during the Marshall crisis. It has also provided the argument that the Involve method (i.e. citizen engagement) may present a new possibility to increase public impact on the policymaking process in crisis management. This could help meet the short-term objective of reducing tensions during a crisis and then help establish partnerships to manage the Maritime commercial lobster fishery over the long term, while respecting First Nations' treaty rights.

Citizen engagement is a necessary component of a modern, democratic society. 
As legal and policy issues become increasingly complex, it is important for governments to recognize that there are public participation tools at their disposal to identify issues and seek resolutions with the help of various groups in society. In the case of the Marshall crisis, the Department of Fisheries and Oceans engaged with individuals, but its public participation methods and related techniques were under traditional public consultation (i.e. Inform and Consult), which was common for the time.

The importance of this case study was to learn from it by considering new public participation possibilities that could lead to improved outcomes in crisis management, while developing and implementing new techniques that can fill some of the public participation gaps that have been identified. Aboriginal rights cases and litigation will not likely abate in the coming years. The hope is that this thesis will enable future government intervention in crises with First Nations, Métis and Inuit peoples to facilitate improved outcomes that will be long lasting and beneficial to all Canadians, while respecting the long fought treaty rights of Canada's first peoples. 


\section{Appendices}

Appendix A

\begin{tabular}{|c|c|}
\hline \multicolumn{2}{|r|}{ Marshall Crisis Timeline ${ }^{22}$} \\
\hline August 1993 & $\begin{array}{l}\text { Donald Marshall Jr. is arrested by the Department of Fisheries and } \\
\text { Oceans for fishing eels out of season, and is "charged for fishing } \\
\text { without a licence, selling eels without a licence and fishing out of } \\
\text { season" (Coates 3-4). He admits that he "caught and sold } 463 \\
\text { pounds of eel without a licence (worth less than } \$ 800 \text { )" (Morellato } \\
\text { 10). }\end{array}$ \\
\hline June 1996 & $\begin{array}{l}\text { Donald Marshall Jr. is convicted of his charges by the Nova } \\
\text { Scotia provincial court (Coates } 5 \text { ). }\end{array}$ \\
\hline March 26, 1997 & $\begin{array}{l}\text { Nova Scotia Court of Appeal upholds Donald Marshall Jr.'s } \\
\text { conviction in a unanimous decision (Coates } 5 \text { and Isaac 106). }\end{array}$ \\
\hline \multicolumn{2}{|r|}{ Marshall I (September 17, 1999) } \\
\hline September 17, 1999 & $\begin{array}{l}\text { Supreme Court of Canada renders first Marshall decision } \\
\text { (Marshall 1), in which "The eighteenth-century treaties between } \\
\text { the British and First Nations covered the commercial use of } \\
\text { resources. The right to use the resources - in this case, eels - was } \\
\text { not unlimited. First Nations could earn a 'moderate income' (not } \\
\text { defined) and were obliged to operate within the framework of } \\
\text { federal government rules" (Coates 7). } \\
\text { Mi'kmaq fishers feel "vindicated" that their treaty rights are } \\
\text { realized through the decision and immediately begin fishing } \\
\text { lobster out of season and without a licence. They gain a new } \\
\text { sense of economic independence based on their treaty right to fish } \\
\text { (Coates 7-10). } \\
\text { Maritime non-Aboriginal fishers become angry, wonder what the } \\
\text { effects will be on the commercial fishery and how the new ruling } \\
\text { will re-distribute the wealth of the commercial fishery among their } \\
\text { groups and Mi'kmaq fishers. They are also concerned that too } \\
\text { much lobster will be fished out of season without a quota, which } \\
\text { could lead to the eventual collapse of the industry (Coates xvii, 9). } \\
\text { The federal government is "caught unaware by the Supreme Court } \\
\text { judgment and its implications...Officials ask for calm and for time }\end{array}$ \\
\hline
\end{tabular}

${ }^{22}$ The Marshall Crisis Timeline is based on Ken Coates' The Marshall Decision and Native Rights and is supplemented by other sources where necessary. 


\begin{tabular}{|c|c|}
\hline & to sort out the ruling..." (Coates 9). \\
\hline $\begin{array}{l}\text { September } 18-28 \text {, } \\
1999\end{array}$ & $\begin{array}{l}\text { A lack of clarification as to what constitutes a "moderate } \\
\text { livelihood" in Marshall I leads Mi'kmaq and non-Aboriginal } \\
\text { fishers to take different perspectives concerning the extent of their } \\
\text { rights, while the federal government, especially the Department of } \\
\text { Fisheries and Oceans, is taken somewhat off guard by the decision } \\
\text { (The Marshall Decision and Beyond). } \\
\text { Mi'kmaq fishers based out of Burnt Church "set out more than } \\
1,000 \text { traps in direct violation of the legal lobster season ( } 1 \text { May to } \\
30 \text { June), infuriating non-Aboriginal fishers who had to watch and } \\
\text { wait for a government response" (Coates } 13 \text { ). }\end{array}$ \\
\hline October 3, 1999 & $\begin{array}{l}\text { Non-Aboriginal fishers "on over } 150 \text { fishing boats from Neguac } \\
\text { and Escuminac" arrive at Yarmouth, Nova Scotia, in a "protest" } \\
\text { over the First Nations fishery. While some call this a "protest," } \\
\text { others refer to it as a "pre-dawn Sunday attack on Mi'kmaq } \\
\text { lobster traps in the Miramichi Bay," in which they destroyed } \\
\text { approximately 3,000 traps. (Coates 139-141). } \\
\text { At Burnt Church, "non-native fishermen destroyed lobster pots } \\
\text { that local Mi'kmaq fishermen had set and temporarily shut down a } \\
\text { fish plant that had been buying lobster from the Mi'kmaq, } \\
\text { wrecking some of the plant's equipment" (Wicken 229). }\end{array}$ \\
\hline October 4, 1999 & $\begin{array}{l}\text { After the damage that ensued on October 3, 1999, Mi'kmaq } \\
\text { Warriors surround and occupy "the wharf at Burnt Church with } \\
\text { flags and teepees," the following day (Coates 141). }\end{array}$ \\
\hline October 6, 1999 & $\begin{array}{l}\text { A critical meeting is held in Halifax among Herb Dhaliwal, } \\
\text { Minister of Fisheries and Oceans, and } 34 \text { "Atlantic First Nations } \\
\text { Chiefs, supported by Aboriginal leaders from across the } \\
\text { country...Although discussions were tense and disagreements } \\
\text { repeatedly surfaced, they did agree to a voluntary thirty-day } \\
\text { moratorium" of the Maritime lobster fishery (Coates 144). }\end{array}$ \\
\hline October $9-10,1999$ & $\begin{array}{l}\text { First Nations communities react negatively to the agreed upon } \\
\text { moratorium of October } 6,1999 \text {, especially in Burnt Church, } \\
\text { where fishers, "hustling to replace their damaged traps (they } \\
\text { ordered } 1,000 \text { at } \$ 70 \text { each), declared their intention to return to the } \\
\text { lobster fishery, screaming their defiance at First Nations chiefs } \\
\text { who they described as 'sellouts."' (Coates } 145 \text { ). } \\
\text { Non-Aboriginal fishers pressure the federal government to allow } \\
\text { them to continue fishing for the remainder of their season. Non- } \\
\text { Aboriginal fishers become anxious, especially in Nova Scotia, as } \\
\text { they feel even a short-term closure could jeopardize the local }\end{array}$ \\
\hline
\end{tabular}




\begin{tabular}{|c|c|}
\hline & $\begin{array}{l}\text { economy: "Fishers from the Bay of Fundy gathered at a meeting } \\
\text { in Nova Scotia on } 9 \text { October, cheering calls for the resignation of } \\
\text { Herb Dhaliwal" (Coates 145). } \\
\text { The Department of Fisheries and Oceans reacts to the increasing } \\
\text { tensions by imposing regulations/establishing a limited lobster } \\
\text { fishery. Minister Dhaliwal announces that a limited Mi'kmaq } \\
\text { fishery will be permitted for "Burnt Church ( } 600 \text { traps) and } \\
\text { Shubenacadie (Indian Brook), Nova Scotia ( } 800 \text { traps)" (Coates } \\
\text { 146). }\end{array}$ \\
\hline October 12,1999 & $\begin{array}{l}\text { Mi'kmaq Chiefs meet to discuss "whether they should continue } \\
\text { with the moratorium, their anger directed at Dhaliwal for } \\
\text { imposing limits" on the lobster fishery (Coates 148). }\end{array}$ \\
\hline October 13,1999 & $\begin{array}{l}\text { Police charge several non-Aboriginal fishers in the Miramichi } \\
\text { provincial court. Charges include: "mischief, obstructing a peace } \\
\text { officer, and breaking and entering to having lobster traps aboard a } \\
\text { vessel out of season" (Coates 149). } \\
\text { On the same day, "Maritime Chiefs formally repealed the } \\
\text { voluntary moratorium... Back at Burnt Church, the First Nations } \\
\text { criticized the minister, accusing him of ignoring their legal rights. } \\
\text { But, to less fanfare, Aboriginal and non-Aboriginal fishers } \\
\text { gathered to discuss ways of integrating First Nations into the } \\
\text { harvest" (Coates 147). }\end{array}$ \\
\hline October 15,1999 & $\begin{array}{l}\text { Non-Aboriginal fishers gather in the water near Yarmouth, } \\
\text { "determined to smash Aboriginal lobster traps and threatening to } \\
\text { close down the fishery" (Coates 148). } \\
\text { The Department of Fisheries and Oceans, recognizing the need to } \\
\text { respond to anger on both sides, appoints James MacKenzie as } \\
\text { Chief Federal Representative to negotiate "interim fisheries } \\
\text { agreements with all thirty-four First Nations in the Maritimes" } \\
\text { (Isaac 151). }\end{array}$ \\
\hline October 19, 1999 & $\begin{array}{l}\text { The first round of negotiations do not fare well, as the "first offer } \\
\text { presented by the federal government was quickly rejected by } \\
\text { [Mi'kmaq] fishers who gathered in Yarmouth on } 19 \text { October to } \\
\text { consider their options - but by the end of the month the issue had } \\
\text { started to settle down," regardless (Coates 148). }\end{array}$ \\
\hline November 1999 & $\begin{array}{l}\text { Minister Dhaliwal appoints Gilles Thériault as Associate Chief } \\
\text { Federal Negotiator (Coates 133). Thériault's role is to provide } \\
\text { support by documenting information and concerns from non- } \\
\text { Aboriginal fishers and relay that information to James MacKenzie } \\
\text { for consideration in negotiations (MacKenzie Interview). }\end{array}$ \\
\hline
\end{tabular}




\begin{tabular}{|c|c|}
\hline \multicolumn{2}{|r|}{ Marshall 2 (November 17, 1999) } \\
\hline November 17,1999 & $\begin{array}{l}\text { The Supreme Court of Canada takes the "unprecedented step" of } \\
\text { providing a unanimous clarification of Marshall } 1 \text { (known as } \\
\text { Marshall 2), while simultaneously rejecting a request for appeal } \\
\text { by the West Nova Fisherman's Coalition to have the Marshall } \\
\text { case reheard (Coates 18) (Cameron 85). } \\
\text { The Court's clarification (Marshall 2) indicates that Marshall } 1 \\
\text { pertained only to fishing eels and not necessarily all natural } \\
\text { resources; and First Nations' right to fish would not take } \\
\text { precedence over "conservation," which enables the Department of } \\
\text { Fisheries and Oceans to enforce the law and does not necessarily } \\
\text { take away non-Aboriginal fishers' rights (Coates 19). }\end{array}$ \\
\hline December 1999 & $\begin{array}{l}\text { It is revealed, based on internal documents, that the Department of } \\
\text { Fisheries and Oceans "did not have a contingency plan for dealing } \\
\text { with a Supreme Court decision" (Coates 131). }\end{array}$ \\
\hline Mid-February 2000 & $\begin{array}{l}\text { Uncertainty remains regarding Marshall decisions. New } \\
\text { Brunswick debates rights to hunt moose and Nova Scotia } \\
\text { witnesses "the seizure of two First Nations crab fishing boats" } \\
\text { from members of Indian Brook First Nation (Coates 173). In } \\
\text { addition, "seven more Indian Brook fishing vessels were seized } \\
\text { later in } 2000 \text { and } 18 \text { people were charged with illegally fishing } \\
\text { lobster" (White, Maxim and Spence 63). } \\
\text { In addition to the troubles at Indian Brook, "Burnt Church } \\
\text { rejected an interim fishing agreement proposed by the Department } \\
\text { [of Fisheries and Oceans] and the Burnt Church people were } \\
\text { raided with } 700 \text { traps being seized and four people arrested" } \\
\text { (White, Maxim and Spence 63). }\end{array}$ \\
\hline April 2000 & $\begin{array}{l}\text { "The Burnt Church dispute continued to attract the time and } \\
\text { attention of the Department of Fisheries and Oceans. In April } \\
2000 \text { community members declared their intention to regulate } \\
\text { their own fishery, even though they anticipated the federal } \\
\text { rejection of their assertion of authority" (Coates 175). }\end{array}$ \\
\hline Late April 2000 & $\begin{array}{l}\text { The Department of Fisheries and Oceans negotiates an agreement } \\
\text { with Burnt Church First Nation, but in the end "the leadership } \\
\text { ultimately refused to negotiate a final settlement" (Coates 175). } \\
\text { In the absence of a final negotiated final settlement, Minister } \\
\text { Dhaliwal "allocates a substantial to the community - the } \\
\text { equivalent of seventeen commercial licences, or more than } 5,100 \\
\text { lobster traps, and over } \$ 300,000 \text { in crab quotas that, according to } \\
\text { the minister, had not been taken up" (Coates 175). }\end{array}$ \\
\hline
\end{tabular}




\begin{tabular}{|l|l|}
\hline & $\begin{array}{l}\text { Minister Dhaliwal remains firm that Burnt Church will not be } \\
\text { permitted to regulate its own fishery on the basis that an entity } \\
\text { cannot accept some parts of a Supreme Court ruling and reject the } \\
\text { rest (Coates 175). }\end{array}$ \\
\hline $\begin{array}{l}\text { Minister Dhaliwal publicly states that 24 "First Nations have } \\
\text { signed interim fishing agreements" (Coates 177). Burnt Church is } \\
\text { the only community that does not sign on to an agreement in the } \\
\text { summer of 2000 (Coates 174). }\end{array}$ \\
\hline June 2000 & $\begin{array}{l}\text { Department of Fisheries and Oceans officers move "aggressively" } \\
\text { at night with "powerful spotlights" across Miramichi Bay, seizing } \\
\text { "700 to 1,000 lobster traps left out the previous day by Burnt } \\
\text { Church fishers"(Coates 181). }\end{array}$ \\
\hline August 14-15,2000 13,2000 & $\begin{array}{l}\text { The conflict escalates. Mi'kmaq fishers pelt Department of } \\
\text { Fisheries and Oceans officers with fish guts. Mi'kmaq fishers and } \\
\text { Fisheries and Oceans officials accuse each other of "provoking } \\
\text { confrontations on the water, resulting in several near-miss } \\
\text { collisions and boat rammings." Department of Fisheries and } \\
\text { Oceans officers use pepper spray on Mi'kmaq fishers. The } \\
\text { Mi'kmaq fishers claim that Department of Fisheries and Oceans } \\
\text { officers used firearms to intimidate protesters (Coates 181). }\end{array}$ \\
\hline August 16, 2000 & $\begin{array}{l}\text { Burnt Church and the Department of Fisheries and Oceans } \\
\text { announce that they have agreed upon a "truce" and have "re- } \\
\text { opened dialogue" (Coates 182). }\end{array}$ \\
\hline September 19,2000 & $\begin{array}{l}\text { Donald Marshall Jr. asks the Mi'kmaq Chiefs "to pull the boats } \\
\text { from the water" and requests that they "negotiate with government } \\
\text { officials" (Coates 137). }\end{array}$ \\
\hline February 9,2001 & $\begin{array}{l}\text { The Ministers of Indian Affairs and Northern Development, and } \\
\text { Fisheries and Oceans announce the Marshall Response Initiative, } \\
\text { which includes building "a better relationship with the Mi'kmaq } \\
\text { and the Maliseet communities." There are two parts to the } \\
\text { strategy: } \\
\text { (1) Department of Indian Affairs and Northern Development } \\
\text { will seek to reach long-term agreements with the Maritime First } \\
\text { Nations regarding their treaty rights, including the possibility of a } \\
\text { modern treaty, and }\end{array}$ \\
\hline
\end{tabular}

${ }^{23}$ Note: Indian and Northern Affairs Canada changed its official departmental title to Aboriginal Affairs and Northern Development Canada at the end of 2011. However, for the purposes of this thesis, the term Indian and Northern Affairs Canada will be used, as all events being described occurred prior to the title change. In some instances, the Department's legal title, Department of Indian Affairs and Northern Development, may also be used when referring to involvement in legal proceedings and Parliamentary business. 


\begin{tabular}{|l|l|}
\hline & $\begin{array}{l}\text { (2) Department of Fisheries and Oceans will continue to negotiate } \\
\text { fishing agreements (supplemented by a budget of approximately } \\
\text { \$500 million over three years) to provide First Nations with } \\
\text { increased access to the fishery (Isaac 157). }\end{array}$ \\
\hline August 20-27,2001 & $\begin{array}{l}\text { Minister Dhaliwal issues a "short-term communal licence" to } \\
\text { Burnt Church, which is intended to prevent a recurrence of } \\
\text { confrontations in Miramichi Bay during the fall of 2000 (Isaac } \\
152)\end{array}$ \\
\hline September 11,2001 & $\begin{array}{l}\text { Minister Dhaliwal appoints former Ontario Premier Bob Rae as } \\
\text { mediator "between the federal government and Burnt Church," as } \\
\text { well as commercial fishers (Isaac 153). }\end{array}$ \\
\hline September 20,2001 & $\begin{array}{l}\text { Bob Rae leaves discussions, fearing that "the Mi'kmaq [of Burnt } \\
\text { Church], commercial fishers and the federal government were too } \\
\text { far apart" (Coates 183). }\end{array}$ \\
\hline 2001-2007 & $\begin{array}{l}\text { Department of Fisheries and Oceans invests approximately \$600 } \\
\text { million in the Marshall Response Initiative, which ended on } \\
\text { March 31, 2007 } \\
\text { (http://www.dfo-mpo.gc.ca/fm-gp/aboriginal- } \\
\text { autochtones/marshall/index-eng.htm). }\end{array}$ \\
\hline
\end{tabular}




\section{Appendix B}

Interview Participants

Réginald Comeau, Full-Time Employee, Maritime Fishermens' Union

James Jones, former Regional Director General (Gulf Region), Department of Fisheries and Oceans

James MacKenzie, former Chief Federal Negotiator, Department of Fisheries and Oceans

Joëlle Montminy, former Associate Federal Negotiator, Indian and Northern Affairs Canada

John Paul, Executive Director, Atlantic Policy Congress of First Nations Chiefs 


\section{Appendix C}

\section{Carleton \\ UN IVERSITY \\ Canada's Capital University}

Letter for Federal Government Employees

Date

Dear Sir or Madam:

My name is Frank Gale and I am a graduate student of the Institute of Political Economy at Carleton University. I am writing a thesis entitled Marshalling Resources: Crisis Engagement with Aboriginal Canadians and the Marshall Decision. The purpose of this research is to demonstrate how the federal government's approach to engaging with provincial governments, First Nations fishers and members of the Maritime Fisherman's Union changed once Marshall 1 was decided. I also want to provide recommendations for engagement approaches that could reduce the possibility of crisis situations in future Aboriginal rights cases.

I would like to request your participation to interview you. I would like to audio record the interview but only with your approval. If you prefer not to be audio recorded I will take handwritten notes. I would like to ask you questions concerning, from your perspective being involved in the Marshall case how effective the federal government was in engaging with specific groups before and after Marshall 1. Your input would be extremely valuable in helping me to provide an accurate portrayal of how engagement occurred before and during the case.

All interviews with government employees are being conducted with the knowledge and permission of your department head.

The interview will take approximately an hour to complete. A follow up interview can be held if you wish to provide additional details or clarification. Interviews will be based on the enclosed questionnaire and can occur in person or over the phone, depending on your preference and geographic availability.

You will be identified by name and position and comments and quotes will be attributed to you but you may request that comments and opinions not be attributed to you.

There is the possibility of some risk to you should your opinions and comments conflict with your employer and colleagues. Therefore, you may refuse to answer any question and may end the interview at any time. Should you decide to end the interview all recordings and notes will be destroyed. 
You may withdraw comments provided during the interview up to (provide date) after which point it will be too difficult to remove your data from the collected material.

All recordings and research notes from the interviews will be kept in a locked cabinet at my place of residence. Only I will have access to the cabinet and the materials.

All recordings and notes will be destroyed or erased six months after successful defence of my thesis at Carleton University. The defence is expected to occur by Decem ber 2010.

Participation in this research is voluntary in nature and as such, there will be no monetary or other compensation provided.

This research project has been reviewed and cleared by the Carleton University Ethics Board.

Should you wish to participate in my research, please sign the enclosed written consent form and return it to me via e-mail (as a scanned PDF) or via postal mail at the following address:

Frank Gale

P.O. Box 1343

KEMPTVILLE ON KOG $1 \mathrm{~J} 0$

If you have any questions about this research you may contact me, my supervisor or the Carleton University Research Ethics Board.

Sincerely,

Frank Gale

Encl.

Researcher:

Frank Gale

e-mail

telephone
Supervisor

Prof. Frances Abele

Public Policy and Administration

Carleton University

Ottawa, ON K1S 5B6

613-520-2600, ext 2553

Frances_abele@carleton.ca
Research Ethics Board

Prof. Antonio Gualtieri, Chair Office of Research Services

Carleton University

Ottawa, ON K1S 5B6

613-520-2517 ethics@carleton.ca 


\section{Carleton \\ UNIVERSITY}

Canada's Capital University

\section{Consent Form for Government Employees}

Title of Research Project: Marshalling Resources: Crisis Engagement with Aboriginal Canadians and the Marshall Decision.

Researcher: Frank Gale, MA student, Institute of Political Economy

Supervisor: Prof. Frances Abele, School of Public Policy and Administration , agree to an interview with Frank Gale, MA student at Carleton

University in the Institute of Political economy on the issue of the Marshall case for his MA thesis.

I understand that the interview will take approximately one hour with the possibility of a follow-up interview to clarify any points I wish to make.

I agree to be audio recorded for the interview

I decline to be audio recorded and understand that the researcher will take handwritten notes.

I understand that my department head is aware of this research project and my participation.

I understand that I will be named and that comments and opinions will be attributed to me unless I request that they not be.

I understand that there is some risk to me as my employer and colleagues may hold different opinions from me on the Marshall case.

I understand that I may refuse to answer questions and that I may end the interview at anytime and withdraw from the study. Should I decide to withdraw from the study I understand that all the recordings and notes will be immediately destroyed.

I have the right to withdraw from the study up until (date) after which time the researcher will be unable to extract my data from the body of data collected for the study.

I understand that my participation in this research is voluntary and I will receive no monetary reward as a result.

I understand that all audio recordings will be kept in a locked "cabinet at the researcher's place of residence when not in use and will be destroyed (erased) six months after the researcher has successfully defended his thesis at Carleton University. The defence is expected to occur by December 2010. 
I understand that the results of this research will appear in the researchers Master's thesis which is a publically available document and that the researcher may publish or present the findings in other forms like academic journals and conferences.

I understand that this project has been reviewed and cleared by the Carleton University Research Ethics Board and any questions or concerns I have may be directed to them or the project supervisor.

Signature of participant

Signature of researcher

Date

Date

Contact information:

Researcher:

Frank Gale

e-mail

telephone
Supervisor

Prof. Frances Abele

Public Policy and Administration

Carleton University

Ottawa, ON K1S 5B6

613-520-2600, ext 2553

Frances_abele@carleton.ca
Research Ethics Board

Prof. Antonio Gualtieri, Chair Office of Research Services

Carleton University

Ottawa, ON K1S 5B6

613-520-2517 ethics@carleton.ca 


\section{Carleton \\ UN IVERSITY}

Canada's Capital University

Letter for Aboriginal fishers and Maritime Fisherman's Union

Date

Dear Sir or Madam:

My name is Frank Gale and I am a graduate student of the Institute of Political Economy at Carleton University. I am writing a thesis entitled Marshalling Resources: Crisis Engagement with Aboriginal Canadians and the Marshall Decision. The purpose of this research is to show how the federal government's approach to engaging with provincial governments, First Nations fishers and members of the Maritime Fisherman's Union changed once Marshall 1 was decided. I also want to provide recommendations for engagement approaches that could reduce the possibility of poor communications situations in future Aboriginal rights cases.

I would like to request your participation to interview you. I would like to audio record the interview but only with your approval. If you prefer not to be audio recorded I will take handwritten notes. I would like to ask you questions concerning, from your perspective being involved in the Marshall case how effective the federal government was in engaging with specific groups before and after Marshall 1. Your input would be extremely valuable in helping me to provide an accurate picture of how communication occurred before and during the case.

The interview will take approximately an hour to complete. A follow up interview can be held if you wish to provide additional details or clarification. Interviews will be based on the enclosed questionnaire and can occur in person or over the phone, depending on your preference and geographic availability.

You will be identified by name and position and comments and quotes will be attributed to you but you may request that comments and opinions not be attributed to you.

There is the possibility of some risk to you should your opinions and comments conflict with your community or organization. Therefore, you may refuse to answer any question and may end the interview at any time. Should you decide to end the interview all recordings and notes will be destroyed.

You may withdraw comments provided during the interview up to (provide date) after which point it will be too difficult to remove your interview from the collected interviews.

All recordings and research notes from the interviews will be kept in a locked cabinet at my place of residence. Only I will have access to the cabinet and the materials. 
All recordings and notes will be destroyed or erased six months after successful defence of my thesis at Carleton University. The defence is expected to occur by December 2010.

Participation in this research is voluntary in nature and as such, there will be no monetary or other compensation provided.

This research project has been reviewed and cleared by the Carleton University Ethics Board.

Should you wish to participate in my research, please sign the enclosed written consent form and return it to me via e-mail (as a scanned PDF) or via postal mail at the following address:

Frank Gale

P.O. Box 1343

KEMPTVILLE ON K0G $1 \mathrm{~J} 0$

If you have any questions about this research you may contact me, my supervisor or the Carleton University Research Ethics Board.

Sincerely,

Frank Gale

Encl.

Researcher:

Frank Gale

e-mail

telephone
Supervisor

Prof. Frances Abele

Public Policy and Administration

Carleton University

Ottawa, ON K1S 5B6

613-520-2600, ext 2553

Frances_abele@carleton.ca
Research Ethics Board

Prof. Antonio Gualtieri, Chair Office of Research Services

Carleton University

Ottawa, ON K1S 5B6

613-520-2517 ethics@carleton.ca 


\section{Carleton \\ U N I VER S I T Y \\ Canada's Capital University}

\section{Consent Form for Aboriginal Fishers and the Maritime Fishermen's Union}

Title of Research Project: Marshalling Resources: Crisis Engagement with Aboriginal Canadians and the Marshall Decision.

Researcher: Frank Gale, MA student, Institute of Political Economy

Supervisor: Prof. Frances Abele, School of Public Policy and Administration

I ,agree to an interview with Frank Gale, MA student at Carleton University in the Institute of Political economy on the issue of the Marshall case for his MA thesis.

I understand that the interview will take approximately one hour with the possibility of a follow-up interview to clarify any points I wish to make.

I agree to be audio recorded for the interview

I decline to be audio recorded and understand that the researcher will take handwritten notes.

I understand that the researcher is speaking to me with the knowledge and permission of (band, tribal council, organization or community research ethics board).

I understand that I will be named and that comments and opinions will be attributed to me unless I request that they not be.

I understand that there is some risk to me as my community or organization may hold different opinions from me on the Marshall case.

I understand that I may refuse to answer questions and that I may end the interview at anytime and withdraw from the study. Should I decide to withdraw from the study I understand that all the recordings and notes will be immediately destroyed.

I have the right to withdraw from the study up until (date) after which time the researcher will be unable to extract my data from the body of data collected for the study.

I understand that my participation in this research is voluntary and I will receive no monetary reward as a result. 
I understand that all audio recordings will be kept in a locked cabinet at the researcher's place of residence when not in use and will be destroyed (erased) six months after the researcher has successfully defended his thesis at Carleton University. The defence is expected to occur by December 2010.

I understand that the results of this research will appear in the researchers Master's thesis which is a publically available document and that the researcher may publish or present the findings in other forms like academic journals and conferences.

I understand that this project has been reviewed and cleared by the Carleton University Research Ethics Board and any questions or concerns I have may be directed to them or the project supervisor.

Signature of participant

$$
\text { Date }
$$

Signature of researcher

\section{Date}

Contact information:

Researcher:

Frank Gale

e-mail

Telephone
Supervisor

Prof. Frances Abele

Public Policy and Administration

Carleton University

Ottawa, ON K1S 5B6

613-520-2600, ext 2553

Frances_abele@carleton.ca
Research Ethics Board

Prof. Antonio Gualtieri, Chair Office of Research Services

Carleton University

Ottawa, ON K1S 5B6

613-520-2517 ethics@carleton.ca 


\section{Questionnaire \\ Marshalling Resources: \\ Crisis Engagement with Aboriginal Peoples and the Marshall Decision}

\section{General Questions}

1. What group/organization were you affiliated with during the crisis period (Note: the crisis period is defined as the time between when Marshall 1 and Marshall II were rendered)? Please answer one of the following four sub-questions:

a) If you worked with the federal government, please describe what department or agency you worked for, you position level and what you worked on.

b) If you worked with a provincial government, please describe what department you worked for, your position level and what files you worked on.

c) If you are a fisher of First Nations ancestry (i.e. Mi'kmaq, Maliseet or Passamaquoddy), please describe your general involvement in the Maritime lobster fishery when the Marshall decisions were rendered.

d) If you are a non-Aboriginal fisher, please describe your general involvement in the Maritime lobster fishery when the Marshall decisions were rendered.

2. If you were a government worker (federal or provincial), how were you involved in engaging with the different groups of fishers prior to and after Marshall I was rendered? Was there a noticeable change in how the federal government attempted to engage with the groups/organizations involved before and after Marshall 1? What was your involvement in making these changes?

3. If you were a First Nations fisher, how did the federal government attempt to engage with you before and after Marshall 1 was rendered? What were the differences in approach? What did you like? What didn't you like?

4. If you were a non-Aboriginal fisher, how did the federal and government attempt to engage with you before and after Marshall 1 was rendered? What were the differences in approach? What did you like? What didn't you like?

5. Looking back on the way Marshall $I$ and the crisis period unfolded after it unfolded, how would you have changed the way the federal government engaged with your group/organization and other involved groups/organizations? What ways would you have approached bringing all of the parties together to develop a means out of the crisis? 


\section{Works Cited}

\section{Aboriginal Treaty Rights and the Legal Duty to Consult and Accommodate}

Government of Canada. Constitution Acts 1867 and 1982.

Morellato, Maria. "The Crown's Constitutional Duty to Consult and Accommodate and Treaty Rights." National Centre for First Nations Governance. Ottawa, Ontario: February, 2008.

White, Jerry P., Paul Maxim and Nicholas Spence. Eds. Permission to Develop: Aboriginal Treaties, Case Law and Regulations. Toronto, Ontario: Thompson Educational Publishing, Inc. 2004.

\section{Citizen Engagement and Public Participation}

Abele, Frances, Katherine Graham, Alex Ker, Antonia Maioni, and Susan Phillips. Talking with Canadians: Citizen Engagement and the Social Union. Ottawa, Ontario: Canadian Council on Social Development, July 1998.

Graham, Katherine A. and Susan D. Phillips. Eds. Citizen Engagement: Lessons in Participation from Local Government. Toronto, Ontario: The Institute of Public Administration of Canada, 1998.

"International Association for Public Participation." IAP2. 2011. Web. 26 February 2012. $<$ http://iap2.org/>.

"International Association for Public Participation Canada." IAP2. 2011. Web. 26 February 2012. <http://iap2canada.ca :

Laforest, Rachel and Susan Phillips. "Citizen Engagement: Rewiring the Policy Process." Critical Policy Studies. Michael Orsini and Miriam Smith. Eds. Vancouver, British Columbia: UBC Press, 2007.

Phillips, Susan D. and Michael Orsini. "Mapping the Links: Citizen Involvement in Policy Processes." Canadian Policy Research Networks Discussion Paper No. F121. Ottawa, Ontario: Canadian Policy Research Networks, April 2002.

Snider, J. H. "Deterring Fake Public Participation" International Journal of Public Participation 4(1) (January 2010): 90-101. 
Sterne, Peter. Public Consultation Guide: Changing the Relationship Between Government and Canadians. Canadian Centre for Management Development, 1997.

\section{Critical and Mass Communication Theory}

Herman, Edward S. and Noam Chomsky. Manufacturing Consent: The Political Economy of the Mass Media. New York: Pantheon Books, 1988.

\section{The Marshall Decisions}

Cameron, Alex M. Power Without Law: The Supreme Court of Canada, the Marshall Decisions, and the Failure of Judicial Activism. Montreal, Quebec: McGillQueen's University Press. 2009.

Canada. Parliament. House of Commons. Standing Committee on Fisheries and Oceans. The Marshall Decision and Beyond: Implications for the Management of the Atlantic Fisheries: Second Report of the Standing Committee on Fisheries and Oceans. 36 ${ }^{\text {th }}$ Parl., $2^{\text {nd }}$ Sess. Ottawa, Ontario: December 1999.

Canada. Department of Fisheries and Oceans. Summative Evaluation of the Marshall Response Initiative. Ottawa, Ontario: 2007.

Coates, Ken S. The Marshall Decision and Native Rights. Montreal, Quebec: McGillQueen's University Press, 2000.

Fitzgerald, Paul. "Fishing for Stories at Burnt Church: The Media, The Marshall Decision and Aboriginal Representation." Canadian Dimension. 34(4). Winnipeg, Manitoba: Jul/Aug 2002. 29.

Isaac, Thomas F. Aboriginal and Treaty Rights in the Maritimes: The Marshall Decision and Beyond. Saskatoon, Saskatchewan: Purich, 2001.

Obomsawin, Alanis. "Is the Crown at War With Us?" National Film Board of Canada. Video. 2002.

Wicken, William C. Mi'kmaq Treaties on Trial: History, Land and Donald Marshall Jr. Toronto, Ontario: University of Toronto Press, 2002.

\section{Organized Labour and the Atlantic Commercial Fishery}

Atlantic Lobster Summit: Market Realities, Challenges and Opportunities -- A Plate to Ocean Approach. Conference Proceedings. Halifax, Nova Scotia: Canadian Centre for Fisheries Innovation: October 2007. 
"Biographical Note: Gilles Thériault." Aboriginal Affairs and Northern Development. 2005. Web. 07 May 2012. <http://www.aadnc-aandc.gc.ca/aiarch/mr/nr/sd2005/02721bk-eng.asp>.

Canada. Parliament. House of Commons. Standing Committee on Fisheries and Oceans. The Canadian Lobster Fishery: Trapped in a Perfect Storm. $40^{\text {th }}$ Parl., $2^{\text {nd }}$ Sess. Ottawa, Ontario: June 2009.

Clement, Wallace. The Struggle to Organize: Resistance in Canada's Fishery. Toronto, Ontario: McLelland and Stewart Limited, 1986.

“About." Lobster Council of Canada. 2012. Web. 9 May 2012. $<\mathrm{http}: / /$ lobstercouncilcanada.ca/about/>.

Primary Source Interviews ${ }^{24}$

Comeau, Réginald. Telephone Interview. 10 January 2011.

Jones, James. Telephone Interview. 20 October 2010.

Mackenzie, James. Personal Interview. 22 October 2010.

Montminy, Joëlle. Personal Interview. 10 September 2010.

Paul, John. Telephone Interview. 11 January 2011.

Supreme Court of Canada Decisions

R. v. Marshall (No. 1) [1999] 3 S.C.R. 456.

R. v. Marshall (No. 2) [1999] 3 S.C.R. 533.

R. v. Sparrow [1990] 1 S.C.R. 1075.

${ }^{24}$ See Appendix B for a list of interview participants, sample interview letters, consent forms and interview questionnaire. 